\title{
RADIOPROTECTION
}

Volume 43, N 6 (2008)

\section{What to do when faced with victims of a criticality accident}

\author{
Alain Miele \\ Laurence Lebaron-Jacobs \\ Coordinators
}

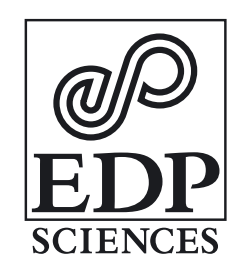

17, avenue du Hoggar

Parc d' Activité de courtabœuf, BP 112

91944 Les Ulis Cedex A, France 
Cover design: photograph by Elisabeth Miele, majolica at the entrance of the summer mosque Khiva, Uzbekistan. From stylized flowers to neutron traces.

ISSN: 0033-8451

ISBN: 978-2-7598-0361-3

This work is subject to copyright. All rights are reserved, whether the whole or part of the material is concerned, especially the rights of translation, reprinting, re-use of illustrations, recitation, broadcasting, reproduction on microfilms or in other ways and storage in data bank. Duplication of this publication or parts thereof is only permitted under the provisions of the French Copyright law of March 11, 1957. Violations fall under the prosecution act of the French Copyright law.

(c) EDP Sciences 2008 
The following recommendations on how to treat the victims of a criticality accident are based on former studies.

The evolution of physiopathological knowledge, of investigation and therapeutic means, and the feedback on recent events have resulted in a need for very practical guidelines for those in charge of treating criticality victims.

This booklet is the result of a work group led by occupational physicians and the biologists in the medical biology laboratories of the CEA and of COGEMA, with the help of physicians working for EDF and the SPRA.

A multidisciplinary approach was used thanks to the contribution of experts from both the IRSN and the CEA Life Science Division (Carmin Task Force).

It consists of the procedures of radioprotection services and the national organization of medical treatment in case of nuclear or radiological accident.

J.M. GIRAUD

Medical Advisor for the CEA

B. QUESNE

Medical Advisor for AREVA 

Phenomenology of a criticality accident ............................................. $\quad 5$

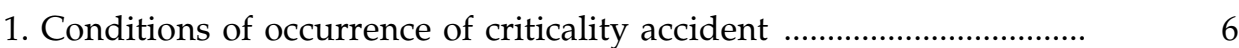

2. Classification of criticality accidents into "families" ............................. 9

Leaflet 1 - Main characteristics of different accident "families" ... 10

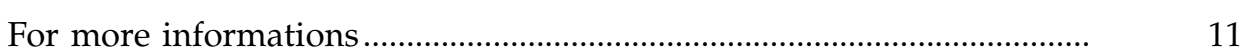

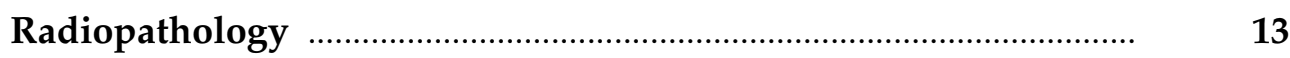

1. Management of irradiated and/or contaminated people in a criticality accident

Leaflet 2 - Estimation of seriousness of irradiation during a criticality accident

Leaflet 3 - The first symptoms: initial syndrome $(24 \mathrm{~h})$.

Leaflet 4 - Recommended approach to an initial syndrome.........

2. Clinical evolution following a criticality accident ................................ 16

Leaflet 5 - What to do in case of hospitalization.............................. 18

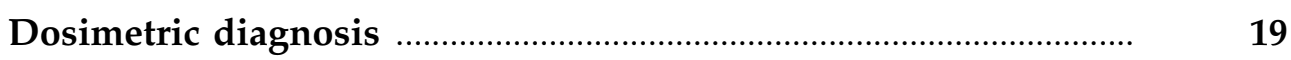

$\begin{array}{ll}\text { 1. Determination of the absorbed dose during a criticality accident ... } & 19\end{array}$

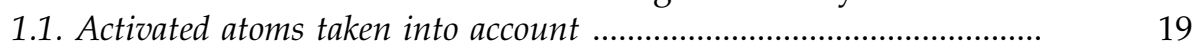

1.2. Measurement methods for activity ..................................................... 20

1.3. Evaluation of the dose due to neutrons using sodium 24 ................. 20

1.4. Evaluation of the dose due to neutrons using phosphorus 32 ........... 21 
2. Determination of the absorbed dose during a criticality accident in the specific case of the external contamination of the subject .....

3. Aids to decision making

Leaflet 6 - Routes

Leaflet 7 - Indications for prescriptions and orientation

of victims

Leaflet 8 - Chronology of examination results (indications)

Leaflet 9 - Interview after the accident

Leaflet 10 - Clinical observations.

4. Biological dosimetry by counting chromosomal aberrations medical/ legal technique

4.1. When should biological dosimetry be used? .........................................

4.2. The different types of chromosomal aberrations ................................

4.3. Operational biological dosimetry .....................................................

4.3.1. Prematurely condensed chromosomes (PCC) by fusion . 35

4.3.2. Prematurely condensed chromosomes (PCC) by chemical induction

4.4. The Tokai-mura accident ....................................................................

4.5. Application to localized irradiation ..................................................... $\quad 36$

5. Biological indicators of radio-induced damage .................................... 37

5.1. The Flt3 ligand, a marker of lesions in the bone marrow .................. 37

5.2. Citrulline, a marker of intestinal mucosa lesions .............................. $\quad 38$

5.3. Oxysterols, markers of multiple organ malfunction ..........................

6. Physical dosimetry ..................................................................................

Leaflet 11 - Physical assessment of the dose in case of a criticality accident

Leaflet 12 - Dosimetres used : Main characteristics

For further information

1. Emergency triage to evacuate the wounded

2. Recommendations for MS and CBL

Leaflet 13 - Classification of injured

Leaflet 14 - Triage and evacuation

Leaflet 15 - Investigations to be carried out in case of a criticality accident.

Leaflet 16 - Specialized samplings 
1. Information on slightly exposed victims, cared for secondarily

2. Information for medical doctors and staff of hospitals concerned... 2.1. What is a criticality accident?

2.2. How were the people involved in the criticality accident taken care of by the medical staff on site?

2.3. What were the criteria for hospitalization?

2.4. How were these patients directed?

2.5. Objective of hospitalization after global irradiation ............................ 56

2.6. Evolution during hospitalization ....................................................

2.7. In all cases, you can contact: ..........................................................

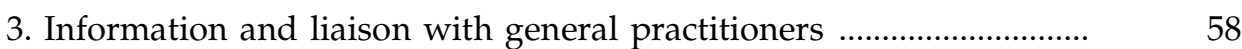

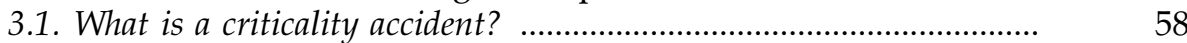

3.2. How were the people involved in the criticality accident taken care of by the occupational medical staff?

3.3. What were the criteria for hospitalization? .........................................

3.4. What were the criteria for ambulatory surveillance? .......................... 5

3.5. What are the criteria of severity requiring hospitalization? ............... 59

3.6. In all cases, you can contact: ............................................................ $\quad 60$

4. Information for those needing surveillance from their general physicians

Annexes.

-IAEA offices and contact information

-Radiological emergencies in France

-History of criticality work group of occupational MS/CBL................ 62

- Criticality accidents.

-Brief bibliography on the Tokai-mura accident. 



\section{Introduction}

The extreme severity of criticality accidents and the recent subsequent deaths (Sarov in 1997 and Tokai-mura in 1999) prove that there is a need for sustained vigilance and specific continuous training. The study of criticality accidents to date provides information on how these events take place. Despite the procedures and protocols implemented, nuclear facilities are in a potentially defective situation, thus entailing a non-nil accident occurrence probability.

The aim of the working group of the Occupational Medical Services (MSs) and of the Clinical Biochemistry Laboratories (CBLs) is to present, in the form of data sheets, essential information on documentation and specific directions when handling a criticality accident victim. Without pretending to be exhaustive, these data sheets are easily accessible and are a valuable aid as a decision-making tool.

These data sheets are meant for the MSs, the CBLs and the Services of Protection against Radiation (SPR), entrusted with the task of implementing the investigation procedures and care given to the people exposed to and then orient them to the adapted medical structures. These initial measures must contribute to individual dosimetric reconstruction and to a later medical follow-up depending on the different levels of exposure.

In parallel, other measures remain to be taken for those people less exposed and to prevent any risk of criticality continuation or resumption. These data sheets include the following chapters:

- Criticality accidents: phenomenology, circumstances, brief description and main characteristics.

- Radiopathology: health effects, time of symptom appearance depending on the dose received.

- Dosimetry: assessment of the dose received and its distribution in the body; assessment methods.

- Triage: main criteria to orient those exposed to a specialized hospital, a general hospital, general medical care or occupational medical care.

- Biological samples: with an aim towards performing radiotoxicological, dosimetric, diagnosis and prognosis aim.

- The aid and assistance procedures between the MSs and CBLs with the appropriate equipment and techniques. 
- Communication data sheets aimed at those people with low or no exposure at all, for concerned hospital services and physicians.

There are also appendices: summaries of previous studies performed by the criticality working group, a bibliography, useful addresses and a list of recorded accidents.

The opinion of the working group, supported by the analysis of the Tokai-mura accident, confirms the difficulties involved in providing care for criticality victims, both on the dosimetric assessment level and the therapeutic treatment level.

Dosimetric reconstruction entails several problems like:

- uncertainty on the topology and kinetics of the accident,

- knowledge on the source term: ratio of neutron dose/gamma dose and energy spectrum,

- maintaining the level of competence in neutron activation measurements on the body or on biological samples: blood and integuments,

- limits of individual dosimeters and area survey instruments.

On the medical management level the specificity of the short- and long-term effects of a combined neutron/gamma exposure (ipso facto heterogeneous) has not been studied enough. The severity of some symptoms appears to be specific of the neutron irradiation (inflammatory or hemorrhagic syndrome, etc.). These symptoms involve a complex treatment, difficult to anticipate and to manage with efficacy. This medical management requires a coordination between specialized teams. The development and the interpretation of clinical and dosimetric biological indicators is a prerequisite to the optimization of the palliative and specific treatments according to the characteristics of the irradiation: level and distribution of the absorbed dose.

The occurrence of criticality accident probability is not nil. The study of accidents provides information on the conditions under which these events occurred: despite the procedures and protocols elaborated to prevent them, reality manifests itself outside these mental constructs. Therefore the facilities built after safety and security studies may potentially have a faulty structure.

The dosimetric diagnosis modeled using a theoretical situation give rise several difficulties: rooms filled with different objects and devices, different shields, neutron kerma, relative biological efficiency, $D_{\mathrm{n}} / D_{\gamma}$ ratio. The fast dosimetric diagnosis made using the neutron activation of the victims is just as difficult: anterior or lateral exposure, partial or whole-body exposure, level of heterogeneity. During the emergency triage phase, the dosimetric estimation can only be approximately based on the signs of severity: activation measurements and the first possible clinical signs. It is only later that all these investigation and measurement results will provide a dosimetric estimate and a prognosis.

Emergency situation and urgency of the situation: an emergency situation is not comparable to a situation of polytraumas with or without contamination. However, several points are important like:

- The HLA typing, so as to be possible, must be done within the first few hours. It meets the medical and legal obligation and is required in the case of future bone marrow transplant. 
- The earliest examinations and their repetition will be precious in the dosimetric diagnosis and the prognosis.

- Reanimation must take into account the significant heterogeneity of the irradiation with a possibility of a massive lysis of tissue at the incidence point.

- Moreover, for people only slightly exposed, the investigations will provide vital information for their later surveillance and the estimation of the stochastic risk (cancer, possible genetic effects).

An initial report could be established within the first $3 \mathrm{~h}$.

The information programmed in several crisis management units by the MS, the CBLs and the SPR should decrease their external solicitations, thus lighten their workload and allow them to focus on their objectives and call upon necessary reinforcements.

The management of victims, the psychological support needed and the evacuations will generate needs in liaison and communication. The evacuation towards hospital structures or the follow-up by the General Practitioner should benefit from documents providing information on the approach to be used.

In conclusion, the "criticality working group" of occupational medical physicians and biologists recommends to the coordinating physicians and the managers of centers:

- Updation of several useful parameters concerning each facility with a criticality risk: the source term, the neutron dose/gamma dose ratio, the number of people potentially implicated, the type and the number of individual dosimeters and area survey meters, isodose curves, the evacuation area, etc.

- Maintaining the level of competence in all the structures implicated in dosimetric assessment and experience feedback on accidental events.

- Optimization of the coordination between the centers for dosimetry.

- Realization of a coordination protocol between the hospital teams and establishment of agreements with the various nuclear companies.

- Harmonization of organizations and agreements between nuclear companies.

- Finally, development of research themes with regard to the short- and longterm effects of an exposure to neutrons. 



\section{Phenomenology of a criticality accident}

Fissile nuclear materials (the main ones being ${ }^{235} \mathrm{U}$ and ${ }^{239} \mathrm{Pu}$ ) can, under certain conditions, maintain chain fission reactions. This property is used to produce energy in nuclear power plants.

Apart from nuclear reactors, in laboratories, plants and transportation, fissile material presents a specific risk: the criticality risk. This means the risk of gathering the conditions needed for triggering and maintaining a chain reaction. This risk can, for example, appear as soon as there is a concentration of $60 \mathrm{~kg}$ of uranium enriched at $3.5 \%$ in ${ }^{235} \mathrm{U}$ or, under certain conditions, of $510 \mathrm{~g}$ of plutonium solution or $870 \mathrm{~g}$ of highly enriched uranium. In nuclear reactors, this same risk can also result in a reactivity accident.

Preventing this criticality risk requires taking specific precautions, which are studied and analyzed at all stages when using fissile materials in the fuel cycle. Despite all the measures taken to prevent the criticality risk, one cannot completely exclude the possibility of a criticality accident occurring very suddenly and without any warning when the quantity of fissile material present exceeds the critical mass. What then happens and what are the risks? It is to answer these questions that study programs on criticality accidents were started: to improve knowledge and model these accidents so as to limit their consequences on man, the environment and the facilities.

It is to be recalled that up to now roughly 60 accidents have been officially recorded throughout the world, two-thirds of which in research facilities and onethird in fuel cycle facilities, causing the death of about 20 operators [1-4].

In France, in the fuel cycle, thanks to the measures taken, no incident resulting in severe irradiation of an operator has ever happened, but situations, which could have led to an accident, occurred in Saclay, without any serious irradiation of personnel.

The circumstances and consequences of criticality accidents differ widely. It is to be noted that the accidents can last a very longtime when the conditions of rapid dispersion of fissile material are not gathered during the first power peak. Moreover, there has never been a criticality accident during transportation. 


\section{Conditions of occurrence of criticality accident}

The criticality accident is the result of the triggering of a fissile chain reaction which is not controlled when the quantities of nuclear materials, uranium or plutonium, present, accidentally exceed a certain threshold called "critical mass" and when there is a source of neutrons triggering the reaction (in general, an internal source of spontaneous fissions is enough).

Regarding neutronics, as soon as the critical state is exceeded, the chain reaction becomes exponentially divergent with a period that depends on the initial reactivity of the system. The result is a rapid evolution of the number of fissions produced within the fissile medium, still called "criticality power excursion". This phenomenon causes a release of energy which is essentially in the form of heat, with the intense emission of neutron and gamma radiation as well as the release of fission gases. The heating of the fissile medium is generally observed, from the neutronic standpoint, with the appearance of feedback mechanisms that reduce the reactivity present until the system becomes sub-critical, if only temporarily. The usual result is therefore a power peak.

After the first power peak, the gas bubbles of radiolysis or steam migrate towards the surface; the resulting anti-reactivity effect disappears and the power excursion starts again. It is this process of appearance and release of these bubbles from the system which is at the source of the oscillating phenomenon generally observed during a criticality accident in a liquid medium (Fig. 1).

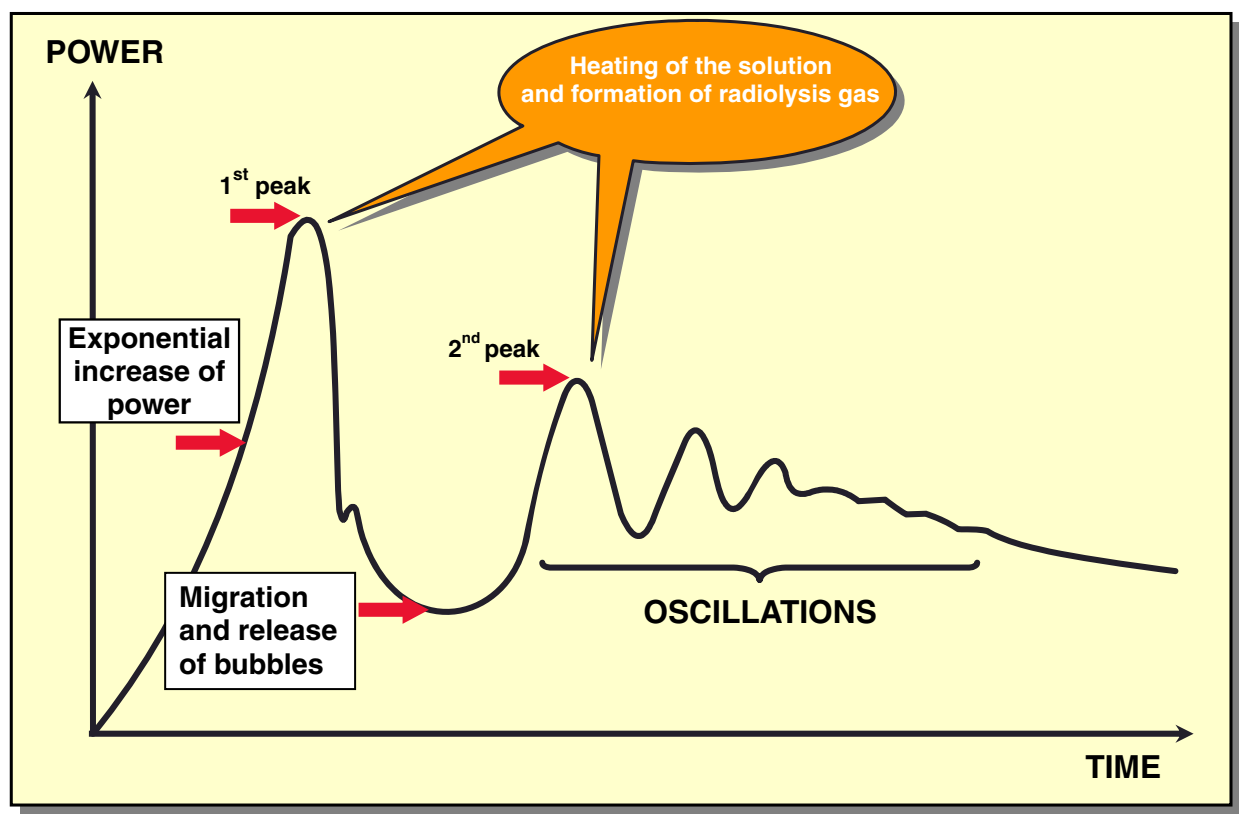

Fig. 1. Typical criticality accident in a fissile solution. 
An accidental criticality excursion is thus generally governed by the following main parameters:

- The physico-chemical nature of the divergent fissile medium.

- The reactivity ${ }^{1}$ of the system.

- The configuration when the accident occurs.

- The initial spontaneous neutron source present at the starting of the accident, which is different depending on whether it is an environment containing unirradiated enriched uranium, uranium and plutonium, or simply plutonium.

The neutron feedback effects result from the following:

- Nuclear temperature (Doppler effects and spectrum variation);

- Expansion effects (density and volume effects).

- Void effect (gas bubbles from radiolysis, steam, etc.).

- The environment of the facility (thermal exchanges with the outside, containment of the divergent system, etc.).

As confirmed by the experiments in the SILENE reactor (CEA Valduc, France), the combination of the previous phenomena with the initial conditions of the accident can lead to three types of behavior (Fig. 2):

1. The divergent system eventually goes back to being sub-critical by modification of the configuration (mixture, ejection or dispersal of material, modification of the geometry, etc.).

2. The system temporarily becomes sub-critical because of the heating of the fissile matter, in this case the divergent reaction will start up again after a more or less longtime depending on the thermal exchanges with the environment.

3. The system, after a significant initial reactivity, reaches the boiling temperature of the medium and the evolution of power then depends on the sub- or over-moderation of the environment. The liquid boiling and the resulting re-concentration of the fissile solution, can indeed lead to an increase or decrease of the system(s) reactivity. The behavior of the divergent system during the post-accident phase is therefore, different depending on whether it is a "closed" system, in other words in which steam can condense and return to the solution, or an "open" system in which the vaporization or ejection of the solution will enable a return to sub-criticality.

This description corresponds to typical situations for solutions, but is by no means complete since each criticality accident is specific, as can be seen with the accidents throughout the world and more particularly that of Tokai-mura, for which a vessel cooling device which was "diverging" modified the occurrence of the post-accident phase.

The criticality accident also generates the emission of neutron and gamma radiation as well as the production and release of gaseous radioactive fission products and aerosols. The experimental programs carried out on SILENE (CEA Valduc, France) allowed to assess the irradiation and contamination risks and helped to design a detection system able to monitor the evolution of the criticality accident during the post-accident phase.

1 Reactivity $\rho$ is the value which characterizes the relative deviation, on the criticality level, of the system between the $k_{\text {eff }}$ effective multiplication factor and the critical state for which $k_{\text {eff }}=1$. Reactivity is often expressed as "per hundred thousand" (p.c.m. $=10^{-5}$ ). 


\section{POST-ACCIDENT PHASE}
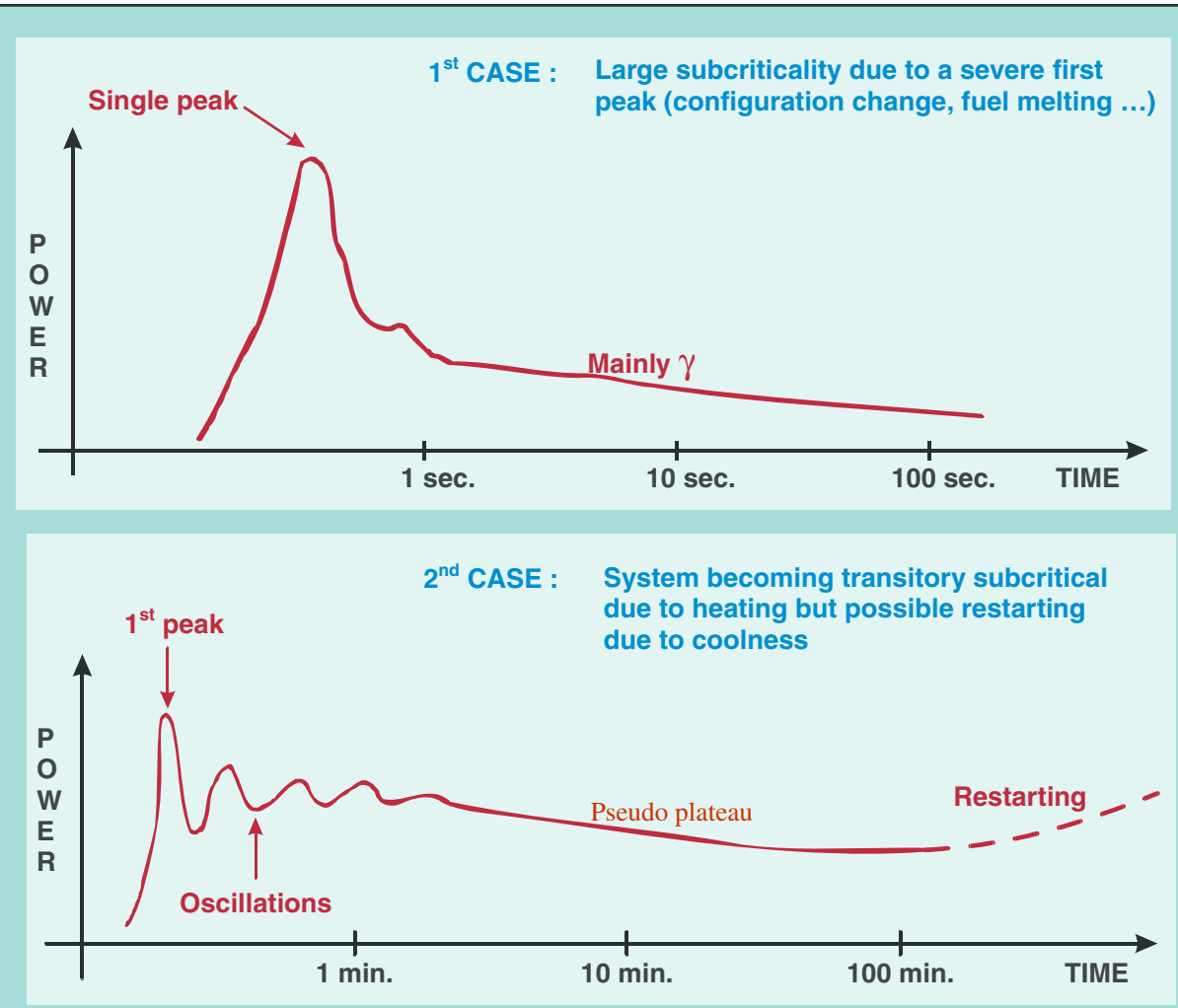

$3^{\text {rd }}$ CASE : Solution boiling

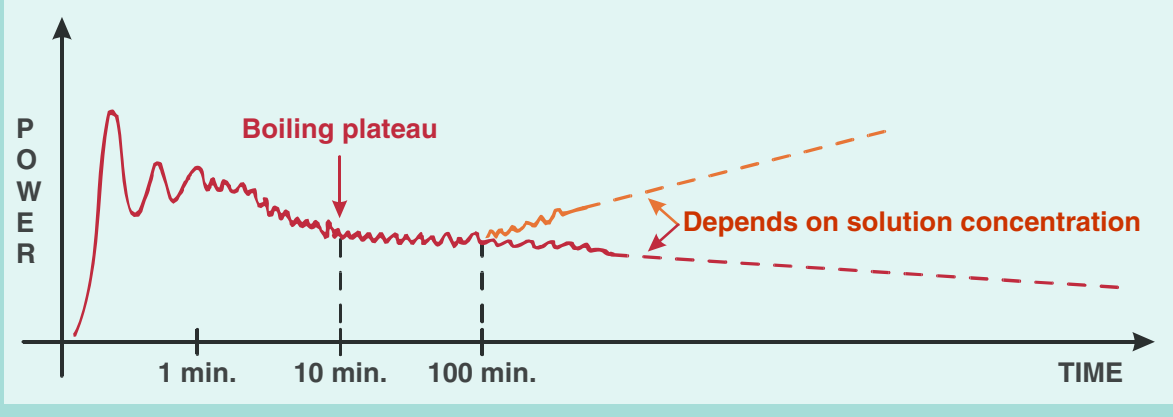

Fig. 2. Typical power excursion during a criticality accident in a fissile solution. 


\section{Classification of criticality accidents into "families"}

So as to better understand the different accident conditions which one can be faced with, a classification of accidents into large "families" was devised, according to their characteristics and their specificities. This approach is not easy as nuclear facilities are different. Some are specialized in fabrication, reprocessing, storage or transport; the type of nuclear material used is also different (solutions, metal, powder, sintered, etc.).

The analysis of criticality safety, carried out within the framework of criticality risk prevention, shows a highly unlikely possibility of an accident occurring. This entails a real problem in the choice of the hypothetical scenario which might lead to an accident.

The classification of accidents in large "families" therefore essentially rests upon the fact that the phenomenology of the criticality accident and the estimation of its potential radiological consequences are highly dependent on the configuration in which the accident occurs (the facility and its environment) and on the physico-chemical form of the nuclear material.

The different types of possible exposures likely to contribute to the estimation of the radiological consequences of a criticality accident are as follows (Fig. 3):

- direct exposure to neutron and gamma rays;

- exposure to fission product release;

- exposure to initial fissile material in suspension (isotopes already present in the fissile matrix before the accident).

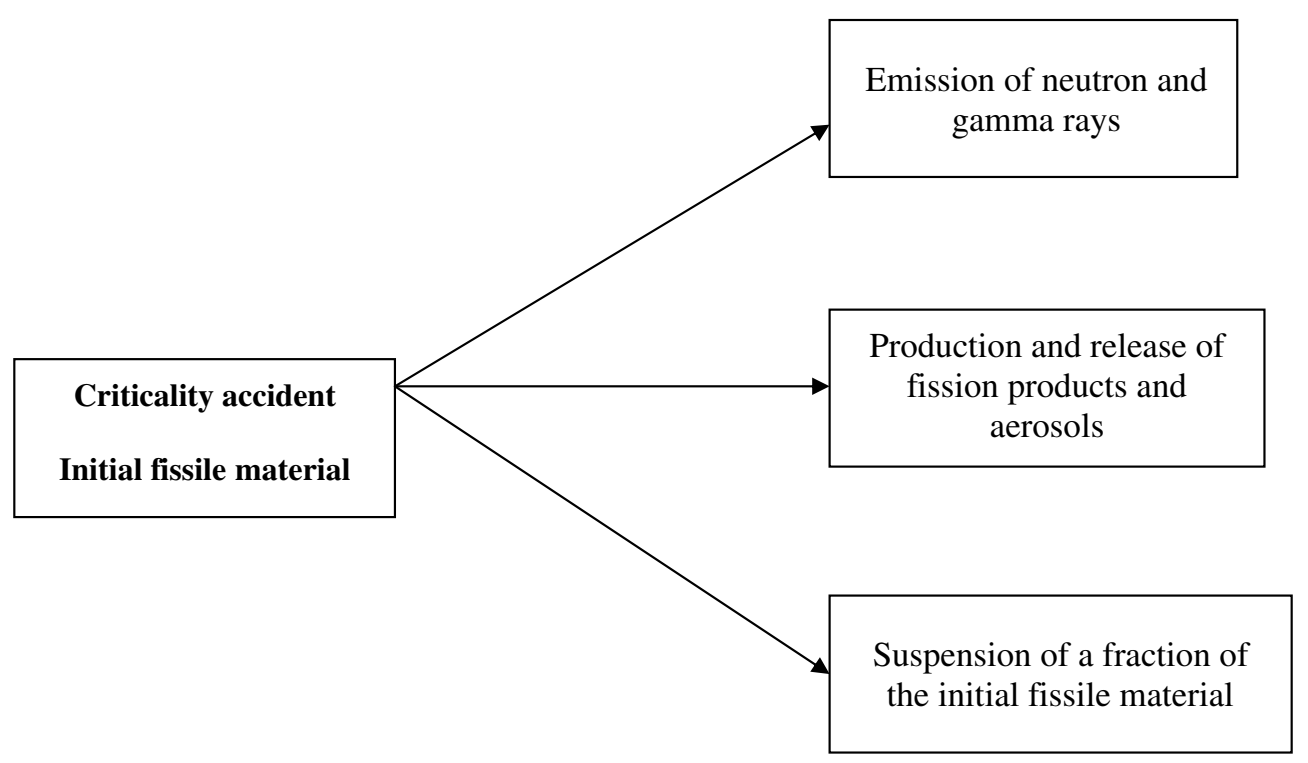

Fig. 3. Exposure types following a criticality accident. 
Based on these considerations and the analysis of accidents having occurred in the world, it is possible to distinguish four large "families" of accident:

Class 1: aqueous fissile media.

Class 2: solid or dry metallic media.

Class 3: "powder" media with moderation (moderation achieved by water or porogenous material).

Class 4: solid/liquid systems (fuel rods + water for example).

\section{Main characteristics of different accident "families"}

Leaflet 1

Class 1: Aqueous fissile media

- Type: nitric, fluohydric solutions, organic aqueous media, etc.

- Facility: chemical engineering, storage, effluents, etc.

- Probability of occurrence: high compared to other accident families.

- Physics: can last several dozen hours.

- Number of fissions: varies between $10^{15}$ and some $10^{19}$ fissions.

- Detection: possible with neutron and gamma detectors.

- Risk of direct exposure high with very different neutron/gamma dose ratios depending on the "moderation" in fissile media and the configuration (dimensions of the material, etc.).

- Neutron/gamma kerma varies roughly between 2 and 0.5 when there is no biological protection.

Reference: radiation field of the SILENE reactor in CEA Valduc (France).

Class 2: solid or dry metallic media

- Type: ingots, metallic parts, etc.

- Probability of occurrence: low.

- Physics: can be very brief (a single peak) if there is dispersion or deformation but can also be prolonged.

- Number of fissions: varies from $10^{15}$ to $10^{17}$.

- Detection: possible with neutron and gamma detectors.

- High risk of direct exposure with a neutron/gamma ratio closer to 10 than to 1 without protection.

Reference: radiation field of the CALIBAN reactor in Valduc (France) or GODIVA in Los Alamos (USA).

Class 3: "powder" media with moderation

- Type: powder bulk + water or powder + moderator materials, etc.

- Facility: fabrication units, powder storage facilities, etc.

- Occurrence probability: low.

- Physics: similar to aqueous fissile media.

- Number of fissions: between $10^{16}$ and $10^{19}$.

- Detection: possible with neutron and gamma detectors.

- Risk of direct exposure: average, between aqueous and solid dry media.

Class 4: solid/liquid mixed media

- Type: fuel elements + water.

- Facility: research reactors and critical mockups, underwater fuel storage, reactor pools, etc.

- Probability of occurrence: low.

- Physics: very complex and difficult to stop on the criticality level.

- Number of fissions: varying from $10^{17}$ to $10^{21}$.

- Detection: difficult by usual means because of the presence of a "shield" of water.

- Risk of direct exposure: low because of the self-shielding provided by water. 


\section{For more informations}

Clefs CEA - Physique nucléaire et sûreté, n 45 - Automne 2001.

F. Barbry - Considérations générales sur l'étude de la phénoménologie des accidents de criticité, Note CEA/DAM/DRMN/SRNC 03-02 (juillet 2003).

H. Carros - "Les accidents de criticité dans les usines et les laboratoires", rapport CEA-DSNQ-MSN 2001/007, mars 2001.

A review of criticality accidents, 2000 revision, Los Alamos National Laboratory report LA 13638 (May 2000). 



\section{Management of irradiated and/or contaminated people in a criticality accident}

- An irradiated or contaminated person is not dangerous to be around.

Medical emergency always supersedes radiological risks.

It must be treated according to the usual medical rules.

There is no radiological risk for the medical personnel.

- The rules to follow are those used for a patient hospitalized for burns, open or closed trauma, immune deficiency, medullar aplasia, inflammatory syndrome. Any source of infection must be avoided (use of once-only material, asepsis, etc.).

- The occupational physician collaborates with the hospital team on all the specific aspects of irradiation:

- on the estimation of the dose and the extent of the overexposed areas at entry point,

- on the integration of specific risks: infection and hemorrhage++,

- on the treatment of contaminations (contamination of cutaneous surfaces, internal contamination); to be performed if this does not disrupt reanimation;

- on the specific surveillance required for the evolution of an inflammatory syndrome +++ and on the following organs:

- the cardio-vascular system and neurological surveillance,

- the ear/nose/throat area and pulmonary area (dyspnea++, inflammatory edema),

- the digestive area (digestive hemorrhage, hydro-electrolytic unbalance),

- hematologic parameters (Full Blood Count (FBC), monitoring of coagulation problems),

- skin++ and indepth damage (muscles),

- radiotoxicological surveillance,

- initial ophthalmologic examination (specific examination of the posterior side of the lens),

- an electroencephalogram (EEG) if there were neurological problems during the prodromal phase. 
- Except for the EMERGENCY itself, the medical or surgical decisions are to be taken according to the clinical state and to the predictable evolution which takes into account the dose heterogeneity and estimations of dose distribution. More specifically, the massive cellular lysis in the overexposed areas can contribute to organ failure (kidney, liver, myocardium).

\section{Estimation of seriousness of irradiation during a criticality accident}

In case of mixed irradiation by neutron and gamma radiation, irradiation is heterogeneous: the doses received by the different organs depend on their orientation versus the source.

\section{SERIOUSNESS: depends on}

- the dose received:

- very high dose: the Central Nervous System (CNS) sideration entails a quick death;

- for doses >1 Gy, the irradiation reduces cellular renewal with a risk of infection and bleeding. The most important consequences are observed among the following tissues:

- bone marrow: FBC is affected, the decrease in the number of cells can reach aplasia;

- cutaneous tissue: radiological burn with deep sub-cutaneous and muscular effects;

- digestive tract: destruction of the mucosa: diarrhea, hemorrhage;

- for doses $<1 \mathrm{~Gy}$, there is no clinical consequence.

- the associated traumas +++;

- the topography of irradiation +++.

EVOLUTION: includes three phases

- The initial signs: for a few hours, followed by a remission phase sometimes including a state of euphoria and excitement.

- The period of clinical latency, the higher the dose, the shorter the time: from a few hours to 3 weeks.

- The clinical phase then the healing phase.

\section{RECOMMENDED PRACTICE}

- Assess the dose and the seriousness, by writing down the times of examinations and the seriousness of the clinical impact by:

- Interrogating the victim +++ for whom the time of symptom appearance will be noted.

- Clinical examination.

- Biological tests.

- The elements gathered to calculate the dose with the localization of each sample.

- Two different situations:

- Immediate hospitalization after placing a catheter and sometimes the first decontamination procedures:

- vision of a blue flash (Cerenkov effect);

- wounds;

- severe symptoms or quickly aggravating. 
- Later hospitalization depending on the symptoms and the dose: hospitalization when the estimated dose is greater than $1 \mathrm{~Gy}$. At the same time, internal and external decontamination procedures.

\section{The first symptoms: initial syndrome $(24 \mathrm{~h})$}

Leaflet 3

Three elements are necessary to evaluate the seriousness: clinical observations, irradiation conditions and biological results.

During the first hours after irradiation, the seriousness is mostly evaluated by means of clinical data and the first dosimetric elements.

CLINICAL: the seriousness is estimated based on the following:

- Precocity, seriousness of clinical signs and symptoms: vomiting, fainting, fever and intense fatigue.

- Topography of radiological lesions.

- Remission which can be accompanied by a phase of euphoria and excitement.

- Clinical examination with tests, diagrams, photos, on which the TIME IS RECORDED:

- Symptoms (by decreasing order of severity):

- state of shock, neurological, cardio-vascular problems.

- drastic loss of consciousness followed by a state of awakeness.

- Severe digestive problems: vomiting, nausea, reflex diarrhea, digestive hemorrhage;

- excitement phase, vigilance problems (drowsiness, asthenia), headaches.

- dry mouth, gum pains;

- pain in overexposed areas;

- nausea, isolated vomiting.

- Upon examination

- fever, tachycardia, modification of Blood Pressure (BP);

- signs of cutaneous overexposure showing the extent of irradiated areas to the incidence point: edema, local heat, erythema (temporary) in particular of the face ++ , aches and pains.

DOSIMETRY: the first elements have been gathered by the Radiation Protection Services (RPS) and are based on:

- The interview with a precise description of the accident conditions

- position of the subject in relation with the source, set landmarks, other people present during the accident;

- probable exposure time and evacuation route.

- Draw a DIAGRAM.

- First procedures:

- DO NOT THROW ANYTHING AWAY, LABEL EVERYTHING.

- Retrieve all available dosimeters.

- Retrieve all objects for dosimetry.

- The rapid dose estimation (RPS, engineer in charge of criticality).

Fill in TRIAGE form (Leaflet 14).

BIOLOGICAL INVESTIGATIONS: to be repeated every $3 \mathrm{~h}$

- The first results are obtained in $\sim 3 \mathrm{~h}$

- See Leaflets 15 and 16 for the choice and the chronology of the samples which have been referenced by time. 


\section{Recommended approach to an initial syndrome}

Leaflet 4

Fill in TRIAGE form (Leaflet 14).

EXAMINATIONS to be immediately performed following the anthropogammametry:

- Label all samples and all documents with the time of sampling and if possible their location.

- Do not forget diagrams and photos.

- Samples of integuments (Leaflets 15 and 16).

- REPEATED blood samples, by decreasing order of importance (see Leaflets 15 and 16).

- FBC, reticulocytes, platelets.

- Cytogenetics.

- HLA I and II typing, erythrocyte group, CMV serology, toxoplasmosis.

- Activated Partial Thromboplastin Time (APTT), Prothrombin Time (PT), fibrinogen, factors II, VII, X.

- Biochemical and enzyme examinations.

- Retrieval of excreta (feces and urines) and samples for radiotoxicology (see Leaflets 15 and 16).

HOSPITALIZATION

The decision to hospitalize mostly depends on the clinical symptoms:

- EMERGENCY hospitalization:

- vision of a blue flash (Cerenkov effect);

- traumas;

- ++ clinical signs as early as the first hour:

State of shock (convulsions, prostration, disorientation), fainting, amnesia, high grade fever $\left(41^{\circ} \mathrm{C}\right)$, digestive trouble (vomiting ++ , hemorrhage ++ , diarrhea).

- LATER hospitalization, based on the symptoms, first examination results and dosimetry:

- symptoms ++ after a few hours:

- vomiting ++, diarrhea, digestive hemorrhage, erythema, fever, awakeness trouble and asthenia;

- signs of local overexposure: edema and/or cutaneous pain;

- biological results + (after 2-3 examinations):

- granulocyte peak, lymphocyte drop, lower PT, etc.

- Dosimetric estimate >1 Gy.

\section{Clinical evolution following a criticality accident}

Irradiation is heterogeneous: the dose received decreases from the entry point of the radiation to the exit point of the radiation. The maximum dose absorbed is located at the entry point of the incident beam.

Cell death and the inflammatory syndrome, which are the consequences of high dose irradiation, are not evenly distributed in the organism and in the 
irradiated organs. Cellular recovery depends on the proportion of surviving cells which will be looked for in different areas of the tissue:

- in the hematopoietic bone marrow samples are taken from different locations to estimate the probability of spontaneous regeneration;

- in cutaneous tissue: at the entry point of the radiation, tissue damage is maximum with an early dermal-epidermal dissociation, followed by the rapid appearance of extensive fibrosis and lysis of muscle cells. Loss of hair can be observed a few days after irradiation, showing a high local dose. It is important for the dosimetric reconstitution to write down the date of appearance, the extent and accurate location of these lesions;

- in the digestive system.

The hematological and digestive lesions are often associated and characterized by:

- a typical coagulation trouble with a decrease in platelets and an increase in fibrinogen;

- a medullar hypoplasia characterized by a very rapid regeneration at the end of the clinical period;

- for the digestive system, transit and absorption problems are sometimes accompanied by a hemorrhage syndrome, affecting all the organs (from the tongue to the colon) except the small intestine.

Ear/nose/throat syndrome, dyspnea and pulmonary failure.

\section{Biological investigations show:}

- a granulocytic peak (within $12 \mathrm{~h}$ ), followed by a rapid drop in lymphocytes, polynuclears, platelets;

- coagulation problems (cf. above) and modification of factors II, VII, X;

- other investigations which are not part of the usual practice show a peak of different growth factors and cytokines and of inflammation biomarkers (IL 6, IL 8, G-CSF, CRP (at Day 1), etc.);

- Increase in $C$ reactive protein (CRP) and in the fibrinogen which show a major inflammatory syndrome and are a bad prognosis.

\section{The severity of the irradiation is estimated, among others, using two specific investigations:}

- Cytogenetics: on lymphocytes, the rate of early chromosomal aberrations follows a dose-effect relation: it is possible to determine a global absorbed dose and to evaluate the degree of heterogeneity of the irradiation.

- EEG: neutron irradiation leads to specific changes in the EEG with fast waves in beam type ("benzodiazepine-like"). Irradiation leads to changes in the EEG according to a dose-effect relation (slowing down of the back rhythm, changes in evoked potentials) which allow the estimation of the global irradiation and the level of the cephalic irradiation. 


\section{What to do in case of hospitalization}

Leaflet 5

- Clinical tests (symptoms, clinical examination) which identify all the changes compared to the initial tests.

- An immediate biological test (with the TIME) which includes (see Leaflets 15 and16):

- a hematological investigation (FBC, reticulocytes, platelets),

- the following investigations if they have not been done prior to hospitalization:

- erythrocyte group, HLA I and II typing;

- cytogenetics.

- coagulation tests (PT, APTT, fibrinogen, factors II, VII, X, etc.);

- check the biomarkers (cytokines, growth factors, CRP, fibrinogen);

- a biochemical test (blood and urine) and enzymology;

- bacteriological samples (depending on the context);

- samples for radiotoxicology (see Leaflets 15 and 16);

- CMV serology, toxoplasmosis if blood transfusions are foreseen.

- An EEG done as soon as possible in a specialized service (according to usual methods, and including a recording time of one hour, with hyperpnea and luminous stimulation tests).

- Later monitoring and repeated investigations depend on clinical evolution (see Leaflet 15), in particular: hepatic, renal and intestinal surveillance:

- specialized samples (see Leaflet 16);

- plan a new cytogenetic investigation within $48 \mathrm{~h}$ if necessary;

- continue radiotoxicological examinations with the occupational physician;

- plan an ophthalmologic examination (especially tests on the back area of the lens).

- Tests on the hematopoietic bone marrow in the different medullar areas is required in case of hypoplasia to estimate spontaneous regeneration potential:

- CD34+ cell count to evaluate quantitative damage of stem cells;

- the sample sites are chosen depending on the dosimetric estimations (with at least one site considered as relatively only slightly irradiated);

- to conduct a morphological study: myelogram and medullar biopsy;

- to estimate the damage at the sampled point: progenitor cultures (taken during the medullar biopsy) over 8 days to 3 weeks;

- Flt3-ligand: see Leaflet 16.

- The treatment principles are based on:

- Prevention of vomiting (antiserotoninergic of type 3).

- Prevention and treatment of any potentially infectious zone, particularly:

- open wounds, burns,

- mouth area.

- The treatment of lesions whose origin can only be determined after running complex tests (digestive syndrome, pulmonary syndrome, medullar aplasia, inflammatory syndrome, etc.).

- Taking into account the evolution of the inflammatory syndrome (a treatment difficult to codify).

- Prevention of multiple organ failure syndrome. 


\section{Determination of the absorbed dose during a criticality accident}

During a criticality accident, the people exposed are submitted to mixed neutron and gamma fields. A "pathognomonic" trace remains, which is due to the activation of some of their atoms by the neutrons, a phenomenon which does not occur during an exposure to only gamma rays unless the latter have an energy much greater than $10 \mathrm{MeV}$, the energy threshold of nuclear reactions $(\gamma, \mathrm{n})$.

Based on this Neutron Induced Gamma Activity (NIGA), the dose received during a criticality accident can be estimated.

\subsection{Activated atoms taken into account}

The activation of two stable isotopes, sodium 23 and sulfur 32, was chosen because of their relative abundance in the human body ${ }^{2}$ and of their specific cross-section to neutrons $(\sigma)$, the number of atoms activated for a given neutron fluence obviously being proportional to the number of atoms present (number of targets).

The respective activation reactions of ${ }^{23} \mathrm{Na}$ and ${ }^{32} \mathrm{~S}$ are:

$$
{ }^{23} \mathrm{Na}(\mathrm{n}, \gamma){ }^{24} \mathrm{Na}
$$

${ }^{24} \mathrm{Na}$ decreases and emits a $\beta\left(E_{\max }=1.39 \mathrm{MeV}, E_{\text {moy }}=0.554 \mathrm{MeV}\right)$ and $2 \gamma(1.369$ and $2.754 \mathrm{MeV}$ ).

$T=14.960 \pm 0.006 \mathrm{~h}$,

$\sigma=0.203$ barn for thermal neutrons.

In the human body there is on average $1.4 \mathrm{~g}$ of ${ }^{23} \mathrm{Na}$ per kilogram of body weight.

$$
{ }^{32} \mathrm{~S}(\mathrm{n}, \mathrm{p})^{32} \mathrm{P}
$$

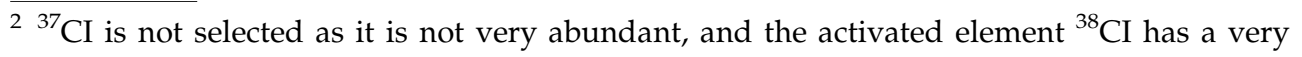
short half-life (37 $\mathrm{min})$. 
${ }^{32} \mathrm{P}$ is a pure $\beta$ emitter $\left(E_{\max }=1.7 \mathrm{MeV}, E_{\operatorname{moy}}=0.695 \mathrm{MeV}\right.$ )

Neutron energy threshold of reaction (2): $2.5 \mathrm{MeV}$,

$T=14.28 \pm 0.02$ days,

$\sigma=0.530$ barn for fast neutrons.

There is on average $45 \mathrm{mg}$ of sulfur per gram of integuments of which $95 \%$ is of ${ }^{32} \mathrm{~S}$. Reaction (1) allows, using the abundance of thermal neutrons, an estimation of the average dose due to all the neutrons present whereas the second reaction is likely to provide two different kinds of information:

- position of the subject during the criticality flash,

- proportion of fast neutrons, in other terms of an energy greater than $2.5 \mathrm{MeV}$ in the radiation fluence of the criticality accident. This determination is essential since the "recoil" absorbed dose mainly comes from neutrons with an energy greater than $100 \mathrm{keV}$.

\subsection{Measurement methods for activity}

The "anthropogammameters" provide an accurate measurement of the gamma activity due to the presence of ${ }^{24} \mathrm{Na}$ in the human body ${ }^{3}$ even if it is only very slight (a few dozen $\mathrm{Bq}$ ). This measurement must be made early ${ }^{4}$ since the half-life of ${ }^{24} \mathrm{Na}$ is relatively short: $14.96 \mathrm{~h}$. The anthropogammametric measurement is used instead of all others for dosimetric estimation. Smaller devices also provide information but are mostly reserved for the initial triage of the individuals assumed to have been exposed.

As for the measurement of radio-induced ${ }^{32} \mathrm{P}$, a $\beta$ counting will be used with a given quantity of integuments whose weight and sulfur content are known. This can be done extremely accurately by liquid scintillation. Physically, it is less urgent since ${ }^{32} \mathrm{P}$ has a relatively long half-life but it has a double advantage which was seen previously by giving information on the distribution of body dose.

\subsection{Evaluation of the dose due to neutrons using sodium 24}

The relation between the kerma and the radio-induced activity due to ${ }^{24} \mathrm{Na}$ is a complex function as nearly in every case when bequerels (Bq) must be taken to grays (Gy) or sieverts (Sv).

In the specific case of neutrons, the energy of the neutrons must be taken into account, thus their emission spectrum since the yield of nuclear reactions ( $\sigma$ crosssection) (1) and (2) is dependent on this energy. Besides, in case of a very short criticality flash, the orientation of the subject at that precise time and the scattering of neutrons must be taken into account since these are always very important.

\footnotetext{
${ }^{3}$ It goes without saying that any external contamination of the subject must be eliminated. In the case of very high contamination, the measurement of ${ }^{24} \mathrm{Na}$ in the blood must be used.

4 Ideally, the measurement should be started at $\mathrm{H}+4 \mathrm{~h}$, when the few short-lived elements have disappeared.
} 
The total dose in Gy or in Gy equivalent can be calculated as follows:

- Either $A$, the activity of the person exposed, expressed in $\mathrm{Bq}$ of ${ }^{24} \mathrm{Na}$ at time $t=0$ (time of flash).

- Either $\delta(k)$, the value of the kerma in $\mathrm{Gy} \mathrm{Bq}^{-1}$ for the given neutron spectrum.

- Either $K=A$. $\delta(k)$, the value of the kerma in Gy due to the exposure to neutrons.

- Either RBE = Relative Biological Efficiency of neutrons for the survival criterion which is assumed to be 1 in this particular case.

- Either $p=D_{\gamma} / K$ the ratio between the gamma dose and the neutron kerma during exposure.

- Either $D_{\mathrm{T}}$, the total dose received in Gy.

$$
D_{T}=K(1+p)
$$

In the absence of any information, it is recommended, for a man weighing $68 \mathrm{~kg}$, to take the following value, an average of four different neutron spectra:

$$
\delta(k)=3.6 \mathrm{rad} \mu \mathrm{Ci}^{-1} \text { either } 0.97 \times 10^{-6} \mathrm{~Gy} \mathrm{~Bq}^{-1} \text { and } p=2 .
$$

The formula thus becomes in this case:

$$
D_{T}(\mathrm{~Gy})=3 \times 10^{-6} A(\mathrm{~Bq})
$$

Because of the approximations made during the estimation of the dose, the total exposure, thus determined, must be considered as a temporary evaluation since the kerma for the neutrons can vary from 0.5 to $3 \times 10^{-6} \mathrm{~Gy} \mathrm{~Bq}^{-1}$ depending on the type of neutron spectrum.

The significant detection threshold is around one milligray.

References:

GT-criticité Report 1984, SMT-LABM.

IAEA, Safety Series No. 211, Dosimetry for Criticality Accidents, a Manual.

ICRP 89, Basic anatomical and physiological data for use in radiological protection: reference values.

Tabardel R., Ricourt A., Parmentier N. (1984) Rapport CEA-R 5276, Evaluation rapide de la dose due aux neutrons à la suite d'un accident de criticité à partir de l'activité du sodium 24 mesurée.

\subsection{Evaluation of the dose due to neutrons using phosphorus 32}

- Based on a counting of the $\beta$ activity of ${ }^{32} \mathrm{P}$ by liquid scintillation, with integuments (at a threshold of 95\%) of around $0.05 \mathrm{~Gy}$, for neutrons with energy of $2.5 \mathrm{MeV}$ as shown in experiments conducted on the SILENE reactor (Valduc, France).

\footnotetext{
${ }^{5}$ In an individual of weight $\mathrm{P}(\mathrm{kg})$, the radio-induced activity is $A^{\prime}=A \mathrm{P} / 68$.
} 
- The measurements on different integument parts thus allow, in the case of a flash, the positioning of the individual in the fluence and therefore provide the physicians with precious information both prognostic and therapeutic (distribution of body dose).

From a "practical" point of view, in the absence of accurate information on the type of spectrum, an estimate of the conversion factor based on the SILENE experiments will be used. In this case, the total neutron dose is equal to:

$$
\text { Total neutron dose }(\mathrm{Gy})=1.2 \times A\left(\mathrm{~Bq} \mathrm{~g}^{-1}\right)
$$

References:

Feng Y., Brown K.S., Casson W.H., Mei G.T., Miller L.F., Thine M. (1993) Determination of Neutron Doses from Criticality Accidents with Bioassays for Sodium-24 in Blood and Phosphorus-32 in Hair, ORNL/TM-12028, Oak Ridge National Laboratory, Oak Ridge, TN.

ICRP 89, Basic anatomical and physiological data for use in radiological protection: reference values.

Lebaron-Jacobs L. et al. (2007) Contribution of Hair Dosimetry following Neutron Irradiation, Health Physics 92, S98-S104.

Lemaire G., Dhermain J., Remy M.L., Masse R. (1992) Estimation de la dose absorbée en cas d'exposition aux neutrons rapides à l'aide de la transmutation du soufre en phosphore dans le système pileux, Radioprotection 27, 17-34.

\section{Determination of the absorbed dose during a criticality accident in the specific case of the external contamination of the subject}

In this case, it is not often possible to determine the activity of sodium radioinduced by the neutron flux using an anthropogammameter. Unless there is an easy and quick decontamination, the activity of ${ }^{24} \mathrm{Na}$ in the blood of the individual must be determined.

Similar to the determination of ${ }^{24} \mathrm{Na}$ activity by anthropogammametry, for a given flux of neutrons, the absorbed dose will depend on the neutron energy spectrum emitted during the criticality accident.

In a very pragmatic way, if the human body contains on average $1.4 \mathrm{~g}$ of ${ }^{23} \mathrm{Na}$ per kilogram of body weight, blood contains slightly more, $1.91 \mathrm{mg} / \mathrm{mL}$.

If the blood sample is taken several days after the accident, the biological period of ${ }^{23} \mathrm{Na}$ will have to be integrated in the analysis. The $R_{t}$ fraction retained in the body is equal to:

$$
R_{t}=0.487 \mathrm{e}^{-0.0815 t}+0.510 \mathrm{e}^{-0.0513 t}+0.0027 \mathrm{e}^{-0.0015 t},
$$

$t$ being expressed in days. 
The radio-induced activity of ${ }^{24} \mathrm{Na}$ is then equal to ${ }^{6}$ :

$$
A_{\mathrm{Na}}=\lambda C F_{\mathrm{a}} / 60 \times E_{\mathrm{f}} V R_{t}\left(\mathrm{e}^{-\lambda t_{1}}-\mathrm{e}^{-\lambda t_{2}}\right) \mathrm{Bq} \mathrm{mL}^{-1}
$$

where, in this formula:

$\lambda$ : the radioactive decrease constant of ${ }^{24} \mathrm{Na}\left(0.00077 \mathrm{~min}^{-1}\right)$,

$C$ : number of counts per minute due to ${ }^{24} \mathrm{Na}$ with background noise correction,

$F_{\mathrm{a}}$ : correction factor in case of no flash,

$E_{\mathrm{f}}$ : efficiency of the detector in the area of interest of the energy spectrum (gamma of $1.368 \mathrm{MeV}$ ),

$V$ : blood volume in $\mathrm{mL}$

$R_{\mathrm{t}}$ : fraction of ${ }^{24} \mathrm{Na}$ in the blood,

$t_{1}$ and $t_{2}$ : beginning and end of counting in minutes since the neutron flash.

As an example, for a very short flash $\left(F_{\mathrm{a}}=1\right)$ produced by a pure fission spectrum, and for a volume of $20 \mathrm{~mL}$ of blood, the efficiency of a HPGe detector is equal to $4.92 \times 10^{-3}$ in the area of interest of the peak $(1.368 \mathrm{MeV})$. Moreover if a measurement of an hour is made in $4 \mathrm{~h}$ after the flash $\left(R_{\mathrm{t}}=1\right)$ and if 1000 shots have been counted in the area of interest, it becomes: $A=$ Activity of ${ }^{24} \mathrm{Na}$ in the blood per $\mathrm{mL}=3.47 \mathrm{~Bq} \mathrm{~mL}^{-1}$.

By assuming that the Dose/ Activity factor is equal to $3.13 \times 10^{-1} \mathrm{~Gy} \mathrm{~Bq}^{-1} \mathrm{~mL}$ for this spectrum (experimental determination using a source of ${ }^{252} \mathrm{Cf}$ ), the neutron dose is then equal to 1.09 Gy (Feng, 1993).

For a spectrum of slow neutrons, the $D / A$ factor, again experimentally determined, is only equal to $5.93 \times 10^{-3} \mathrm{~Gy} \mathrm{~Bq}^{-1} \mathrm{~mL}$.

In the absence of accurate information on the type of spectrum, a value of 0.3 Gy $\mathrm{Bq}^{-1} \mathrm{~mL}$ will be used as a reference value and the estimated neutron dose will then be equal to:

$$
D(\mathrm{~Gy})=0.3 \times A\left(\mathrm{~Bq} \mathrm{~mL} \mathrm{~m}^{-1}\right)
$$

Remarks:

For a blood sample of $20 \mathrm{~mL}$ the sensitivity of the measurement varies between 0.01 and $0.02 \mathrm{~Gy}$ of total neutron dose for fast neutrons and is lower than $0.005 \mathrm{~Gy}$ for spectra with "soft" neutrons. This is for a measurement (counting) lasting between 30 and $60 \mathrm{~min}$.

The gamma dose associated to the neutron dose can be estimated as above but the external contamination of the subject must also be considered.

\section{References:}

Feng Y., Brown K.S., Casson W.H., Mei G.T., Miller L.F., Thine M. (1993)

Determination of Neutron Doses from Criticality Accidents with Bioassays for Sodium-24 in Blood and Phosphorus-32 in Hair, ORNL/TM-12028, Oak Ridge National Laboratory, Oak Ridge, TN.

\footnotetext{
${ }^{6}$ If the accident was not a very short flash, the decrease of ${ }^{24} \mathrm{Na}$ radio-induced by the neutrons for the duration of the exposure must be taken into account. A correction factor $F_{\mathrm{c}}=\lambda t_{\mathrm{a}} / 1-\exp \left(-\lambda t_{\mathrm{a}}\right)$, where $t_{\mathrm{a}}$ represents the duration of exposure in minutes and $\lambda=0.00077 \mathrm{~min}^{-1}$, is then introduced.
} 
CIPR 89, Basic anatomical and physiological data for use in radiological protection: reference values.

\title{
3. Aids to decision making
}

\author{
Routes

\section{BNF or nuclear site circuits} \\ The Internal Plan of Emergency (IPE) ensures the organization and implementation of the \\ means. The general principle is structured as follows: \\ - The medical/surgical emergencies are directly sent to the hospitals after advice from \\ the physician in charge. \\ - Outside the exclusion area, the evacuation of people to the gathering point allows \\ them to be sent to the triage center. \\ - Neutron activation and contamination measurements will define the order in which \\ patients are taken care of. \\ - Then, from the triage center, the people to be taken care of by the on site medical \\ service are sent to be tested and possibly to be accurately decontaminated.
}

\section{The BNF medical service}

The recommendations and reflex leaflets organize the means used to take care of patients and the role of the different members of the medical team, those of the biochemistry analysis laboratory and the Radiation Protection Service:

- The serious irradiation cases with symptoms are directly taken care of in the medical rooms.

- At the Occupational Medical Service, triage of the irradiated patients, then of involved victims.

- Anthroporadiametry.

- Medical examination with questionnaire and individual patient records.

- Additional hematological, biochemical, radiotoxicological examinations with samples taken of integuments depending on the estimated level of exposure.

- Summary and transport to appropriate medical structures.

\section{Outside the center}

Several situations require specific procedures, and some of them, assistance conventions:

- Later follow-up and possible assistance to medical structures: family physicians, internal medicine or specialized hospital structures.

- Liaison with the different specialists and the authorities.

- Team back-up. 


\section{Indications for prescriptions and orientation of victims}

\section{Depending on the neutron dose estimated during triage}

Table I. Sensitivity of examinations and orientation depending on the dose.

\begin{tabular}{llll}
\hline $\begin{array}{l}\text { Sensitivity } \\
\text { thresholds } \\
\text { of techniques used }\end{array}$ & Examinations & $\begin{array}{l}\text { Response } \\
\text { time }\end{array}$ & Orientation \\
\hline $10^{-3} \mathrm{~Gy}$ & $\begin{array}{l}\text { Anthropogammametry } \\
10^{-2} \mathrm{~Gy}\end{array}$ & $\mathrm{H}+3$ & \\
$10^{-1} \mathrm{~Gy}$ & $\begin{array}{l}\text { Activation measurement } \\
\text { (SPP2, SPP3, DG5) }\end{array}$ & $\mathrm{H}+1$ & \\
$1 \mathrm{~Gy}$ & $\begin{array}{l}\text { Dosimeter readings } \\
\text { ICD }+ \text { belts }\end{array}$ & $\mathrm{H}+6$ & General Practitioner $^{(2)}$ \\
& Clinical examination & $\mathrm{H}+3$ & Hospital $^{(2)}$ \\
\hline
\end{tabular}

(1): depending on the number.

(2): except for medical/surgical emergencies or clinical and biological problems.

Table II. Examinations to prescribe depending on the dose.

\begin{tabular}{ll}
\hline Doses & Examinations to prescribe \\
\hline $10^{-3} \mathrm{~Gy}$ & Anthropogammametry \\
$10^{-2} \mathrm{~Gy}$ & Activity ${ }^{24} \mathrm{Na}\left(\right.$ blood tubes $\left.^{(1)}\right)$ \\
$10^{-1} \mathrm{~Gy}$ & Hematology - Biochemistry Cytogenetics \\
$5 \times 10^{-1} \mathrm{~Gy}$ & Integuments \\
$1 \mathrm{~Gy}$ & HLA typing \\
\hline
\end{tabular}

(1): in case no physical measurements can be taken.

Table III. Examinations allowing to measure doses.

\begin{tabular}{|c|c|c|c|}
\hline $\begin{array}{l}\text { Clinical and } \\
\text { biological signs }\end{array}$ & $\begin{array}{l}\text { Bio-physical } \\
\text { examinations }\end{array}$ & $\begin{array}{l}\text { Physical } \\
\text { dosimetry }\end{array}$ & $\begin{array}{l}\text { Indications on dose } \\
\text { measured }\end{array}$ \\
\hline \multirow[t]{2}{*}{ Clinical ( >1 Gy) } & \multicolumn{3}{|c|}{ 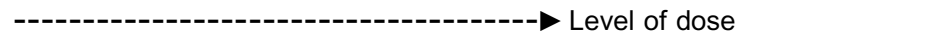 } \\
\hline & \multicolumn{2}{|c|}{ Activity of ${ }^{24} \mathrm{Na}$} & Neutron dose \\
\hline \multirow{2}{*}{$\begin{array}{l}\text { Hematology } \\
\text { - Biochemistry }\end{array}$} & \multicolumn{3}{|c|}{ - Average whole-body dose ${ }^{(1)}$} \\
\hline & Integuments & $----1--1-$ & $\begin{array}{l}\text { Orientation and distribution of } \\
\text { neutron dose }\end{array}$ \\
\hline \multirow[t]{5}{*}{ Cytogenetics } & \multicolumn{3}{|c|}{$\begin{array}{l}\text { Average whole-body dose and } \\
\text { heterogeneity index }\end{array}$} \\
\hline & $\mathrm{EPR}^{(3)}$ & ---------- & Gamma dose essentially \\
\hline & \multicolumn{3}{|c|}{$\begin{array}{c}\text { Individual dosimetry }--\rightarrow \\
\text { Total dose }(n+\gamma) \text { and } \\
\text { orientation }\end{array}$} \\
\hline & \multicolumn{3}{|c|}{ Ambient dosimetry $\rightarrow--$ Total dose $(n+\gamma)$} \\
\hline & \multicolumn{3}{|c|}{$\begin{array}{l}\text { Physical }-1-1-1 \text { Distribution of dose and total } \\
\text { reconstitution } \\
\text { of dose }\end{array}$} \\
\hline
\end{tabular}

(1): average dose to the organism, not taking into account the heterogeneous distribution of the dose. (2): distribution of lymphocyte anomalies.

(3): Electronic Paramagnetic Resonance (EPR): measurement of the quantity of radical species created in the hydroxyapatite (teeth, bones) by an irradiation. EPR is a retrospective dosimetric method (the species created are stable over time). 


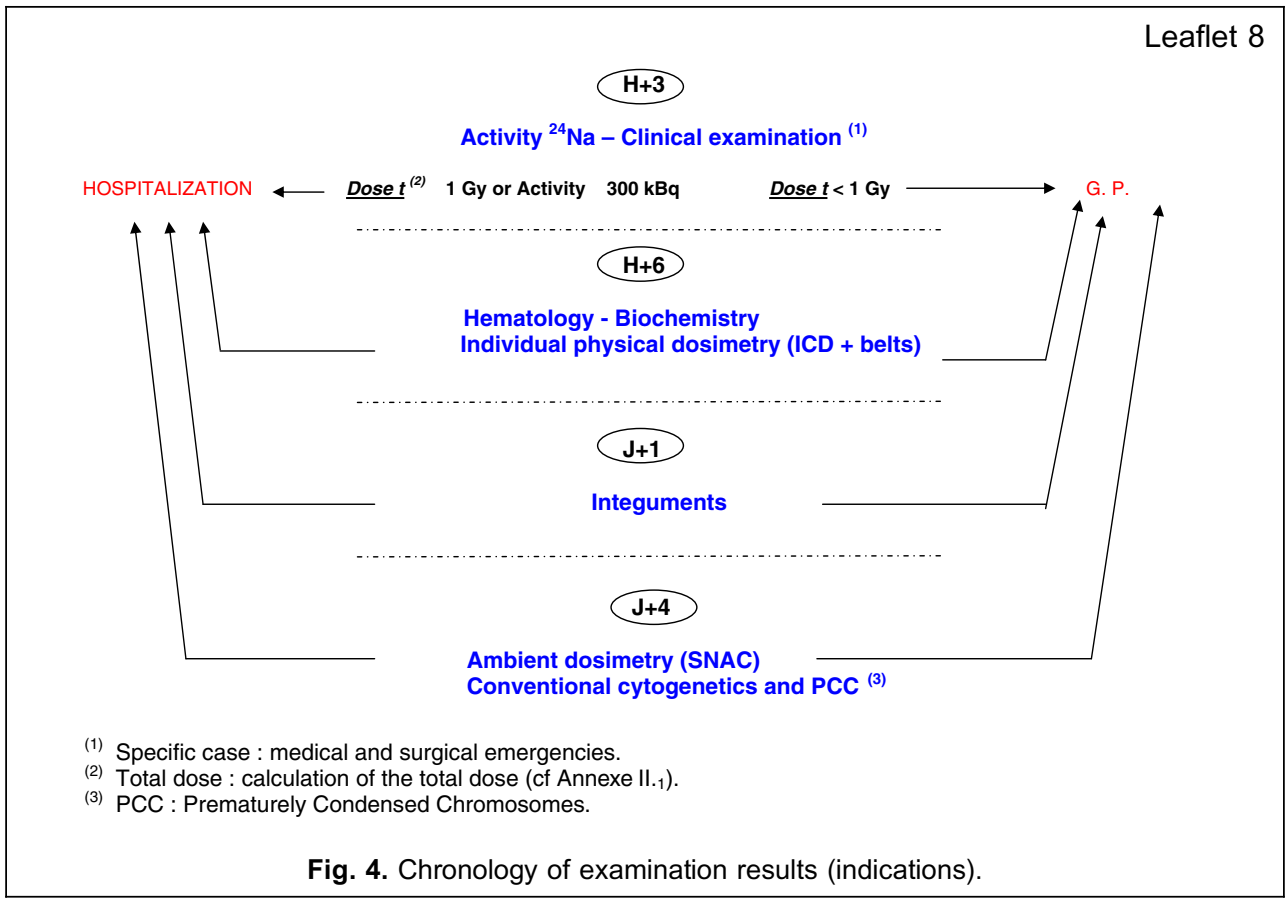

\section{Interview after the accident}

Leaflet 9

Identification of the patient
NAME:
First name:
Date of birth:

Date and time at the beginning of the interview:

Circumstances of the accident

Warning: if the subject vomits, write it down with the time

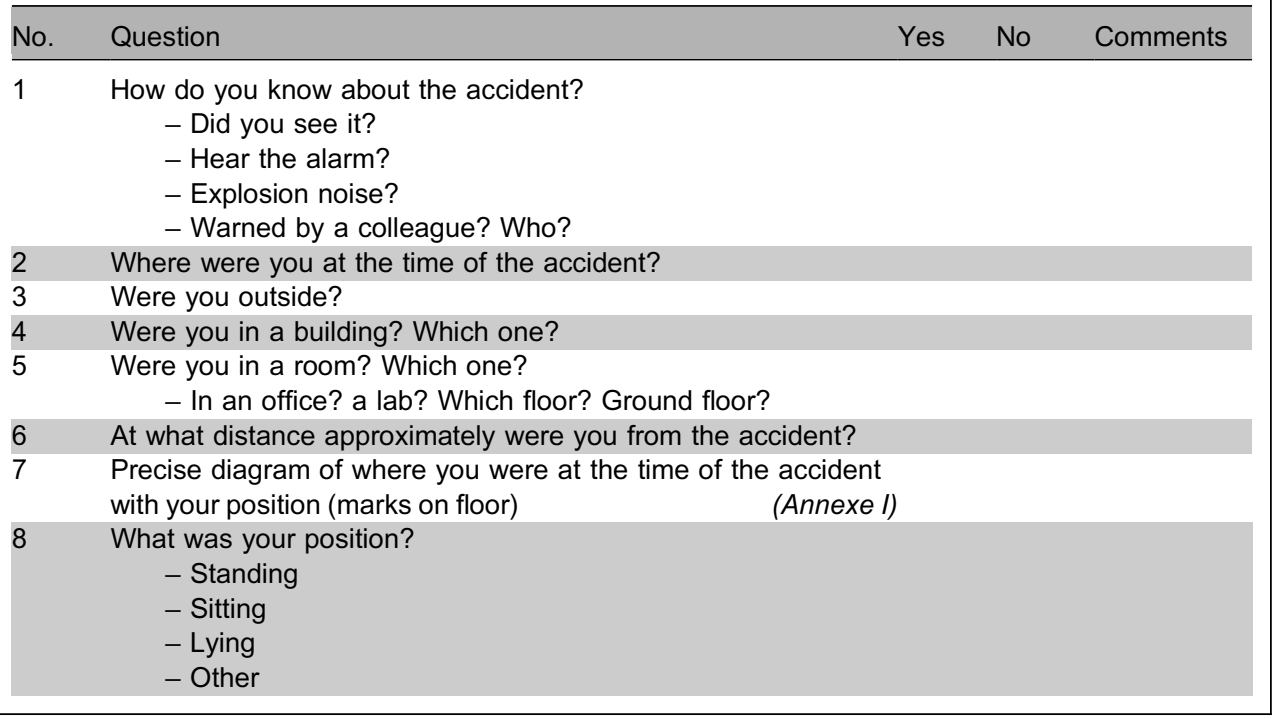


Leaflet 9, continued

\begin{tabular}{|c|c|c|c|}
\hline No. & Question & No & Comments \\
\hline 9 & $\begin{array}{l}\text { Describe your immediate environment: } \\
\text { - Were you near thick concrete elements? } \\
\text { - Were these between you and the accident? } \\
\text { - Were you near metallic elements which were a shield } \\
\text { between you and the accident? } \\
\text { - Can you give their approximate size? }\end{array}$ & & \\
\hline 10 & $\begin{array}{l}\text { Draw on a diagram these different elements as accurately as } \\
\text { possible and position yourself on the floor and in space } \\
\text { (Annexe II) }\end{array}$ & & \\
\hline 11 & $\begin{array}{l}\text { Were other people with you and near you? } \\
\quad \text { - How many? } \\
\quad \text { - Who? (names) }\end{array}$ & & \\
\hline 12 & $\begin{array}{l}\text { Precise diagram of these people's position versus yours } \\
\text { (Annexe III) }\end{array}$ & & \\
\hline 13 & Can you estimate their distance from you? & & \\
\hline 14 & $\begin{array}{l}\text { How long did they stay near you? } \\
\text { What were their respective postures? } \\
\quad \text { - Standing, sitting, lying, other? }\end{array}$ & & \\
\hline 15 & $\begin{array}{l}\text { Accurately describe what you were doing at the time of the } \\
\text { accident }\end{array}$ & & \\
\hline 16 & $\begin{array}{l}\text { Accurately describe, at the time of the accident: } \\
\text { - What you saw? } \\
\text { - What you heard? } \\
\text { - What you smelled? }\end{array}$ & & \\
\hline 17 & How much time has each of your acts taken since the accident? & & \\
\hline 18 & $\begin{array}{l}\text { Which route did you take to join the gathering point? } \\
\text { Who was with you? }\end{array}$ & & \\
\hline 19 & How much time did it take you to reach the gathering point? & & \\
\hline 20 & $\begin{array}{l}\text { Draw a precise diagram of your itinerary to join the gathering } \\
\text { point } \\
\text { (Annexe IV) }\end{array}$ & & \\
\hline
\end{tabular}

Time at the end of interview and examination:

Name of the person conducting the interview:

\section{ANNEXE I}

Precise diagram of where you were at the time of the accident with your position (marks on floor).

ANNEXE II

Draw on a diagram these different elements as accurately as possible and position yourself on the floor and in space.

ANNEXE III

Precise diagram of these people's position versus yours.

ANNEXE IV

Draw a precise diagram of your itinerary to join the gathering point. 


\section{Clinical observations}

Identification of patient

NAME:

First name:

Date of birth:

Date and time at the beginning of the examination:

\begin{tabular}{|l|l|}
\hline Pulse & \\
\hline Blood pressure & \\
\hline Temperature & \\
\hline
\end{tabular}

No. Question Yes No Comments

1 Does the patient have a rash, a burn, a wound?

Since when?

Locate it precisely:

- Face

- Hands

- Other (diagram or photo)

2 Is the patient asthenic, sleepy, euphoric?

Since when?

Moderately, intensely?

$3 \quad$ Has the patient had nausea since the accident?

Moderate, intense?

$4 \quad$ Does the patient have abdominal pains?

Since when?

Moderate, intense?

- Precise location on diagram

$5 \quad$ Has the patient vomited?

When?

Moderately, intensely?

Projectile vomiting?

How many times since the accident?

- Write down the times

6 Does the patient have diarrhea?

Since when?

Moderate, intense?

How many stools since the accident?

- Liquid or formed?

- Write down the times

$7 \quad$ Does the patient have trouble swallowing?

Aspect of the ear/nose/throat mucous?

- Normal?

- Inflamed?

8 Does the patient have headaches?

Since when?

Moderate, intense?

- Describe them 


\begin{tabular}{|c|c|c|c|c|}
\hline & & \multicolumn{3}{|c|}{ Leaflet 10 , continuec } \\
\hline No. & Question & Yes & No & Comments \\
\hline 9 & $\begin{array}{l}\text { Has the patient experienced dizziness? } \\
\text { Since when? } \\
\text { Moderately, intensely? } \\
\quad \text { - Describe these spells }\end{array}$ & & & \\
\hline 10 & $\begin{array}{l}\text { Has the patient fainted? } \\
\text { How many times? } \\
\text { - Describe }\end{array}$ & & & \\
\hline 11 & $\begin{array}{l}\text { Is the patient disoriented in time and space? } \\
\text { Moderately, intensely? } \\
\text { - Describe }\end{array}$ & & & \\
\hline 12 & $\begin{array}{l}\text { Does the patient have ataxia? } \\
\text { Moderate, intense? } \\
\text { - Describe }\end{array}$ & & & \\
\hline 13 & Quick cardio-vascular examination & & & \\
\hline 14 & Quick pulmonary examination & & & \\
\hline
\end{tabular}

If it is possible, again take patient's:

\begin{tabular}{|l|l|}
\hline Pulse & \\
\hline Blood pressure & \\
\hline Temperature & \\
\hline
\end{tabular}

Time at the end of the examination:

Identification of the person who had conducted the clinical examination:

\section{Biological dosimetry by counting chromosomal aberrations medical/legal technique}

\section{What is biological dosimetry?}

Biological dosimetry by means of cytogenetics is a technique to evaluate the dose received by a person who has probably been accidentally irradiated. This technique is based on the counting of chromosomal aberrations in the lymphocytes circulating in the blood sample taken.

The frequency of radio-induced chromosomal aberrations is linked to the type of irradiation source, the exposure time and the dose rate.

Dose-effect curves help to estimate, based on the frequency of chromosomic anomalies, the absorbed dose by the whole body. The minimum dose which can be detected depends on the number of cells observed and the background of the population (1 dicentric for 1000 cells). The minimum dose is of about $0.1 \mathrm{~Gy}$ when 500 cells are observed. 


\subsection{When should biological dosimetry be used?}

Irradiation accidents involve all categories of the population, general public and workers. Biological dosimetry helps define the state of the patient, by completing the physical dosimetry (dosifilm) and the clinical examination. It is especially useful when the person who might have been irradiated was not wearing a dosimeter at the time of exposure. Its first role is to check whether the exposure actually occurred; then, if this is the case, to estimate the dose received according to the type of radiation.

The counting of chromosomal aberrations of unstable type (dicentric, centric rings) is now considered as the most accurate and sensitive biological dosimetry method. It is of medico-legal value (Fig. 5).

The Biological Dosimetry Laboratory (BDL) of the IRSN is the only laboratory in France using biological dosimetry in cases of exposure to ionizing radiation. Two hundred cases were studied by the laboratory between 1992 and 2003.

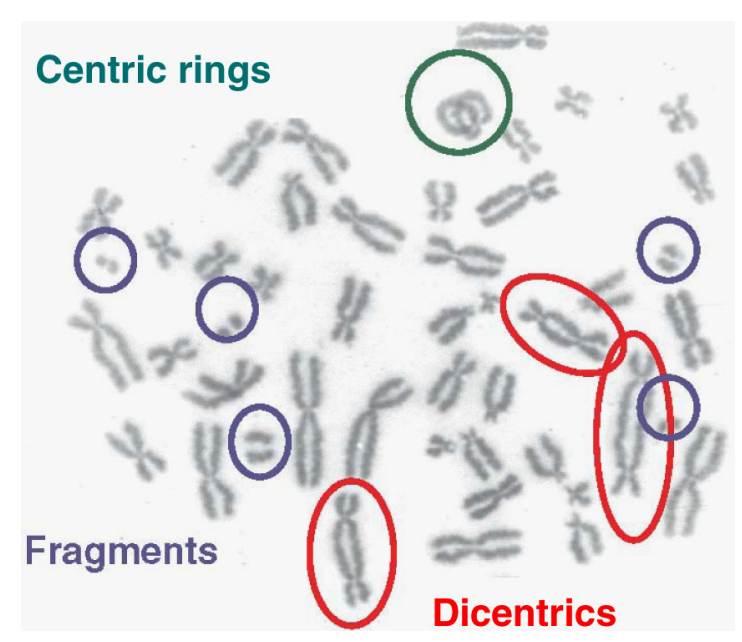

Fig. 5. Unstable chromosomal aberrations.

The need for expertise in biological dosimetry. The BDL can respond at any time to a request for expertise from a physician.

A quality assurance procedure is used to regulate the relations between the BDL and their clients, especially concerning the confidentiality of the medical information required to estimate the dose.

The BDL is accredited in case of large scale accident. Moreover, it is part of an international network of similar laboratories.

Institut de Radioprotection et Sûreté Nucléaire, DRPH/SRBE

Chef du Laboratoire de Dosimétrie Biologique BP No. 17

F-92262 Fontenay-aux-Roses cedex, France

Tel.: +33158357260 - Fax:+33158348467 


\subsection{The different types of chromosomal aberrations}

Ionizing radiation causes energy deposits within the molecular structure of the deoxyribonucleic acid (DNA). Despite efficient repair mechanisms, damage can subsist and lead to the appearance of chromosomal aberrations which can be observed within the blood lymphocytes during cellular division (metaphase).

The type of aberration depends on its formation mechanism (see Fig. 6):

- fragment, deletion: break not repaired of a chromosome,

- inversion, centric ring: incomplete repair of the chromosome itself,

- dicentric, translocation: exchange of genetic material between two chromosomes.

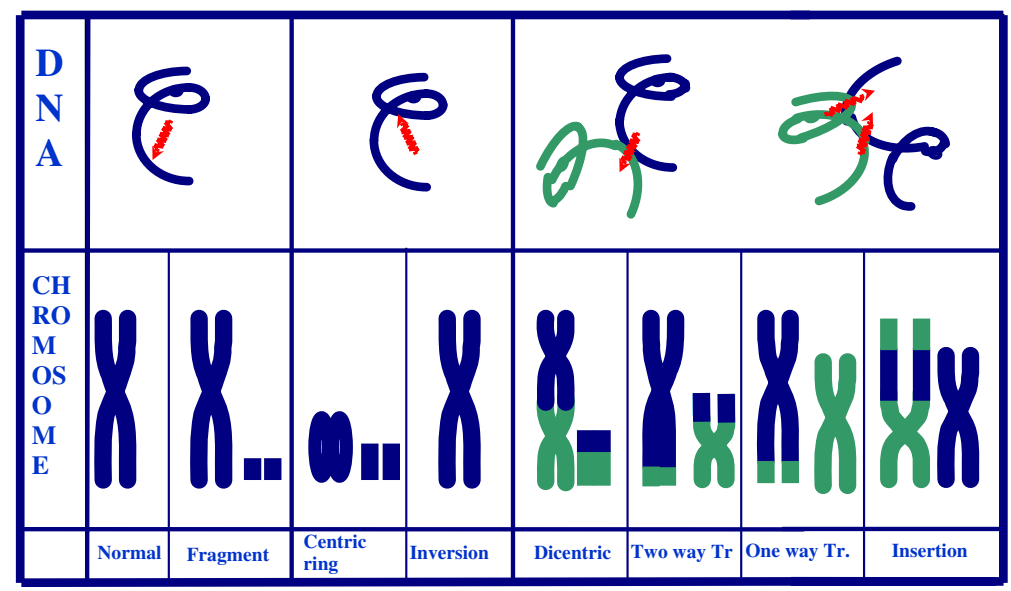

Fig. 6. Different types of chromosomal aberrations.

\section{Case of a heterogeneous irradiation}

The dose estimated by the biological dosimetry techniques is the average dose received by the whole body. This technique is thus very well adapted to a global and homogeneous use. In this case, the number of chromosomal aberrations per cell follows the Poisson Law.

The study of the distribution of these chromosomal aberrations often allows the global exposures to be differentiated from the heterogeneous exposures.

In the case of heterogeneous exposure, the use of appropriate mathematical models can more accurately define the dose received by part of the irradiated body. However, the irradiated body fraction must be greater than $10 \%$ of the total body volume.

\section{Stability of aberrations}

Severe damage to the shape of the chromosome means problems for the cell during cellular division. Therefore, the cells with dicentrics will disappear over time. 
The dicentric, centric ring and fragment aberrations are called "unstable". Consequently, the dose estimation by means of medico-legal technique is only valid in the few weeks after exposure.

On the contrary, inversions and translocations are aberrations which do not change the general shape of the chromosomes. The shape can be maintained after cell division and thus these are called "stable" aberrations. Because of this stability, they can be the mark of a former irradiation.
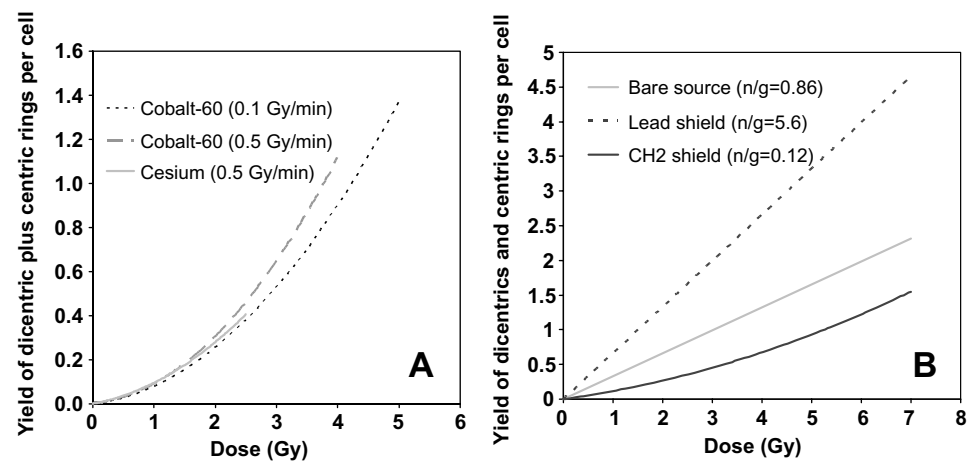

Fig. 7. Dose-effect relation.

\section{Dose-effect relation}

If exposure to ionizing radiation is confirmed, it is interesting to know the correspondence between the number of dicentrics observed and the dose potentially received by the victim (Fig. 7).

Reference curves are established by irradiating blood in vitro with a defined radiation source. These are different depending on the quality of the radiation and the dose rate. These curves come from different laboratories since they are drawn in the same methodological conditions as the expert analyses.

\section{Accuracy of dose measurement}

The accuracy of the estimation of the dose for the whole body obtained using the counting of dicentrics depends on several factors (Fig. 8):

- The number of cells observed for the expert analysis. Generally, 500 cells are observed per expert analysis. When greater accuracy is needed, 1000 to 2000 cells can be examined.

- The value of the background level in the population. This is of 1 dicentric per 1000 cells, the gender and age of the people being indifferent.

- The accuracy of the reference curve used, especially for low doses.

That is why it is necessary to complete the estimation of the dose by a confidence interval which integrates all these parameters.

\section{Confidence interval of the dose (Table IV)}

Evaluation of the dose (D) in Gray and of its confidence interval at 95\% (IC95) depending on the number of dicentrics observed for a set number of cells. These 


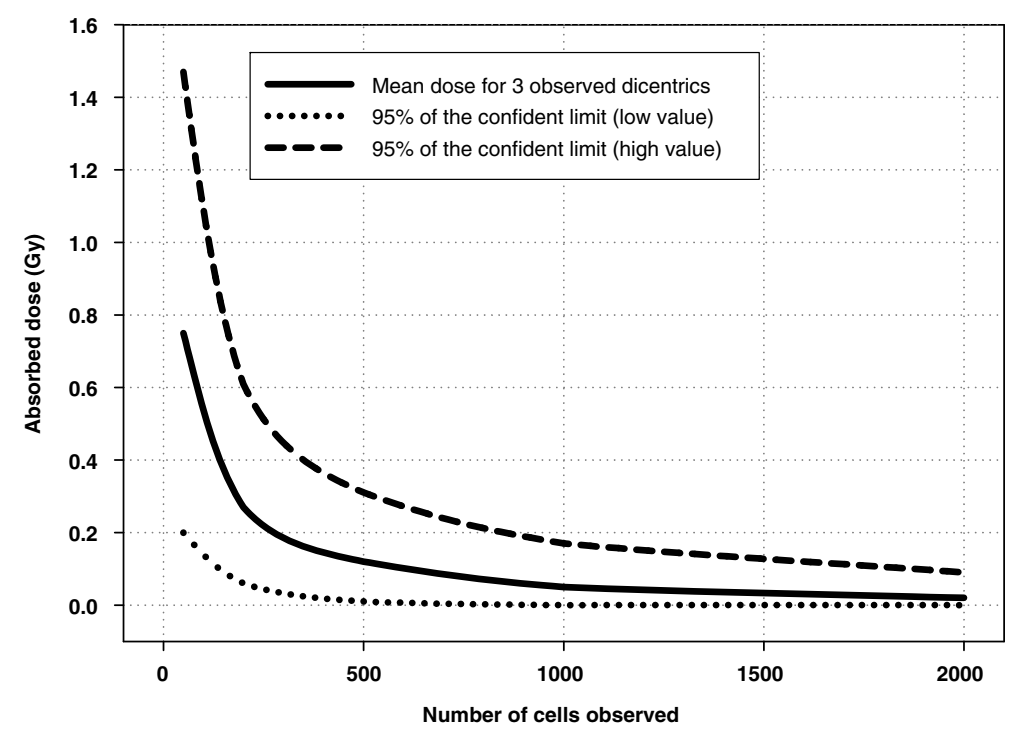

Fig. 8. Accuracy of the dose measurement.

Table IV. Confidence interval of dose.

\begin{tabular}{|c|c|c|c|c|c|c|c|c|}
\hline \multirow{3}{*}{$\begin{array}{l}\text { Number of } \\
\text { dicentrics }\end{array}$} & \multicolumn{8}{|c|}{ Number of cells scored } \\
\hline & \multicolumn{2}{|c|}{50} & \multicolumn{2}{|c|}{250} & \multicolumn{2}{|c|}{500} & \multicolumn{2}{|c|}{1000} \\
\hline & Dose & IC $95 \%$ & Dose & IC $95 \%$ & Dose & IC $95 \%$ & Dose & IC $95 \%$ \\
\hline 0 & 0 & {$[0-2.7]$} & 0 & {$[0-0.8]$} & 0 & {$[0-0.5]$} & 0 & {$[0-0.2]$} \\
\hline 1 & 0.4 & {$[0-3.5]$} & 0.08 & {$[0-1.1]$} & 0.03 & {$[0-0.7]$} & 0 & {$[0-0.3]$} \\
\hline 2 & 0.6 & {$[0.05-4.1]$} & 0.2 & {$[0-1.4]$} & 0.08 & {$[0-0.8]$} & 0.03 & {$[0-0.3]$} \\
\hline 3 & 0.8 & {$[0.2-4.6]$} & 0.2 & {$[0.02-1.6]$} & 0.1 & {$[0-0.9]$} & 0.05 & {$[0-0.5]$} \\
\hline 4 & 0.9 & {$[0.2-5.0]$} & 0.3 & [0.05-1.8] & 0.2 & {$[0.01-1.1]$} & 0.08 & {$[0-0.2]$} \\
\hline 5 & 1.08 & {$[0.3-5.4]$} & 0.4 & {$[0.08-2.0]$} & 0.2 & {$[0.03-1.2]$} & 0.1 & {$[0-0.7]$} \\
\hline 6 & 1.2 & [0.4-5.8] & 0.4 & [0.1-2.1] & 0.2 & [0.05-1.3] & 0.1 & [0.01-0.7] \\
\hline 7 & 1.3 & [0.5-6.1] & 0.5 & [0.1-2.3] & 0.3 & [0.07-1.4] & 0.1 & [0.02-0.8] \\
\hline
\end{tabular}

calculations are made, using the reference curve of the laboratory, and by assuming that the frequency of the dicentrics per cell follows Poisson's Law: [freq dic] $=0.001+$ 0.034 [Dose] + 0.053 [Dose $]^{2}$.

\section{Case of high doses}

During the Tokai-mura accident the doses to the 3 patients were of a few grays to over $10 \mathrm{~Gy}$. In this case, the reference technique has its limits since there is saturation above $5 \mathrm{~Gy}$.

The centric rings represent $10 \%$ of the dicentrics and saturation is observed for doses above 30 Gy. The number of rings is thus a good indicator for higher irradiations (Fig. 9). 

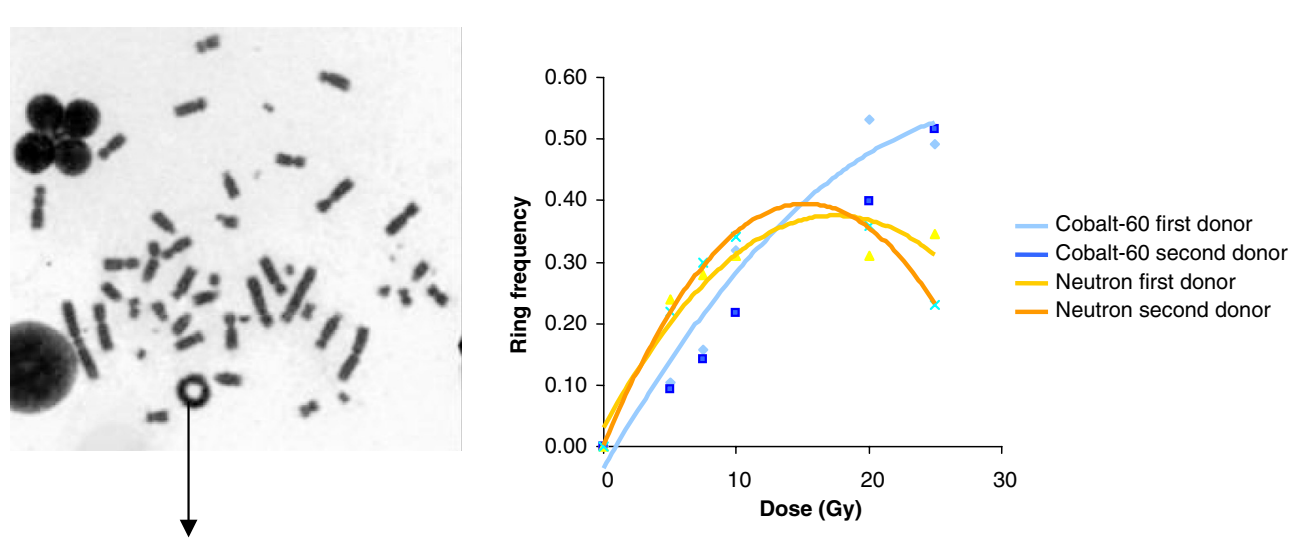

Centric ring

Fig. 9. Dose-effect relation in case of high dose.

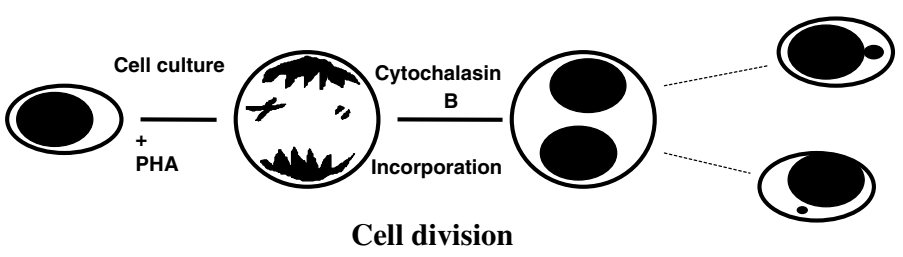

Fig. 10. Micro-nuclei technique.

\section{Case of population triage}

If the number of samples to be analyzed exceeds 10, a great accuracy on the dose will not be as expected as a quick triage of the individuals potentially exposed versus those not exposed. The quickness of the test is thus of utmost importance. Several strategies have been used:

- the analysis of dicentrics in 50 cells instead of 500 in the case of expert analysis,

- advanced automation which accelerates the treatment time,

- the use of the micro-nuclei technique (Fig. 10).

The time needed to obtain a dose and a sensitivity limit, depending on the number of individuals potentially involved and on the dosimetric techniques used, is roughly given in Table V.

\section{The micro-nuclei technique}

Micro-nuclei are the result of the release of damaged chromosomal material, during cell division. These are observed in binucleated cells, obtained by specific treatment.

Micro-nuclei are easy to identify and allow a much faster counting than dicentrics but are less specific to irradiation because of a higher background level ( 1 for 100 cells). Consequently, the sensitivity limit of this technique is less high, of about 0.3 Gy for 1000 binucleated cells observed. 
Table V. Times needed depending on the number of individuals.

\begin{tabular}{llll}
\hline $\begin{array}{l}\text { Number } \\
\text { of individuals }\end{array}$ & $\begin{array}{l}\text { Biological } \\
\text { dosimeter }\end{array}$ & $\begin{array}{l}\text { Time needed } \\
\text { to obtain a dose }\end{array}$ & Sensitivity limit \\
\hline From 10 to 100 & Dicentric & 1.5 week & $1 \mathrm{~Gy}$ \\
From 101 to 200 & Dicentric & 2 semaines & $1 \mathrm{~Gy}$ \\
More than 300 & $\begin{array}{l}\text { Dicentric or } \\
\text { micronuclei }\end{array}$ & $\begin{array}{l}\text { Call on a } \\
\text { European network }\end{array}$ & $1 \mathrm{~Gy}$ \\
\hline
\end{tabular}

\subsection{Operational biological dosimetry}

\subsubsection{Prematurely condensed chromosomes (PCC) by fusion}

Initially, the PCC technique was based on the work of Johnson and Rao ${ }^{7}$, in 1970, who demonstrated the possibility of visualizing chromosomes without prior culture, by means of cellular fusion ${ }^{8}$. Starting with a blood sample, the PCC technique consists in binding quiescent lymphocytes from the peripheral blood with cells in mitosis from a cell line of Chinese Hamster Ovaries (CHO). The substances released by the $\mathrm{CHO}$ cells induce a reaction of "prophase" type (first step in cellular division) in the lymphocyte in interphase. The result is a dissolution of the nuclear membrane and a premature condensation of the lymphocyte chromosomes in the shape of a simple individual strain since DNA duplication has not occurred yet. Despite the repair processes after irradiation, the lymphocytes preserve part of their unstable aberrations, in the form of excess fragments, which leads to a greater number of objects than the 46 chromosomes present in a normal cell. There is a linear relation between this number of excess fragments and the irradiation dose. However the slope of the curve decreases with time because of repair mechanisms: the interpretation becomes difficult. Contrary to conventional cytogenetics which, by using culture, only allows the lymphocytes having reached metaphase stage, where the chromosomes can be seen, to be observed, the PCC technique does not cause an artificial selection of lymphocytes. The cells observed are thus a sample chosen at random. Oppositely, a relatively low fusion rate, DNA repair times and the need to constantly have CHOs in culture make this technique difficult to apply to accident dosimetry.

\subsubsection{Prematurely condensed chromosomes (PCC) by chemical induction}

A new recently published technique shows that several chemical products, such as calyculine A, okadaic acid, tauromycine, added to lymphocyte cultures, cause the premature condensation of chromosomes in whatever phase of the cycle. This

7 Johson R.T., Rao P.N. (1970) Mammalian cell fusion: induction of premature chromosome condensation in interphase nuclei, Nature, May 23; 226 (5247): 717-722.

8 Chemical or physical process consisting in assembling under the same cellular envelope the contents of two cells either of the same or of different types. 
condensation mechanism seems to be complex and is still poorly known. It is known that the increase in the intracellular concentration of MPF (mitotic promoting factor) during the cellular cycle is vital to the condensation of chromosomes prior to mitosis. This condensation is controlled by phosphatase proteins. By inhibiting the action of these phosphatase proteins okadaic acid or calyculine A allows the chromosomes to condense independently from the time needed for mitosis. From a methodological point of view, lymphocytes are cultivated for $48 \mathrm{~h}$ of which 24 in the presence of colcemide. Calyculine A is added in the last hour. Rest of the treatment is identical to that of conventional cytogenetics. In this case, the dicentrics can no longer be observed and only the centric and acentric rings can be seen. A dose-effect relation was established by the BDL of the IRSN for doses between 5 and 15 Gy, by using the gamma radiation of cobalt 60 . Even at $15 \mathrm{~Gy}$, the mitotic index is very high. The main disadvantage of this technique is that the time required is close to that required by conventional cytogenetics since the metaphases are observed. On the other hand, many of these metaphases remain compact which does not make it easy to read them. That is why the addition of the FISH technique (Fluorescent in situ Hybridization) to the PCC technique has been adopted, with the marking of chromosome 4.

\subsection{The Tokai-mura accident}

Dr Hayata (NIRS) applied for the first time the chemical induction method of the PCC to three patients irradiated by a mixed neutron/gamma flux, during the Tokai-mura accident, and the results were compared to those provided by conventional cytogenetics and by the activation of ${ }^{24} \mathrm{Na}$ in the blood. The estimation of the doses received was calculated using a calibration code established for gamma radiation several years ago, by Professor Sasaki (University of Tokyo). In Table VI, the results are comparable which means this method can be used for exposure cases at very high doses.

\subsection{Application to localized irradiation}

To improve the diagnosis and the prognosis of the evolution of tissue after irradiation, the strategy is based on research on indicators which could be accessed through skin biopsies. These bio-indicators should enable the mapping of the areas damaged, with their depth and extent.

The cytogenetic techniques used require working on cells which divide. Primary cultures of fibroblasts and of keratinocytes, obtained by skin biopsies, were

Table VI. Comparison of results obtained with the three most irradiated patients of the Tokaimura accident, by using the activation of ${ }^{24} \mathrm{Na}$ in the blood, the counting of dicentrics and the counting of PCC rings in the lymphocytes.

\begin{tabular}{llll}
\hline Techniques & Patient " $\mathrm{O}$ " & Patient " S " & Patient " ${ }^{\prime \prime}$ \\
\hline${ }^{24} \mathrm{Na}$ & 15.4 & 8.4 & 2.0 \\
Dicentrics & $(21)$ & $>6$ & $2.4-3.2$ \\
Modified PCCs & $>20$ & 7.8 & 2.6 \\
\hline
\end{tabular}


established at the IRSN and the detection of translocations by means of FISH was adapted to chromosome 4. Dose-effect relations were obtained for both cellular types at gamma irradiation doses ranging from 0 to $10 \mathrm{~Gy}$. The time needed to obtain the result is about two weeks, which corresponds to the time needed for culture to obtain a sufficient number of cells in metaphase.

The IRSN was involved in the management of the accident which occurred in Georgia, in December 2001. One of the people accidentally irradiated and presenting a significant radio-induced cutaneous syndrome was hospitalized at the beginning of 2002 at the Center for Treatment of Burns of the military hospital of Percy (France). Within this framework, skin biopsies of this patient were obtained and the PCC-FISH analysis showed doses ranging from 5 to $21 \mathrm{~Gy}$. These results are in agreement with clinical data, but also with the physical data established using the Monte-Carlo simulation.

\section{Biological indicators of radio-induced damage}

The estimation of the dose received (by physical and/or biological dosimetry) is useful in helping the medical team in charge of the irradiated patient(s) to define the extent of radio-induced damages. It remains insufficient to establish a diagnosis and does not allow the follow-up of the evolution of the pathology over time. Indeed, for a given dose, there is a significant individual variability of the response to irradiation. Moreover, accident situations are mostly heterogeneous irradiations. As a result, and depending on the number of organs present in the irradiation field, the people exposed can suffer multi-organ damage involving their vital prognosis. It is therefore necessary to find biological and/or bio-physical indicators which not only assess the extent of the damage in a person accidentally irradiated but also assess the consequences. The concept of prognostic or diagnostic indicators implies as for that of dose, inherent characteristics: specific of a target organ (structure) or of a physiological function, sensitive to the instantaneous physiology and to its evolution, easily accessed and used routinely. The specificity to ionizing radiations no longer seems a necessary condition insofar as the number of structural or functional problems observed after irradiation can also be initiated by other causes. Nevertheless in many cases these same functional problems created by irradiation follow a specific evolution, different from that observed in other pathologies.

\subsection{The Flt3 ligand, a marker of lesions in the bone marrow}

The hematopoietic syndrome appears for irradiation doses between 1 and $10 \mathrm{~Gy}$. It is seen by a destruction of the bone marrow and the progressive disappearance of blood cells. A simple and sensitive marker of radio-induced lesions to the bone marrow must be available to determine the appropriate therapeutic strategy. This shows that this parameter is a physiological marker which is potentially useful in the surveillance of radio-induced lesions of the bone marrow during the medical care of an irradiated patient. 
The Laboratory of Cellular Therapy and Accident Radiation protection (LTCRA) has developed in the last years the use of the Flt3 ligand as a bioindicator of radio-induced damage to the bone marrow. The Flt3 ligand is a cytokine of roughly $17 \mathrm{kD}$, discovered in 1994 . It is produced ubiquitously in the body by $T$ lymphocytes, endothelial cells and medullar micro-environment cells. This cytokine essentially acts by inducing the proliferation of lymphoid and myeloid progenitors of the bone marrow and of the thymus, but also by inducing differentiation of monocytes in dendritic cells.

Studies carried out in our laboratory on a non-human primate model helped to determine a basic concentration (in normal physiological situation) of roughly $132 \mathrm{pg} / \mathrm{mL}$ of plasma. This basic level does not change with age or gender, nor does it depend on the circadian rhythm. It was demonstrated that the concentration of the Flt3 ligand was increased after irradiation, in correlation with the irradiation dose. Moreover, it was shown that the concentration of the Flt3 ligand on the 5th day after irradiation is predictive of the extent of the aplasia in the non-human primate, and this, whatever the irradiation dose and the type of ionizing radiation (pure gamma radiation or gamma/neutron mixed flux).

Different studies on man confirmed these results. Actually, the basal concentration of the Flt3 ligand in a healthy population of donors from 20 to 68 years was determined. The results showed a basal concentration of $119 \mathrm{pg} / \mathrm{mL}$, which does not vary with either the gender or the age of the donors. The evolution of the Flt3 ligand in patients having received a localized irradiation within the framework of an anti-cancer therapeutic protocol was then studied. The results showed not only that the concentration of the Flt3 ligand was increased after irradiation but also that this increase is directly correlated both to the cumulated irradiation dose received and to the fraction of the irradiated bone marrow. This study demonstrated that the observation of the variations in the concentration of the Flt3 ligand is a good bio-indicator of radio-induced damage to the bone marrow including situations of heterogeneous and fractioned irradiation.

On the whole, our results show that the Flt3 ligand is a bio-indicator which is easy to dose (ELISA dose using a $\mathrm{mL}$ of blood sampled on EDTA), inducing minimum stress during sampling, reliable, specific to the bone marrow damage and with a very high signal/noise ratio, which makes it easy to interpret. In practice, it is however necessary to monitor the patient over several days, if not during the entire hospitalization, with a daily blood sample, made with EDTA anti-coagulant.

\subsection{Citrulline, a marker of intestinal mucosa lesions}

The gastro-intestinal syndrome appears within 4-5 days after a general exposure to doses higher than 10-12 Gy. It is associated to a hemorrhaging diarrhea and the disappearance of the intestinal mucosa. Prior to this lethal and last stage, the extent of the damage to the intestinal mucosa and the radio-induced lesions must be assessed so as to integrate them in the therapeutic strategy. The plasma concentration of citrulline, an amino-acid produced nearly exclusively by enterocytes (cells in the intestinal mucosa), is a marker of the functional enterocyte mass. Moreover, Lutgens and coll showed that the plasma concentration of citrulline could be used as a bio-indicator of epithelial lesions of the small intestine induced by ionizing radiation. Indeed, the plasma concentration of citrulline is 
inversely proportional to the irradiation dose and to the extent of the epithelial lesions caused by radiation to the intestinal mucosa. These data suggest that the dosage of plasma citrulline could be clinically applied to the evaluation and monitoring of the evolution of intestinal epithelium lesions induced by radiation.

\subsection{Oxysterols, markers of multiple organ malfunction}

Oxysterols are products of oxidation and of hydroxylation of cholesterol by enzyme catalysis from different tissues such as the brain, the lungs and the liver. Plasma variations in the concentrations of some oxysterols have recently been proposed as physiological indicators of different pathologies (degenerative diseases of the nervous systems or hepatic pathologies showing a functional or structural malfunction specific to different organs). The monitoring of the plasma concentrations of some oxysterols such as 24S-hydroxycholesterol (24S-OH), 27-hydroxycholesterol $(27-\mathrm{OH})$ and 7-hydroxycholesterol $(7-\mathrm{OH})$ as specific indicators of lesions, respectively, cerebral, pulmonary and hepatic after exposure to ionizing radiation is carried out. A simple and rapid technique by means of High Performance Liquid Chromatography (HPLC) was developed by the IRSN to simultaneously detect plasma concentrations in these three oxysterols. Preliminary data suggest the existence of modifications in the plasma concentration of some oxysterols after exposure to radiation. The variations observed for $7-\mathrm{OH}$ and for $24 \mathrm{~S}-\mathrm{OH}$ could be indicators of lesions, respectively, cerebral, pulmonary and hepatic showing some modifications of the metabolism of cholesterol in these organs. These variations were correlated to functional modifications in target tissue. A study is in progress to validate the use of oxysterols in clinical practice for the diagnosis of lesions induced by ionizing radiation in different organs (radiotherapy).

\section{Physical dosimetry}

Leaflet 11

\section{Physical assessment of the dose in case of a criticality accident}

1. Data required for the physical reconstruction of the dose

- Characteristics of the radiation source:

a. Nature of the particles released (neutrons, photons)

b. Fluence rate or activity or emission per second in $4 \pi$

c. Energy distribution of the particles released

d. Spatial distribution (if non-isotropic source)

e. If necessary, characteristics of the geometry (or of the shape) of the source (dimensions, material)

- Topology of the accident:

a. Relative positions of the source and the victim (a dimensioned plan would be interesting)

b. Posture of the victim and how he or she is placed towards the radiation source

c. Dimensions and materials constituent of the existing facilities (that can make up possible biological protections) 
d. Dimensions and materials constituent of the room walls (bottom and top) where the accident happened

- How long the exposure lasts:

a. Exposure time

b. AND number of fissions in case of a criticality accident

- OR possibility of linking up the calculation to a physical point where the dose is known': Standardization point to be planned rapidly in the case of a reconstruction by the Monte-Carlo calculation.

Warning: During a criticality accident, the radiation field which is generated is a mixed field (neutron, gamma) where the energy spectra may vary a lot, and depend, in every point of the space, on the present potential shields and on the scattering by the facilities structure.

\section{Coordinating the different approaches}

According to the accident characteristics, the dosimetric reconstruction will move towards one and/or the other of the methods, and the dosimetry laboratory concerned must be contacted as soon as possible:

- In the case of a point source, or of a short distance between the source and the victim, or of relatively insignificant shields $\rightarrow$ analytical calculation is possible.

Laboratory to be contacted quickly: Department of radiological protection of the facility concerned.

- In the case of an extensive or complex source, or of a significant distance between the source and the victim, or of numerous or varied shields $\rightarrow$ a computer model is preferable.

Laboratory to be contacted as soon as possible (the calculation standardization point must be chosen before the calculation definition):

IRSN/DRPH/SDE

BP No.17

92262 Fontenay-aux-Roses Cedex, France

Tel.: + 33158357862 - Fax: + 33147469777

\section{A few landmarks}

- Dose profile in a body:

a. High heterogeneity of the neutron dose, which rapidly decreases as the neutrons slow down all along their path. Between the phantom entry facing and its exit facing, the neutron dose may decrease of a factor 4-10.

b. Relative constancy of the dose due to the photons. Indeed, the exit dose is generally reduced by a factor rarely higher than 2 (except if there is a major geometric effect ${ }^{10}$ ).

The dose heterogeneity in the biological tissue may come from the incident radiation attenuation by tissue and also from the geometric factor (distance effect and shield effect).

- Example of values of the "gamma dose" on "neutron kerma" ratio measured in the SILENE reactor (CEA Valduc, France).

NB: the ratio value depends on the type of experiment and on the distance from the source.

9 The standardization of the dose calculation can be achieved by the knowledge of the total number of incident particles. Since this kind of data is rarely known, the standardization can then be achieved when the dose is known at a given point, either at the level of an area survey instrument or a personal dosimeter, or by using the dosimetry results on a biological tissue.

10 The lower the distance between the source and the victim, the more significant the dose gradient according to the distance. 
- Without shield $D_{\gamma} / D_{\mathrm{n}} \approx 1$ à 1.5

Leaflet 11, continued

- With a lead shield of $10 \mathrm{~cm}$ around the reactor $D_{\gamma} / D_{\mathrm{n}} \approx 0.1$ à 0.3

- With a polyethylene shield of $10 \mathrm{~cm}$ around the reactor $D_{\gamma} / D_{\mathrm{n}} \approx 6$ à 11

These values are valid without additional shielding. Given the ionizing radiation attenuation in the tissue, and the different interaction modes of neutrons and gamma in the tissue, this ratio value will obviously evolve according to the depth in the tissue.

\section{Expected results of the dose physical reconstruction}

\subsection{Analytical calculation}

Analytical calculation leads to a tissue kerma value at a given point, which can generally be considered tantamount to the absorbed dose, for the incident neutrons and photons. It will not give the absorbed dose due to secondary photons generated by incident neutrons.

- Asset: performed in a few minutes at a given point.

- Drawbacks: the analytical calculation cannot provide the dose due to secondary photons (but it can only estimate it from the dose due to primary neutrons). It will not provide a complete cartography. Its level of accuracy may be difficult to estimate and it does not take the scattered radiation into account. The contribution of the scattered radiation can be estimated by using a build-up ${ }^{11}$ factor, together with, in this case, an uncertainty that can be high regarding the value obtained.

\subsection{Monte-Carlo calculation}

The Monte-Carlo method depends on the probabilistic nature of the basic interactions between ionizing radiation and the material. Each particle is monitored all the way through its story and its interactions within the material. The calculation result corresponds to all the basic events occurring to each particle.

The code thus provides the following quantities:

1. Global quantities: they are defined in a given volume, they can be either of a radiometric nature (distribution of energy particles, or spatial distribution within this volume), or of a dosimetric nature (absorbed dose in this volume).

2. Point quantities: they can be defined at several points of the space and they can constitute distributions (cartography of the dose within a volume which enables the construction of isodoses), or at a single point (energy or value distribution of the dose at a detector point).

- Assets: this method allows working in a complex geometry because it deals with all the direct and scattered radiation. This method can provide a complete cartography of the dose inside the body. The result accuracy essentially depends on the accuracy with which the geometric modeling is achieved and on the number of particles generated (stories). Therefore, the uncertainty towards the calculation can theoretically be controlled.

- Drawbacks: specific geometric tools are required (anthropomorphic phantom with a size and a position which can be adapted, a geometry tool for the environment simulation). The time required to define these tools may be prohibitive (from several hours to several days) if the laboratory does not dispose off adapted tools. The calculation time depends on the mathematical codes which are used and on the accuracy required. Particularly for the "voxel" phantoms, the more accurate the segmentation, the longer the calculations. Similarly, the calculation time is proportional to the number of particles generated. A dose calculation may take from several hours to several days. Finally, in practice, the uncertainty caused by geometric approximations cannot always be quantified.

11 Enables the consideration of the multi-scattering within the material. 


\section{Dosimeters used: Main characteristics}

Table VII. Main characteristics of the dosimeters used.

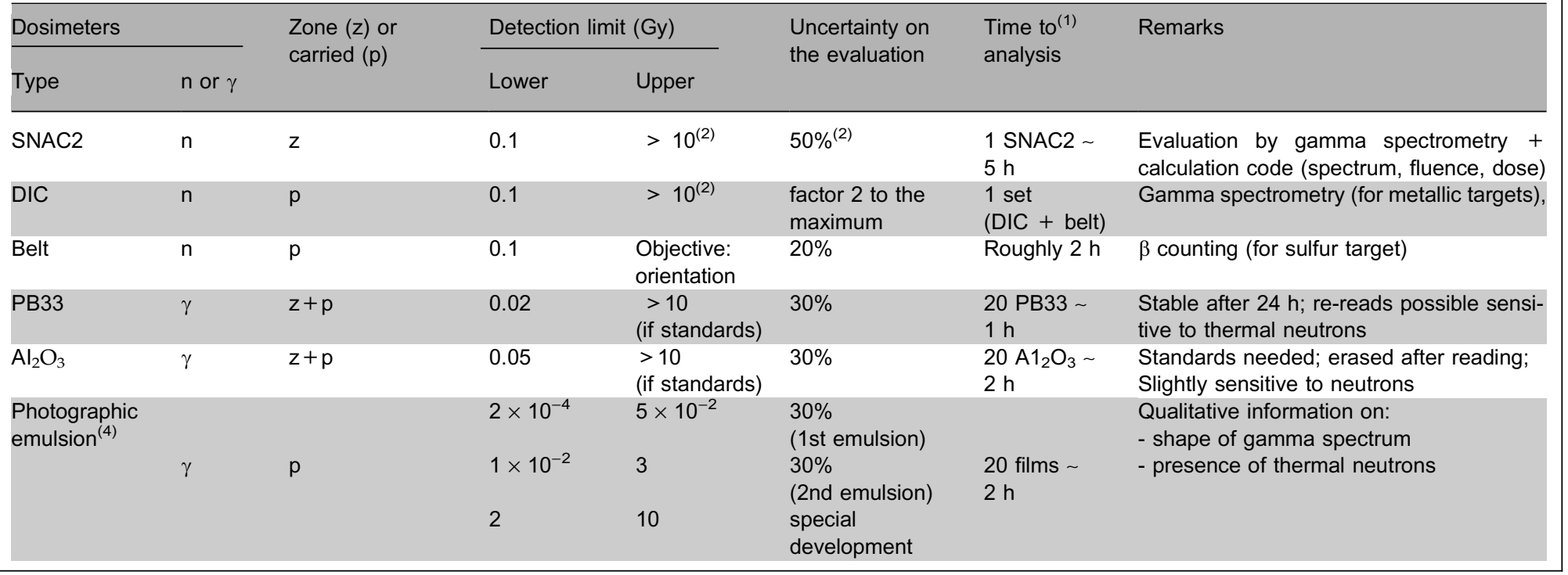




\begin{tabular}{|c|c|c|c|c|c|c|c|}
\hline \multicolumn{8}{|r|}{ Leaflet 12 , continued } \\
\hline \multicolumn{2}{|l|}{ Dosimeters } & \multirow{2}{*}{$\begin{array}{l}\text { Zone or } \\
\text { carried }(p)\end{array}$} & \multicolumn{2}{|c|}{ Detection limit (Gy) } & \multirow{2}{*}{$\begin{array}{l}\text { Uncertainty on } \\
\text { the evaluation }\end{array}$} & \multirow{2}{*}{$\begin{array}{l}\text { Time to }{ }^{(1)} \\
\text { analysis }\end{array}$} & \multirow[t]{2}{*}{ Remarks } \\
\hline Type & $\mathrm{n}$ or $\gamma$ & & Lower & Upper & & & \\
\hline$P G P I^{(5)}$ & $\gamma$ & $\mathrm{p}$ & $2 \times 10^{-4}$ & 0.2 & $30 \%$ & $\begin{array}{l}20 \text { PGP1 } \\
2 \mathrm{~h}\end{array}$ & Erased during reading \\
\hline $\begin{array}{l}\text { PGPDIN or }{ }^{(5)} \\
\text { CODEBADGE }\end{array}$ & $\mathrm{n}$ & $\mathrm{p}$ & $5 \times 10^{-4}$ & 0.2 & Factor $1-5$ & $\begin{array}{l}20 \\
\text { PGPDIN } \\
2 \mathrm{~h}\end{array}$ & $\begin{array}{l}\text { Erased during reading albedo: } \\
\text { calibration by workplace }\end{array}$ \\
\hline $\mathrm{PN} 3^{(5)}$ & $\mathrm{n}$ & $z+p$ & $\sim 2 \times 10^{-4}$ & $\sim 0.2$ & $20-50 \%$ & $\begin{array}{l}20 \mathrm{PN} 3 \sim \\
12 \mathrm{~h}\end{array}$ & $\begin{array}{l}\text { Track detector }\left(0.2 \mathrm{MeV}<E_{\mathrm{n}}<15 \mathrm{MeV}\right) \text {. } \\
\text { Completely insensitive to neutrons }\end{array}$ \\
\hline \multicolumn{8}{|c|}{$\begin{array}{l}\text { (1): After arrival at analysis laboratory } \\
\text { (2): Limitation due to pause in the measurement device used. } \\
\text { (3): Greatly dependent on the shape of neutron spectrum. } \\
\text { (4): For the CEA centers, AGFA film has replaced KODAK film. } \\
\text { (5EA: films developed by the IRSN/DRPH/LSDOS/FAR. AREVA: films developed at La Hague. } \\
\text { (5) planned for Criticality Dosimetry. Dosimeters mentioned for information purposes. }\end{array}$} \\
\hline
\end{tabular}




\section{For further information}

Feng Y., Brown K.S., Casson W.H., Mei G.T., Miller L.F., Thine M. (1993) Determination of Neutron Doses from Criticality Accidents with Bioassays for Sodium-24 in Blood and Phosphorus-32 in Hair, ORNL/TM-12028, Oak Ridge National Laboratory, Oak Ridge, TN.

ICRP 89, Basic anatomical and physiological data for use in radiological protection: reference values.

International Atomic Energy Agency (1982) Dosimetry for Criticality Accidents, a Manual, IAEA Safety Series No. 211, Vienna.

International Atomic Energy Agency (2001) Cytogenetic Analysis for Radiation Dose Assessment, IAEA Technical Reports series No. 405, Vienna.

Lebaron-Jacobs L. et al. (2007) Contribution of hair dosimetry following neutron irradiation, Health Physics 92, S98-S104.

Lebaron-Jacobs L. et al. (2008) Dosimetric management during a criticality accident, Nuclear Technology 161, 27-34.

Lemaire G., Dhermain J., Remy M.L., Masse R. (1992) Estimation de la dose absorbée en cas d'exposition aux neutrons rapides à l'aide de la transmutation $\mathrm{du}$ soufre en phosphore dans le systmème pileux, Radioprotection 27, 17-34.

Miele A., Lebaron-Jacobs L. (2005) Conduite à tenir face aux victimes d'un accident de criticité, Radioprotection 40, Suppl. 2.

Rapport du GT-criticité (1984) SMT-LABM CEA (internal document).

Revue Rayonnements ionisants (2005) Techniques de Mesures et de Protection. Le tri au cours d'un accident de criticité. Rôle du SST et du LABM dans une INBCEA, Revue ATSR, 34.

Sorokine-Durm I., Durand V., Le Roy A., Paillole N., Roy L., Voisin P. (1997) Is FISH-painting an appropriate biological marker for dose estimates of suspected accidental radiation overexposure? A review of cases investigated in France from 1995 to 1996, Environmental Health Perspective 105 (suppl 6), 1427-1432.

Supplément du British Journal of Radiology 27 (2005).

Tabardel R., Ricourt A., Parmentier N. (1984) Report CEA-R 5276, Évaluation rapide de la dose due aux neutrons à la suite d'un accident de criticité à partir de l'activité du sodium-24 mesurée.

Voisin P., Barquinero F., Blakely B., Lindholm C., Lloyd D., Luccioni C., Miller S., Palitti F., Prasanna PGS., Stephan G., Thierens H., Turai I., Wilkinson D., Wojcik A. (2002) Towards a standardization of biological dosimetry by cytogenetics, Cellular and Molecular Biology 48, 501-504.

Voisin P., Benderitter M., Chambrette V., Claraz M., Delbos M., Durand V., Paillole N., Roy L., Sorokine-Durm I. (2002) La dosimétrie biologique de l'accident d'irradiation, Radioprotection 37, 27-40.

Voisin P., Lloyd D., Edwards A.A. (1997) Chromosome aberration scoring for biological dosimetry in a criticality accident, Radiation Protection Dosimetry 70, 467-470. 


\section{Organization of first aids}

A criticality accident may concern few persons to one hundred people of each facility. On the evacuation and gathering area, the first data useful to physical dosimetry (ambiance dosimeters) are collected by the staff of the damaged building and given to the agents of the Radiation Protection Service (RPS) for reading. The victims are sent to the triage center where their clinical state is evaluated: the irradiated people who directly present clinical signs are evacuated to occupational medical emergencies.

\section{Emergency triage to evacuate the wounded}

At the triage center, the RPS carries out a triage according to the results of the individual operational dosimeter reading and the gamma measurement of body ${ }^{24} \mathrm{Na}$ activity to tell the irradiated people (external irradiation and/or contamination) from those only implicated (slightly or not irradiated). The dosimetric assessment is obviously approximate at this stage: activation or non-activation, with or without contamination. However it allows carrying out an emergency triage of the victims. The irradiated victims are rapidly sent in order of importance to the Occupational Medical Service (MS), where they will be examined and tested: biological samplings, ${ }^{24} \mathrm{Na}$ activity measurement on contact or by anthropogammametry (according to general state), and especially a symptomatic treatment according to the clinical state (shock, etc.). The psychological troubles typically presented following an accidental situation will have to be considered. A first biological check-up has to be carried out in the three first hours after the accident. Other biological and physical parameters will later allow to estimate more precisely the dose received (hematology, cytogenetics, dosimeters) and the heterogeneity of the neutron dose (integuments), and to assess the prognosis (biochemistry) with variable times for data delivery. Moreover, the implicated victims are sent to the Occupational MS, where they are examined and possibly have an anthropogammametry in the Clinical Biochemistry Laboratory (CBL). Then, they fill the form "post-accident interview" (Leaflet 9), which will allow assessing the distance and their orientation from the source, and the exposure duration. In parallel, the first gestures of internal and external decontamination have to be carried out. 
Medico-surgical emergency always supersedes radiological risks. It must be treated according to the usual medical rules. Finally, according to clinical, biological and dosimetric check-up, the victims can be directly hospitalized (in case of aggravation of the clinical state) or they can be managed by their General Practitioner. The decision of the emergency hospitalization will be taken according to:

- probable first clinical signs: if the victim saw a blue flash (Cerenkov effect), if he/she is injured or the symtomatology is serious, or if his/her condition rapidly deteriorates;

- the result of ${ }^{24} \mathrm{Na}$ activation measurement (dose of $1 \mathrm{~Gy}$ or ${ }^{24} \mathrm{Na}$ activity of $300 \mathrm{kBq}$ ). A leaflet is written for each victim (Leaflet 14). This leaflet summarizes all the observations and the actions carried out by the RPS agents and by the MS/CBL staff. This leaflet accompanies the patient in case of evacuation to a hospital and in case of management by the General Practitioner.

\section{Recommendations for MS and CBL}

For each establishment concerned, the MS and CBL must make sure:

- that their internal procedures are up to date,

- that the regulations of the Emergency Internal Plan, the criticality leaflets and the isodose curves of the facilities concerned are available.

To make the analyses:

- Establish a procedure summarizing the analyses to be made (according to Leaflet 5).

- For radiotoxicological analyses, establish or update a protocol of technical assistance between the CBL or MS of centers nearby.

- For specific analyses, including HLA typing, have a management protocol with the competent establishments.

To hospitalize patients:

- Establish or update an agreement with the ad hoc hospital structures.

- Send information data (p. 55) with that of triage to the hospitals where the patients will be sent.

For patients sent to their General Practitioner:

- Give them information data (pp. 58 and 60).

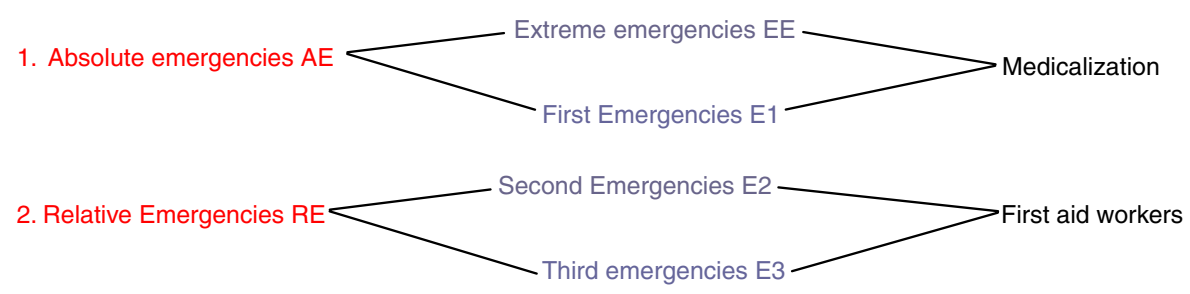

Fig. 11. Types of emergencies. 


\section{Classification of injured}

Leaflet 13

Criteria used for choosing an Advanced Medical Unit (AMU)/Emergency Medical Unit (EMU):

- as close as possible to the accident;

- without risk;

- sheltered from bad weather;

- near road access;

- if possible DZ close by;

- different entrance and exit;

- telephone, water, electricity, heating if possible.

\section{Classification of injured at the AMU/EMU}

1. Absolute emergencies (AE)

Extreme emergencies (EE)

- acute asphyxia with immediate respiratory distress,

- hemorrhage difficult to control (large veins).

EEs require immediate reanimation, sometimes surgery as soon as possible.

First emergencies (E1)

- polytrauma,

- stable abdominal lesion,

- serious burns ( $>40 \%$ ).

E1s require reanimation but can wait for surgery for maximum $6 \mathrm{~h}$.

2. Relative emergencies (RE)

Second emergencies (E2)

E2s do not have a vital prognosis (diaphysis fracture, localized burns, not deteriorating wounds of members, etc.) but require immobilization, bandaging and other care prior to transportation.

Third emergencies (E3)

E3s are the lightly wounded to which can be added the psychological traumas. 


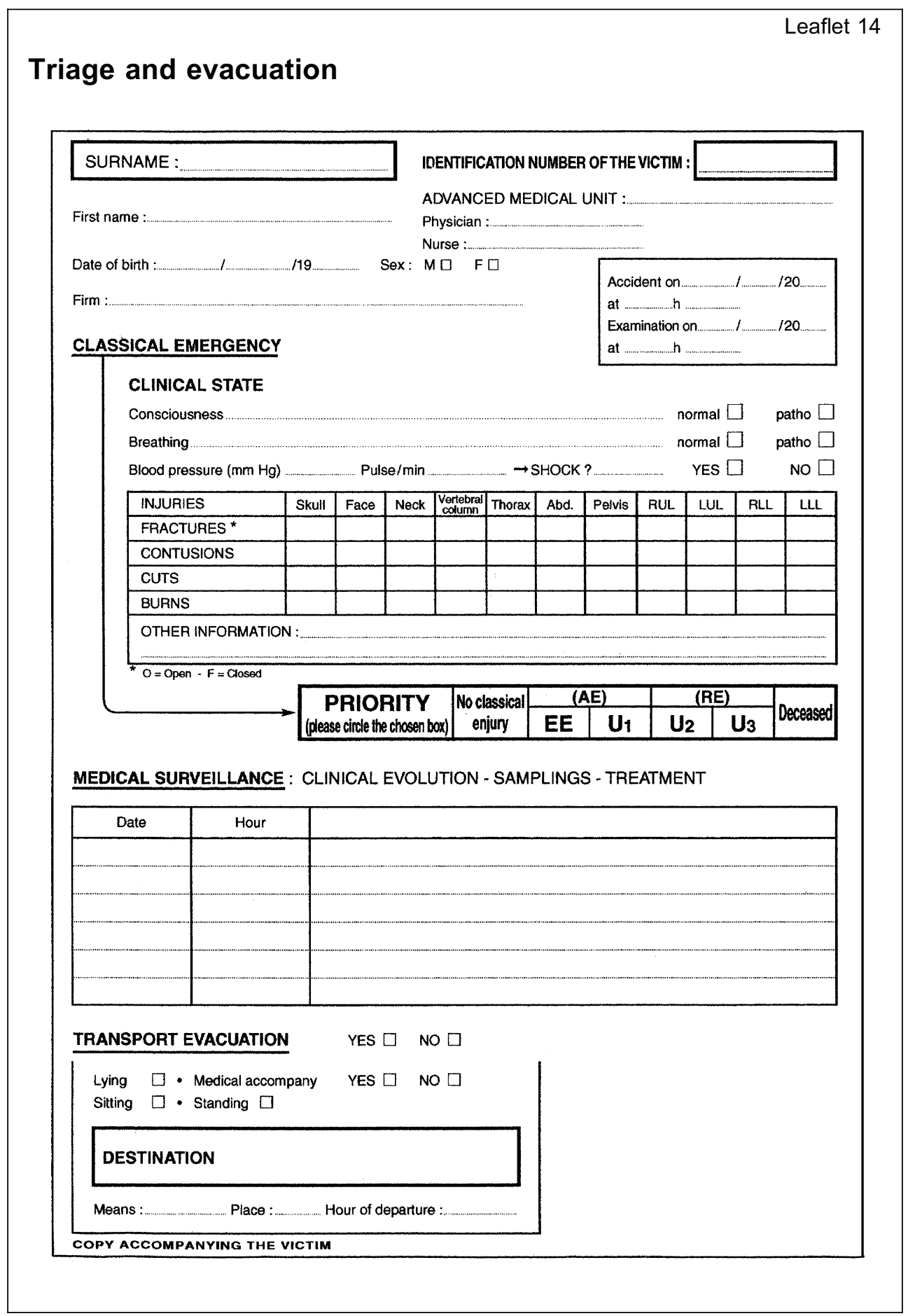




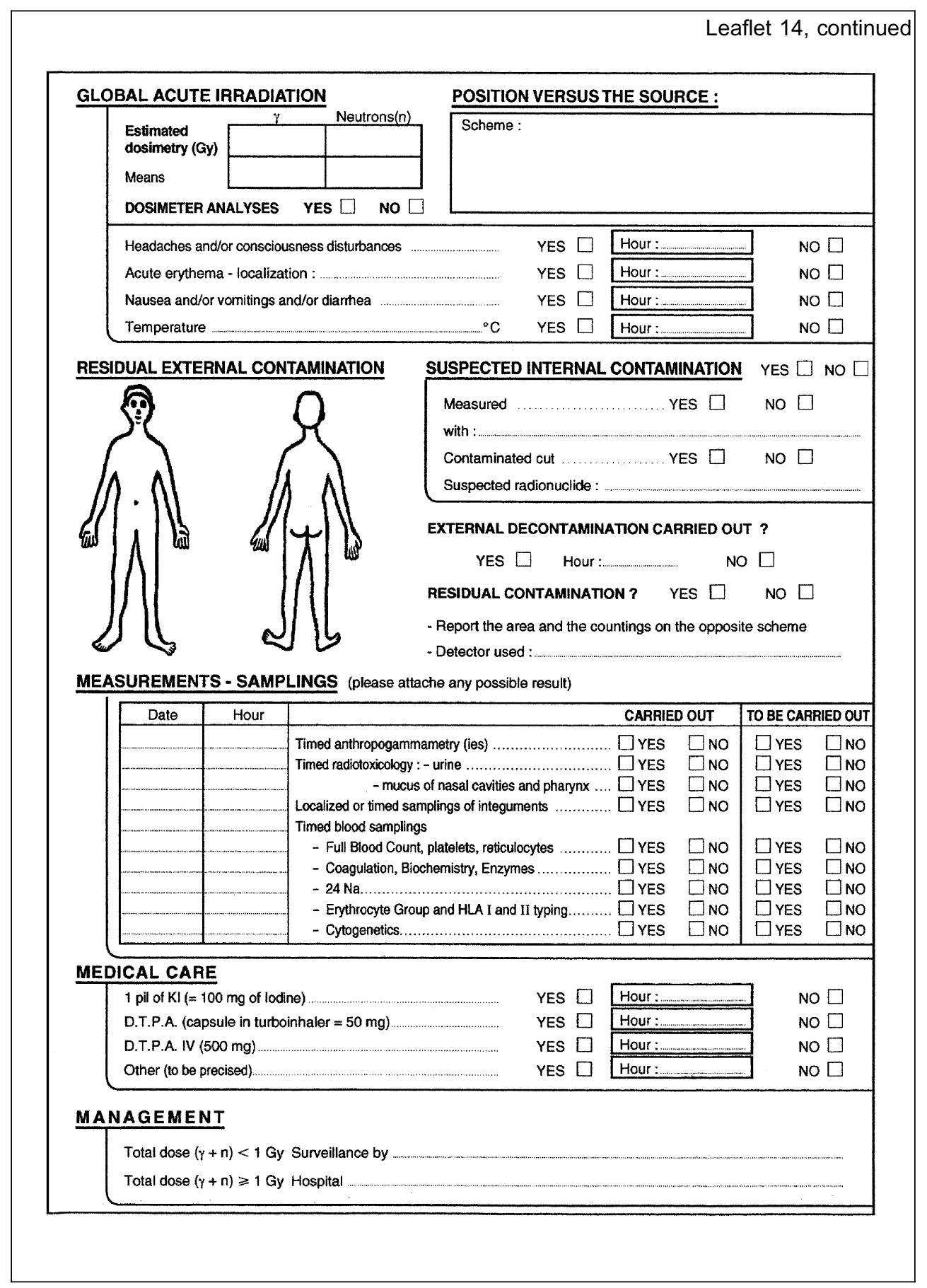




\section{Investigations to be carried out in case of a criticality accident}

Table VIII. Systematic samplings.

\begin{tabular}{|c|c|c|c|}
\hline \multirow[b]{2}{*}{ Sampling hour } & \multicolumn{2}{|c|}{ MEDICAL BIOLOGY (blood and urine tubes) } & \multirow[t]{2}{*}{ RADIOTOXICOLOGY } \\
\hline & $\begin{array}{l}\text { Nature and number of tubes } \\
\text { of sampling/person }\end{array}$ & Investigation & \\
\hline \multirow{3}{*}{ *Hi INITIAL CHECK-UP } & 1 black tube ( $5 \mathrm{~mL}$ citrate) & Erythrocyte sedimentation rate & \multirow{3}{*}{$\begin{array}{l}\text { Anthroporadiametry } \\
\text { Total body }{ }^{24} \mathrm{Na} \\
\text { Integument sampling } \\
\left({ }^{32} \mathrm{P} \text { dosage }\right) \\
{ }^{24} \mathrm{Na} \text { in blood } \\
\text { (2 purple } 5 \mathrm{~mL} \text { EDTA tubes) } \\
\text { Urine: urination according to } \\
\text { medical prescription } \\
\text { Nasal samplings according to } \\
\text { medical prescription }\end{array}$} \\
\hline & & $\mathrm{Na} \mathrm{K} \mathrm{Cl}$ proteins (1 tube) & \\
\hline & 2 orange tubes ( $5 \mathrm{~mL}$ dry tube) & $\begin{array}{l}\text { TGO, TGP, amylase, LDH, serum iron, } \\
\text { ferritin, total iron-binding capacity (TIBC), } \\
\text { cortisol, ACTH ( } 1 \text { tube) }\end{array}$ & \\
\hline${ }^{*} \mathrm{H}+3$ & 1 purple tube (5 $\mathrm{mL}$ EDTA) & FBC, platelets, reticulocytes & \\
\hline \multirow[t]{2}{*}{$\mathrm{H}+9$} & 1 purple tube (5 mL EDTA) & FBC, platelets, reticulocytes & \\
\hline & 2 green tubes ( $5 \mathrm{~mL}$ Li heparinate) & Cytogenetics & \\
\hline
\end{tabular}




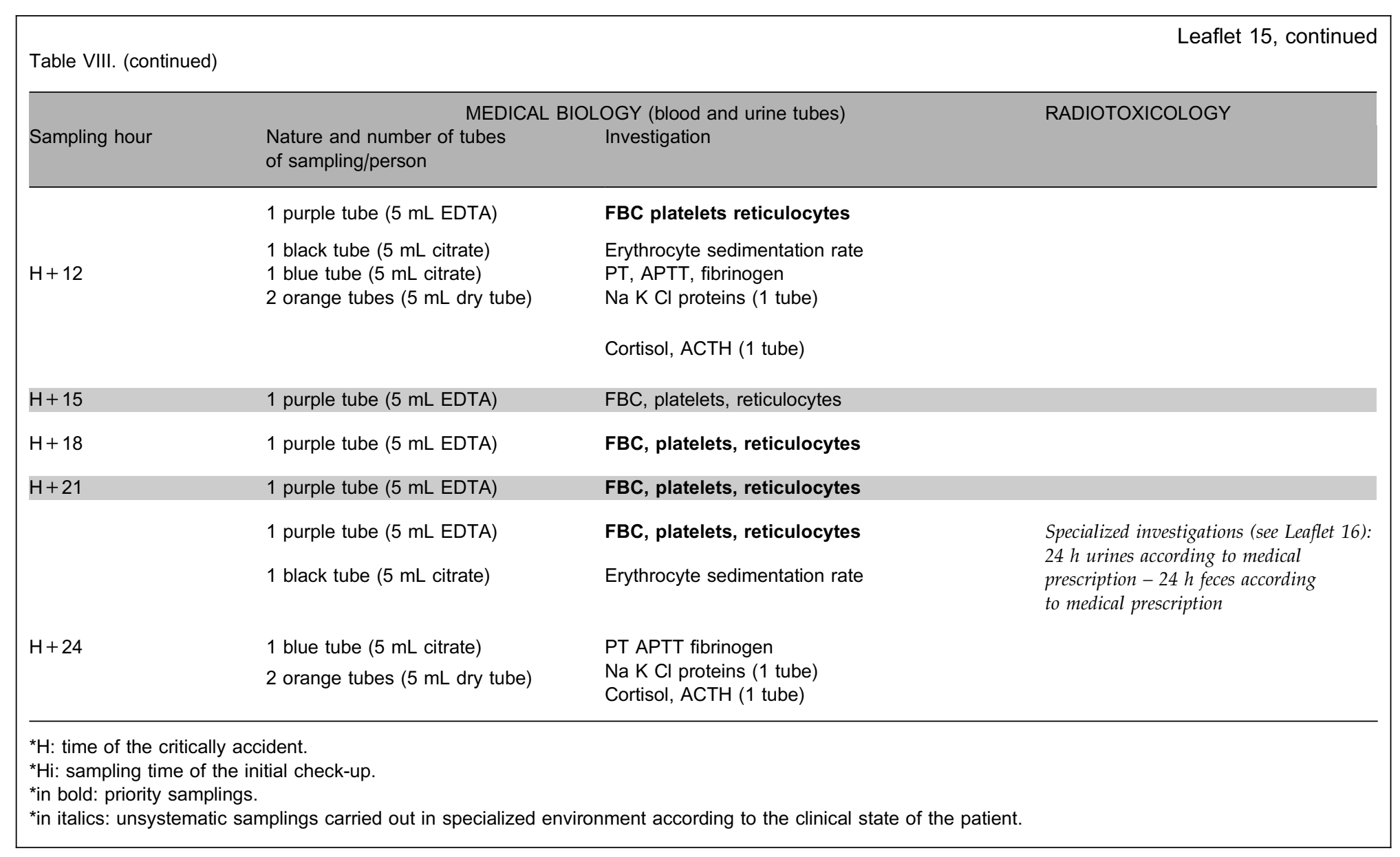




\section{Specialized samplings}

These specialized samplings are not common practice. They are made in the area of research and could possibly be done in a specialized environment if the dose is greater than $1 \mathrm{~Gy}$.

Their results are additional elements for the prognosis.

Table IX. Definitions.

\begin{tabular}{llll}
\hline $\begin{array}{l}\text { Inflammation } \\
\text { molecules }\end{array}$ & Flt3-Ligand & Citrulline & Oxysterols \\
\hline CRP & $\begin{array}{l}\text { Marker of bone } \\
\text { marrow lesions }\end{array}$ & $\begin{array}{l}\text { Marker of intestinal } \\
\text { mucosa lesions }\end{array}$ & $\begin{array}{l}\text { Markers of multiple } \\
\text { dysfunction of organs }\end{array}$ \\
IL-1 $\alpha$ and IL-1 $\beta$, IL-6, IL-8, IL-6Rs & & \\
RANTES & & \\
TNF $\alpha$, TNF- $\alpha$ Rs & & \\
SICAM-1, sVCAM-1 & \\
ELAM & & \\
SE- Selectine & \\
MIP-1 $\alpha$ & & \\
\hline
\end{tabular}

Table X. Sampling and conditioning.

\begin{tabular}{|c|c|c|}
\hline $\begin{array}{l}\text { Inflammation } \\
\text { molecules }\end{array}$ & Flt3-Ligand & Oxysterols \\
\hline Blood & Blood & Blood \\
\hline $5 \mathrm{~mL}$ on EDTA & $\begin{array}{l}1-2 \mathrm{~mL} \text { on EDTA } \\
\text { Upon admission }\end{array}$ & $1-2$ tubes of $4.5 \mathrm{~mL}$ on EDTA \\
\hline Centrifuge & $\begin{array}{l}\text { Each day during the } \\
\text { entire hospitalization }\end{array}$ & $\begin{array}{l}\text { Centrifuge for } 10 \mathrm{~min} \text { at } 4000 \mathrm{~g} \text { at }+4{ }^{\circ} \mathrm{C} \\
1 \mathrm{~mL} \text { of plasma in } 2 \text { white Eppendorf tubes } \\
(1.5 \mathrm{~mL})+\text { (if possible) } 50 \mu \mathrm{l} \text { of } \mathrm{BHT} \\
\text { at } 3 \mathrm{mg} / 150 \mathrm{~mL} \text { methanol (prepared } \\
\text { extemporaneously) in each Eppendorf tube. }\end{array}$ \\
\hline Freezing at $-80^{\circ} \mathrm{C}$ & $\begin{array}{l}\text { Samples must be } \\
\text { kept at room } \\
\text { temperature and } \\
\text { sent within } \\
24 \mathrm{~h} \text { to the } \\
\text { laboratory }\end{array}$ & $\begin{array}{l}\text { Samples must be kept at }-80^{\circ} \mathrm{C} \\
\text { and sent as soon as possible to the laboratory }\end{array}$ \\
\hline
\end{tabular}




\section{Communication}

Paragraphs 1 to 4 are to be used for information to the personnel involved and to the different participants.

\section{Information on slightly exposed victims, cared for secondarily}
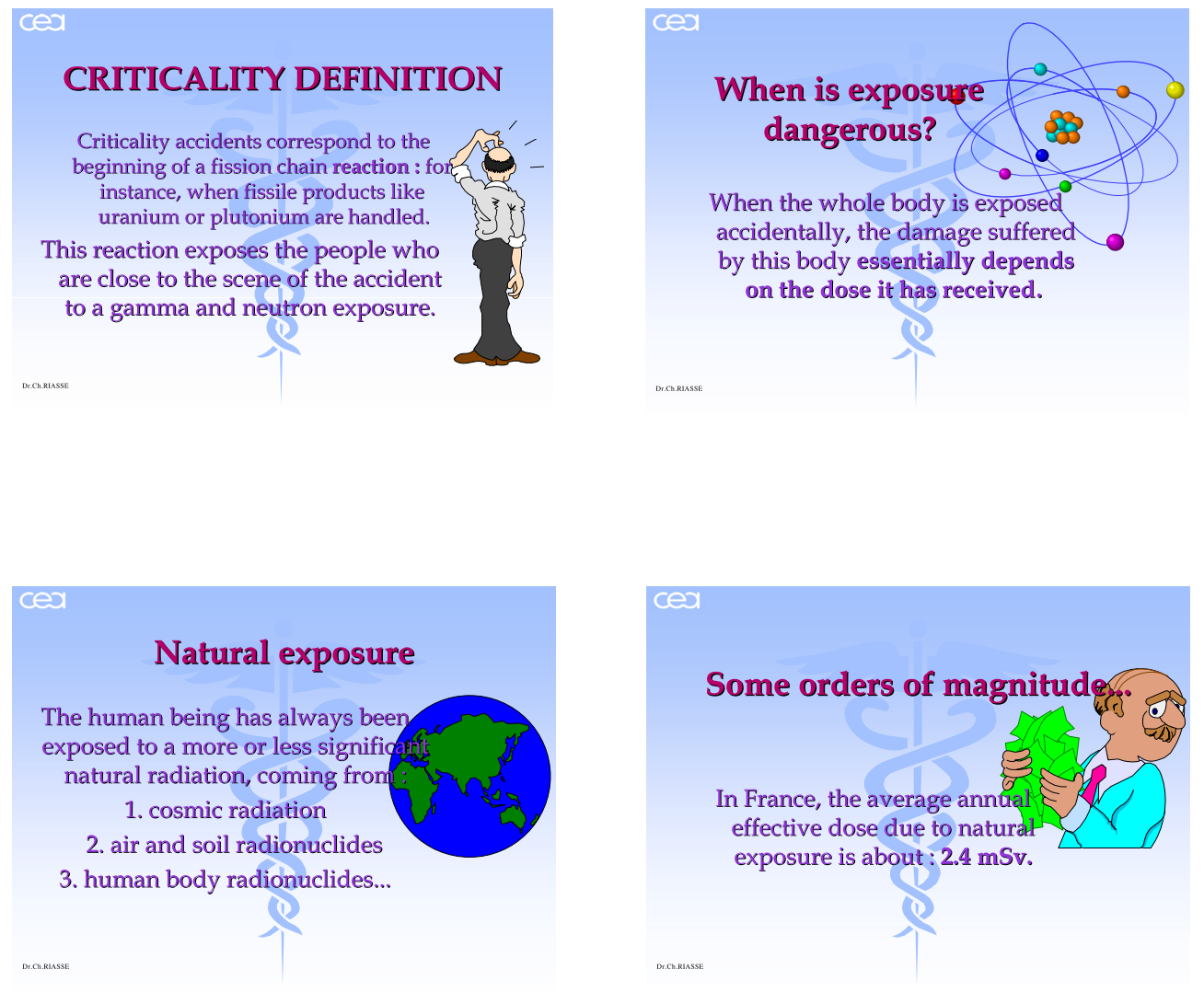


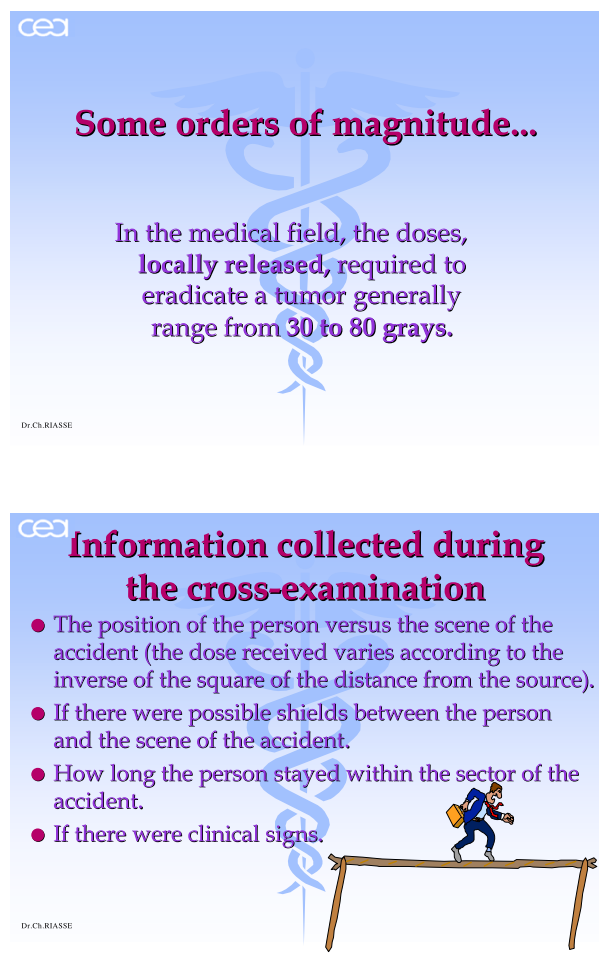

When a criticality accident happens, it is essential to question the people who were more or less directly involved in the accident...

To specify in which circumstances they were exposed and to estimate the dose received.
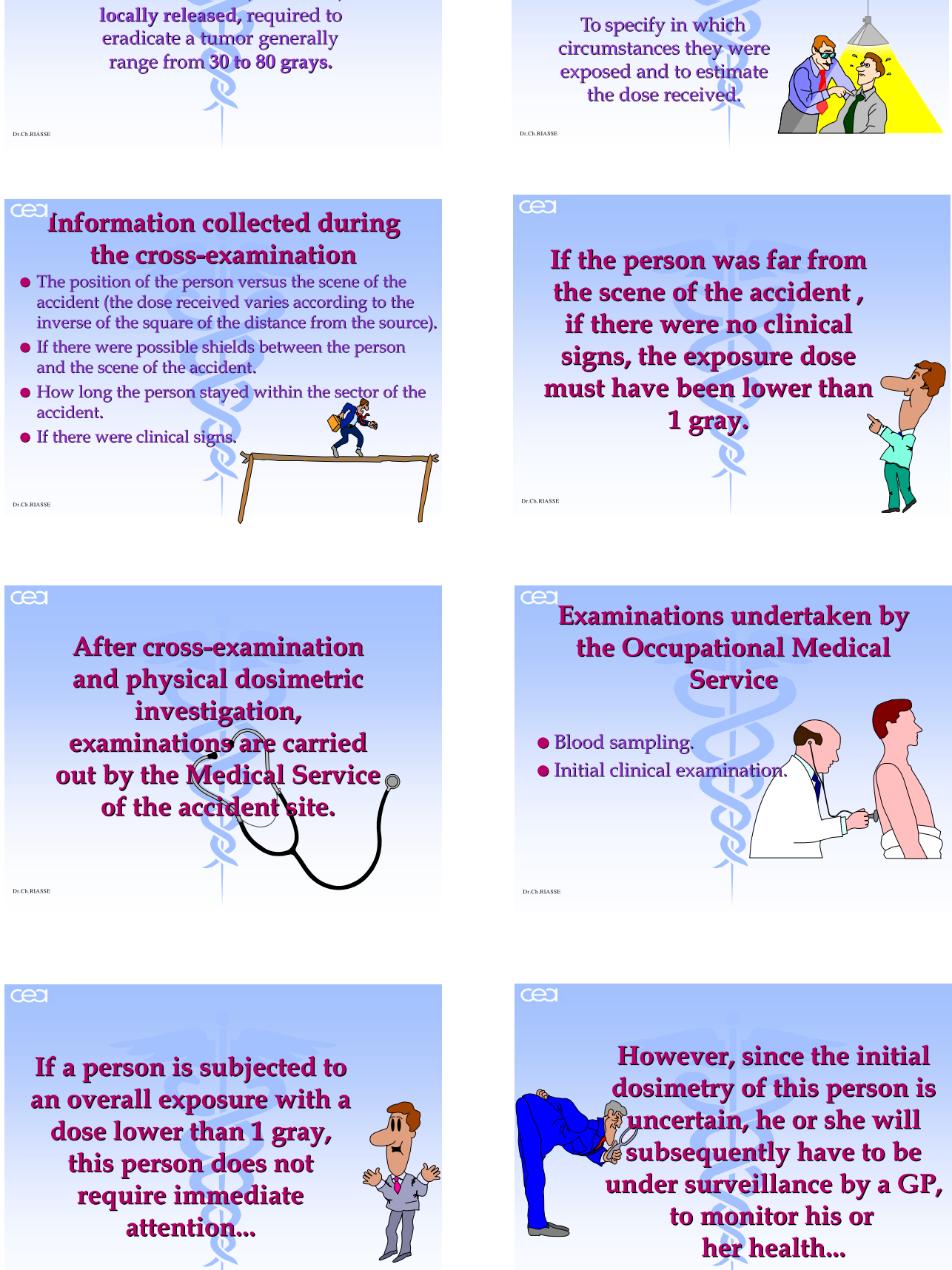


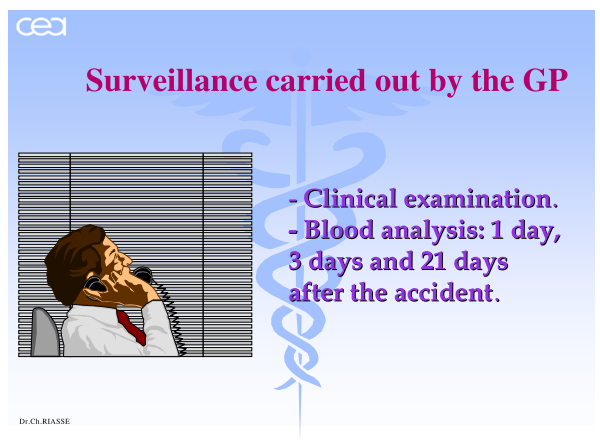

\section{Case of a pregnant mother}

- The risk can vary according to the estimated dose received in the abdominal region.

- In any case, a specialist's opinion is required.

\section{Information for medical doctors and staff of hospitals concerned}

\subsection{What is a criticality accident?}

Criticality accidents correspond to an uncontrollable triggering of a fission chain reaction during the manipulation of fissile elements, uranium and plutonium. This reaction exposes the people near the location of the accident to an acute gamma and neutron irradiation.

External irradiation was received during the accident. The irradiated individual presents no radiological risk to his environment and particularly to the medical staff.

\subsection{How were the people involved in the criticality accident taken care of by the medical staff on site?}

Besides the victims requiring medical and surgical emergency care or reanimation, and who were immediately evacuated to hospitals, the other people involved were taken care of as follows:

- Search and control of any associated contamination by the Occupational Medical Service (MS):

- In case of radioactive external contamination by cutaneous deposit shown by radioactivity detectors, the person was decontaminated by means of water, liquid soap and specialized products (DTPA) depending on the radio-isotope.

- A series of samples to determine internal contamination (urine, feces, nasal mucus samples for radiotoxicological analysis and spectrometry) was started and must be continued in the hospital in liaison with the occupational medical staff.

- If required, immediate treatment of a suspected internal contamination was given (stable iodine, DTPA). 
- Clinical examination, symptomatic treatment, initial biological analyses, samples from personal effects and integuments to estimate neutron dosimetry, spectrometry.

After these tests on site, the seriousness to which each person might have been exposed was evaluated to help make a decision on future orientation (hospital, family physician).

For each person, a file with all the observations and actions performed during this time has been compiled. This file stays with the patient in case of evacuation to a hospital.

\subsection{What were the criteria for hospitalization?}

Except for medical and surgical emergencies, those people evacuated to a hospital structure are:

- patients having received a global external irradiation with at least one of the following initial clinical signs which could mean an exposure to over $1 \mathrm{~Gy}$ :

- digestive signs: nausea, vomiting, diarrhea, hemorrhage;

- cutaneous signs: rash, edema or pain;

- state of shock, neurovegetative and vasomotor signs (hyperthermia, troubles of vigilance, tachycardia and rhythm disturbances);

- painful edema of parotids, dry mouth;

- neurological signs: disorientation, obsession, convulsions, asthenia.

- patients whose exposure was partial, in other words inferior to $18 \%$ of the body surface, according to the "rule of 9" with a local rash, an edema and pain leading to an assumption that a local dose greater than 4 Gy was received.

\subsection{How were these patients directed?}

Depending on the dosimetry initially estimated from clinical, biological data and the physical dosimetry investigation made where the accident occurred:

- the patients globally exposed:

- to doses between 1 and 2 Gy were sent to MS;

- to doses estimated at greater than 2 Gy were sent to Hematology services.

- the patients whose exposure was partial were sent to the Burns centers.

\subsection{Objective of hospitalization after global irradiation}

The medical/surgical emergency is paramount.

The procedure to be followed during hospitalization is described in Leaflets $2-5$

(Radiopathology). This includes:

- clinical examinations;

- biological investigations;

- investigations of the hematopoietic bone marrow in case of hypoplasia; 
- the symptomatic and preventive treatment of the initial clinical signs, the prevention and treatment of any potential infection source. The pathologies not related to irradiation will be treated in a conventional manner.

The clinical and biological surveillance in hospital must allow a more accurate dosimetric diagnosis for the prognosis.

\subsection{Evolution during hospitalization}

After the initial phase (or prodromal phase) a period of latency, from a few hours to three weeks, sooner the higher the dose absorbed, then a critical phase corresponding to cellular destruction (skin, bone marrow, intestinal mucosa) or to the malfunction of critical organs (central nervous system).

- For patients hospitalized in non-specialized services, a clinical and hematological surveillance is necessary: FBC, platelets at day 3 , day 8 , day 15 , day 31 , day 40 . The presence of one of the following hematological criteria might mean a higher dose than that initially estimated and should lead to the transfer of the patient to a specialized center according to the recommendations of the Occupational MS:

- lymphocyte rate lower than half of that of the first reference sample or lower than $1000 / \mathrm{mm}^{3}$;

- neutrophile polynuclear rate lower than $1500 / \mathrm{mm}^{3}$;

- platelet rate lower than $5000 / \mathrm{mm}^{3}$.

- In a specialized hematological center, the following investigations should be done:

- Investigations of the functioning of the hematopoietic bone marrow.

- Symptomatically treat a possible medullar aplasia (transfusions of irradiated blood products, CMV - if necessary, treatments of digestive or pulmonary syndromes)

- Discuss the therapeutic attitude depending on the results of the specialized investigations (severity of the aplasia, heterogeneity of the medullar damage):

- wait for spontaneous medullar reconstitution,

- bone marrow graft,

- hematopoietic growth factors.

During a criticality accident, the dose will be heterogeneous and the indications for a bone marrow graft will be very limited.

\subsection{In all cases, you can contact:}

- the Occupational MS of the site of the accident

- the following specialized service:

Institut de Radioprotection et de Sûreté Nucléaire (IRSN)

BP 17 - 92262 Fontenay-aux-Roses Cedex, France

(c) 0033158358888

Engineer on duty at the IRSN $24 \mathrm{~h}$ a day, 7 days a week: 0033607315663 


\section{Information and liaison with general practitioners}

\subsection{What is a criticality accident?}

Criticality accidents correspond to an uncontrollable triggering of a fission chain reaction during the manipulation of fissile elements, uranium and plutonium. This reaction exposes the people near the location of the accident to an acute gamma and neutron irradiation.

External irradiation was received during the accident. The irradiated individual presents no radiological risk to his environment and particularly to the medical staff.

\subsection{How were the people involved in the criticality accident taken care of by the occupational medical staff?}

Besides the victims requiring medical and surgical emergency care or reanimation, and who were immediately evacuated to hospitals, the other people involved were taken care of as follows:

- Search and control of any associated contamination by the Occupational MS:

- In case of radioactive external contamination by cutaneous deposit shown by radioactivity detectors, the person was decontaminated by means of water, liquid soap and specialized products (DTPA) depending on the radio-isotope.

- A series of investigations to determine internal contamination (urine, feces, nasal mucus samples for radiotoxicological analysis and spectrometry) was started and must be continued in the hospital in liaison with the occupational medical staff.

- If required, immediate treatment of a suspected internal contamination was given (stable iodine, DTPA).

- Clinical examination, symptomatic treatment, initial biological analyses, samples from personal effects and integuments in order to estimate neutron dosimetry, spectrometry.

After these tests on site, the extent to which each person might have been exposed was evaluated to help make a decision on future orientation (hospital, GP).

For each person a pouch, containing a triage file and an information file with all the observations and actions performed during this time, has been made up and given to each upon leaving the site. 


\subsection{What were the criteria for hospitalization?}

Except for medical and surgical emergencies, those people evacuated to a hospital structure are:

- patients whose global external irradiation was estimated to be greater than $1 \mathrm{~Gy}$;

- patients whose exposure was partial, in other words inferior to $18 \%$ of the body surface, according to the "rule of 9" with a local rash, an edema and pain leading to an assumption that a local dose greater than $4 \mathrm{~Gy}$ was received.

\subsection{What were the criteria for ambulatory surveillance?}

Those with no clinical signs during the initial examinations, and having been exposed to a source estimated at less than $1 \mathrm{~Gy}$ (global irradiation suspected in view of their location versus the source during the accident), are requested to see their family physician for surveillance.

What does this surveillance include?

- a clinical examination and an initial FBC;

- collating all the medical data:

- FBC results on the work site,

- results from the physical dosimetric investigation;

- a clinical and hematological surveillance at D3 and D21.

\subsection{What are the criteria of severity requiring hospitalization?}

The initial estimated dosimetry presents uncertainties justifying outpatient surveillance. The following criteria of severity must have a dose greater than 1 Gy suspected and managed to a hospitalization according to the recommendations of the occupational medical physician of the site:

- Appearance of clinical signs:

- digestive signs: nausea, vomiting, diarrhea, hemorrhage;

- cutaneous signs: rash, edema or pain;

- state of shock, neurovegetative and vasomotor signs (hyperthermia, troubles of vigilance, tachycardia and rhythm disturbances);

- painful edema of parotids, dry mouth;

- neurological signs: disorientation, obsession, convulsions, asthenia.

- Appearance of anomalies on the FBC. For doses lower than $1 \mathrm{~Gy}$, a discreet and temporary drop in the lymphocytes (whose rate must however remain within normal range) can be observed. 


\subsection{In all cases, you can contact:}

- the MS of the work site of the accident

- the following specialized service:

Institut de Radioprotection et de Sûreté Nucléaire (IRSN)

BP 17 - 92262 Fontenay-aux-Roses Cedex, France

(c) 0033158358888

Engineer on duty at the IRSN 24 h a day, 7 days a week: 0033607315663

\section{Information for those needing surveillance from their general physicians}

After the criticality accident, the dosimetric investigation and the examinations you have undergone at the Occupational MS have not shown any element justifying your hospitalization or any specialized surveillance. Consequently, you have been authorized to go home.

However, you need to consult your family physician the day after the accident.

Your personal file with all the observations and actions taken on the site must be given to you as well as the results of the examinations made on site which you may possibly have. An information leaflet entitled "Information and liaison with general physicians" has also been given to you.

Moreover, in the case of appearance of one or several of the following signs:

- nausea, vomiting, diarrhea;

- skin rash, swelling or pain;

- fever, disturbances of vigilance, palpitations;

- dry mouth;

- fatigue, drowsiness.

Immediately contact your GP. 


\section{IAEA offices and contact information}

Headquarters offices:

International Atomic Energy Agency

P.O. Box 100

Wagramer Strasse 5

A-1400 Vienna, Austria

8 (+431) 2600-0 - Fax: (+431) 2600-7

E-mail: Official.Mail@iaea.org

Website: www.iaea.org

\section{Radiological emergencies in France}

Institute of Radioprotection and Nuclear Safety (IRSN)

BP 17 - 92262 Fontenay-aux-Roses Cedex, France

8P 0033158358888

The IRSN engineer on duty can be reached $24 \mathrm{~h}$ a day, 7 days a week at: 0033607315663 .

Army Service of Radiological Protection (SPRA)

1 bis rue du Lieutenant Raoul-Batany - 92141 Clamart, France

甶00331414671

Hospitals in Paris which can treat radiological accidents

Hopital d'instruction des armees percy

101 avenue Henri Barbusse - 92141 Clamart, France

\&. 0033141466000

Working hours: 80033141466010 (MD in charge) 0033141466012 (secretary) 
0033141466013 (general secretarial office)

0033141466491 (Fax)

Outside office hours: $\mathbf{8} 0033141466385$

Burn Treatment Center (CTB):

MD in charge:

오 0033141466210 or 0033141466211 (secretary)

Fax: 0033140950872

\section{Institut Curie}

26 rue d'Ulm - 75005 Paris, France

8̊ 0033144324000

Radiotherapy Service Director:

\& 0033144324624 or 0033144324622 (secretary)

\section{Hopital Saint-Antoine}

184 rue du Faubourg Saint Antoine - 75012 Paris, France

в 0033149282000

Director of Service for Blood Diseases and Cellular Therapy

ه 0033149282619 or 0033149282620 (secretary)

Fax: 0033149282000

Outside office hours: $\mathbf{8} 0033149282000$ (BIP 312)

\section{History of criticality work group of occupational MS/CBL}

The main phases

February $1984-$ Conclusions of Criticality WG: Rules to respect in case of criticality accident.

This very significant study, after recalling the phenomenology, establishes the rules of triage by means of leaflets: rapid triage based on clinical signs and activation of ${ }^{24} \mathrm{Na}$. An operational formula is given:

$$
D(\mathrm{~Sv})=K \cdot A_{0} \cdot \mathrm{EBR} .
$$

EBR: Relative Biological Efficiency

$D(\mathrm{~Sv})$ : Equivalent dose since it is multiplied by the EBR

K: $\quad$ (average neutron kerma empirically estimated) $10^{-6} \mathrm{~Gy} \cdot \mathrm{Bq}^{-1}$ of ${ }^{24} \mathrm{Na}$

$A_{0}: \quad$ Activity in ${ }^{24} \mathrm{Na}$ in $\mathrm{Bq}$ at $t=0$ (time of criticality accident)

By assuming the EBR of these neutrons to be equal to 1 in the range of neutron dose from 1 to $4 \mathrm{~Gy}$ and a gamma component equal to twice that of neutrons, we obtain:

$$
D(\mathrm{~Sv})=3 \times 10^{-6} . A_{0}
$$


However, the following are missing from these recommendations: HLA typing, indications on additional help, time needed to obtain physical dosimetry, hospital and specialized services and some communication and information elements.

29 September 1987 - Publication of Note DGS 3A3E/1102 organization of medical treatment the first day in case of nuclear or radiological accident (amended in 2002).

6 December 1988 - Publication of Note DGS 3A3B on the monitoring and treatment of irradiated patients.

These documents which are very thorough and include the results and treatment to be implemented are written for emergency and hospital services.

They include an individual irradiation form and indications on the monitoring by the MDs in charge or on the hospitalizations depending on the irradiation level. Integuments analyses (activation of ${ }^{32} \mathrm{~S}$ and ${ }^{32} \mathrm{P}$, useful depending on the neutron energy and mostly the orientation of the patient) are not mentioned.

24 October 1991 - Upon request from the criticality WG of the SPR, the Occupational MS/CBL group resumed headed by the Medical Advisor. The subject studied was medical triage and knowledge of the operational needs in dosimetry to plan an operational strategy. This strategy was developed as well as physical dosimetry and its delivery period of results.

The dose rate chosen for the dosimetry to be used in an emergency was from 2 to 4 Gy.

Some proposals on studies to be carried out are sent to DCS with conclusions from the criticality WG.

17 January 1994 - The General Instruction Note 363 replaces Note YS 446 of 3 August 1979. Measures to be taken by the MSs in case of high external or internal exposure to ionizing radiation.

March 1994

24 October 1995

December 1998

March 2001
- Publication of the minutes of SPR criticality dosimetry drill.

- Mission letter from the Medical Advisor to reactivate the Criticality WG of the MS/CBL.

- Latest update by WG 3 of MS/CBL of the list of Paris hospitals likely to treat radiological accidents.

- Update of report following feedback from the Tokai-mura accident. 


\section{Criticality accidents}

Tables XI and XII below list the accidents recorded by the IAEA (International Atomic Energy Agency), Vienna, Austria.

Table XI. Criticality accidents on critical assemblies in laboratories and experimental reactors.

\begin{tabular}{|c|c|c|c|}
\hline $\begin{array}{l}\text { Date } \\
\text { and place }\end{array}$ & $\begin{array}{l}\text { People } \\
\text { irradiated }\end{array}$ & $\begin{array}{l}\text { Number } \\
\text { of fissions }\end{array}$ & $\begin{array}{l}\text { Circumstances, } \\
\text { sequence of events } \\
\text { and causes }\end{array}$ \\
\hline $\begin{array}{l}02 / 11 / 45 \\
\text { Los Alamos }\end{array}$ & No-one irradiated & $6 \times 10^{15}$ fissions & $\begin{array}{l}\text { DRAGON reactor (UH3 in styrex); } \\
\text { reactor operated in the fast-critical } \\
\text { mode; calculation error. }\end{array}$ \\
\hline $\begin{array}{l}\text { 06/06/45 } \\
\text { Los Alamos }\end{array}$ & No-one irradiated & $4 \times 10^{16}$ fissions & $\begin{array}{l}79.2 \% \text { enriched uranium; water } \\
\text { ingress. }\end{array}$ \\
\hline $\begin{array}{l}08 / 21 / 45 \\
\text { Los Alamos }\end{array}$ & 1 dead & $10^{16}$ fissions & $\begin{array}{l}\text { Pure plutonium, manual } \\
\text { installation of a reflector. }\end{array}$ \\
\hline $\begin{array}{l}05 / 21 / 46 \\
\text { Los Alamos }\end{array}$ & 1 dead & $3 \times 10^{15}$ fissions & $\begin{array}{l}\text { Pure plutonium, manual } \\
\text { installation of a reflector. }\end{array}$ \\
\hline $\begin{array}{l}\text { 12/49 } \\
\text { Los Alamos }\end{array}$ & No-one irradiated & $3 \times 10^{16}$ fissions & $\begin{array}{l}\text { Accident in a uranyl nitrate } \\
\text { solution; withdrawal of } 2 \text { control } \\
\text { rods. }\end{array}$ \\
\hline $\begin{array}{l}1950 \\
\text { Chalk River } \\
\text { (Canada) }\end{array}$ & No-one irradiated & & $\begin{array}{l}\text { Natural uranium in heavy } \\
\text { water; moderator excess. }\end{array}$ \\
\hline $\begin{array}{l}11 / 16 / 51 \\
\text { Handford }\end{array}$ & No-one irradiated & $8 \times 10^{16}$ fissions & $\begin{array}{l}\text { Accident in a plutonium nitrate } \\
\text { solution; control rods } \\
\text { withdrawn too quickly. }\end{array}$ \\
\hline $\begin{array}{l}03 / 01 / 51 \\
\text { Los Alamos }\end{array}$ & No-one irradiated & $10^{17}$ fissions & $\begin{array}{l}93 \% \text { enriched uranium; } \\
\text { poor engineering of the } \\
\text { emergency shutdown system. }\end{array}$ \\
\hline $\begin{array}{l}04 / 18 / 52 \\
\text { Los Alamos }\end{array}$ & No-one irradiated & $\begin{array}{l}1.5 \times 10^{16} \\
\text { fissions }\end{array}$ & $\begin{array}{l}\text { 93\% enriched uranium; } \\
\text { calculation error. }\end{array}$ \\
\hline $\begin{array}{l}06 / 02 / 52 \\
\text { Argonne } \\
\text { National } \\
\text { Laboratory }\end{array}$ & No-one irradiated & $\begin{array}{l}1.22 \times 10^{17} \\
\text { fissions }\end{array}$ & $\begin{array}{l}\text { Fuel elements of } 93 \% \text { enriched } \\
\text { uranium oxide in plastic; } \\
\text { instrumentation removed and } \\
\text { failure of the water draining } \\
\text { system. }\end{array}$ \\
\hline $\begin{array}{l}12 / 12 / 52 \\
\text { Chalk River } \\
\text { (Canada) }\end{array}$ & No-one irradiated & $\begin{array}{l}1.2 \times 10^{20} \\
\text { fissions }\end{array}$ & $\begin{array}{l}\text { Natural uranium in heavy } \\
\text { water; positive vacuum coefficient. }\end{array}$ \\
\hline $\begin{array}{l}04 / 09 / 53 \\
\text { VVIIEF }\end{array}$ & $\begin{array}{l}2 \text { people slightly } \\
\text { irradiated }(\sim 1 \mathrm{rem})\end{array}$ & $10^{16}$ fissions & $\begin{array}{l}\text { Error of an operator who was } \\
\text { working alone on a critical } \\
\text { assembly (two } 10 \mathrm{~cm} \text { in } \\
\text { diameter half-spheres of } \\
\text { plutonium); meltdown of a part. }\end{array}$ \\
\hline $\begin{array}{l}1954 \\
\text { USSR }\end{array}$ & & $10^{16}$ fissions & Unknown details \\
\hline
\end{tabular}


Table XI. (continued)

\begin{tabular}{|c|c|c|c|}
\hline $\begin{array}{l}\text { Date } \\
\text { and place }\end{array}$ & $\begin{array}{l}\text { People } \\
\text { irradiated }\end{array}$ & $\begin{array}{l}\text { Number } \\
\text { of fissions }\end{array}$ & $\begin{array}{l}\text { Circumstances, } \\
\text { sequence of events } \\
\text { and causes }\end{array}$ \\
\hline $\begin{array}{l}05 / 26 / 54 \\
\text { Oak Ridge }\end{array}$ & No-one irradiated & $10^{1 /}$ fissions & $\begin{array}{l}\text { Accident in a uranyl fluoride } \\
\text { solution in two coaxial tubular } \\
\text { containers; the internal cylinder } \\
\text { moved into the annular external } \\
\text { cylinder. }\end{array}$ \\
\hline $\begin{array}{l}02 / 03 / 54 \\
\text { Los Alamos }\end{array}$ & No-one irradiated & $\begin{array}{l}5.6 \times 10^{16} \\
\text { fissions }\end{array}$ & $\begin{array}{l}93 \% \text { enriched uranium; handling } \\
\text { error. }\end{array}$ \\
\hline $\begin{array}{l}07 / 22 / 54 \\
\text { Idaho Reactor } \\
\text { Testing Area }\end{array}$ & No-one irradiated & $\begin{array}{l}4.68 \times 10^{18} \\
\text { fissions }\end{array}$ & $\begin{array}{l}93 \% \text { enriched uranium in heavy } \\
\text { water; operator error which led } \\
\text { to an excessively rapid transient. }\end{array}$ \\
\hline $\begin{array}{l}11 / 29 / 55 \\
\text { Argonne } \\
\text { National } \\
\text { Laboratory }\end{array}$ & No-one irradiated & $\begin{array}{l}4 \times 10^{17} \\
\text { fissions }\end{array}$ & $\begin{array}{l}\text { Fast neutron breeder reactor (fuel } \\
\text { elements of enriched uranium, } \\
52 \mathrm{~kg} \text {, into Na K); emergency } \\
\text { shutdown delay in an } \\
\text { experimental transient intended } \\
\text { to study the power coefficient; } \\
\text { meltdown of half the core. }\end{array}$ \\
\hline $\begin{array}{l}02 / 01 / 56 \\
\text { Oak Ridge }\end{array}$ & No-one irradiated & $1.6 \times 10^{17}$ fissions & $\begin{array}{l}\text { Accident in a uranyl fluoride } \\
\text { solution due to a change in the } \\
\text { geometry of an emergency } \\
\text { shutdown rod. }\end{array}$ \\
\hline $\begin{array}{l}\text { 07/03/56 } \\
\text { Los Alamos }\end{array}$ & No-one irradiated & $\begin{array}{l}3.2 \times 10^{16} \\
\text { fissions }\end{array}$ & $\begin{array}{l}\text { Honeycomb reactor zero power; } \\
\text { fuel elements of } 93 \% \text { enriched } \\
\text { uranium in graphite; excessively } \\
\text { fast critical approach which led } \\
\text { to fast-criticality. }\end{array}$ \\
\hline $\begin{array}{l}02 / 12 / 57 \\
\text { Los Alamos }\end{array}$ & No-one irradiated & $\begin{array}{l}1.2 \times 10^{17} \\
\text { fissions }\end{array}$ & $\begin{array}{l}\text { 93\% enriched uranium; } \\
\text { equipment removal. }\end{array}$ \\
\hline $\begin{array}{l}10 / 15 / 58 \\
\text { Vinca } \\
\text { (Yougoslavia) }\end{array}$ & 1 dead & $\begin{array}{l}2.6 \times 10^{18} \\
\text { fissions }\end{array}$ & $\begin{array}{l}\text { Natural uranium in heavy water; } \\
\text { faulty power measurement. }\end{array}$ \\
\hline $\begin{array}{l}11 / 18 / 58 \\
\text { Idaho Reactor } \\
\text { Testing Area }\end{array}$ & No-one irradiated & $\begin{array}{l}2.5 \times 10^{19} \\
\text { fissions }\end{array}$ & $\begin{array}{l}\text { Air-powered prototype reactor; } \\
\text { instrumentation breakdown } \\
\text { which led to control problems. }\end{array}$ \\
\hline $\begin{array}{l}03 / 15 / 60 \\
\text { Saclay }\end{array}$ & No-one irradiated & $\begin{array}{l}3 \times 10^{18} \\
\text { fissions }\end{array}$ & $\begin{array}{l}\text { Withdrawal of an absorber rod } \\
\text { from } 1.5 \% \text { enriched uranium } \\
\text { oxide rods in a critical mockup } \\
\text { (Alize) in water. }\end{array}$ \\
\hline $\begin{array}{l}06 / 17 / 60 \\
\text { Los Alamos }\end{array}$ & No-one irradiated & $\begin{array}{l}6 \times 10^{16} \\
\text { fissions }\end{array}$ & $\begin{array}{l}\text { 93\% enriched uranium; } \\
\text { excessive matter was added. }\end{array}$ \\
\hline
\end{tabular}


Table XI. (continued)

\begin{tabular}{|c|c|c|c|}
\hline $\begin{array}{l}\text { Date } \\
\text { and place }\end{array}$ & $\begin{array}{l}\text { People } \\
\text { irradiated }\end{array}$ & $\begin{array}{l}\text { Number } \\
\text { of fissions }\end{array}$ & $\begin{array}{l}\text { Circumstances, } \\
\text { sequence of events } \\
\text { and causes }\end{array}$ \\
\hline $\begin{array}{l}01 / 03 / 61 \\
\text { Idaho Reactor } \\
\text { Testing Area }\end{array}$ & 3 dead & $\begin{array}{l}4.4 \times 10^{18} \\
\text { fissions }\end{array}$ & $\begin{array}{l}\text { Fuel elements of } 93 \% \text { enriched } \\
\text { uranium in water; withdrawal } \\
\text { of a control rod. }\end{array}$ \\
\hline $\begin{array}{l}\text { 11/10/61 } \\
\text { Oak Ridge }\end{array}$ & No-one irradiated & $10^{16}$ fissions & $\begin{array}{l}\text { 93\% enriched uranium; } \\
\text { excessive matter was added. }\end{array}$ \\
\hline $\begin{array}{l}11 / 05 / 62 \\
\text { Idaho Reactor } \\
\text { Testing Area }\end{array}$ & No-one irradiated & $10^{18}$ fissions & $\begin{array}{l}\text { Fuel elements of } 93 \% \text { enriched } \\
\text { uranium in water; excessively } \\
\text { fast transient. }\end{array}$ \\
\hline $\begin{array}{l}12 / 11 / 62 \\
\text { Los Alamos }\end{array}$ & No-one irradiated & $3 \times 10^{16}$ fissions & $\begin{array}{l}\text { Critical assembly of } 93 \% \\
\text { enriched uranium in graphite; } \\
\text { error in the critical approach. }\end{array}$ \\
\hline $\begin{array}{l}03 / 26 / 63 \\
\text { VNIIEF }\end{array}$ & 6 people irradiated & $\begin{array}{l}5 \times 10^{15} \text { fissions } \\
370 \text { à } 500 \text { rems } \\
(3.7 \text { à } 5 \mathrm{~Sv})\end{array}$ & $\begin{array}{l}\text { No respect of instructions in } \\
\text { an experiment on a critical } \\
\text { assembly (two } 135 \mathrm{~mm} \text { in } \\
\text { diameter half-spheres of } \\
\text { plutonium); no consequence on } \\
\text { the assembly. }\end{array}$ \\
\hline $\begin{array}{l}03 / 06 / 63 \\
\text { Livermore } \\
\text { Laboratory }\end{array}$ & No-one irradiated & $10^{18}$ fissions & $\begin{array}{l}93 \% \text { enriched uranium; the } \\
\text { assembly upper part dropped. }\end{array}$ \\
\hline $\begin{array}{l}10 / 08 / 65 \\
\text { White Sands }\end{array}$ & No-one irradiated & $1.5 \times 10^{17}$ fissions & $\begin{array}{l}\text { 93\% enriched uranium; } \\
\text { handling error. }\end{array}$ \\
\hline $\begin{array}{l}\text { 12/30/65 } \\
\text { Mol (Belgium) }\end{array}$ & 1 person irradiated & $4 \times 10^{17}$ fissions & $\begin{array}{l}7 \% \text { enriched uranium oxide in } \\
\text { water and heavy water; error of } \\
\text { an operator (did not drain water } \\
\text { before intervening on the core). }\end{array}$ \\
\hline $\begin{array}{l}09 / 06 / 68 \\
\text { Aberdeen }\end{array}$ & No-one irradiated & $6.1 \times 10^{17}$ fissions & $\begin{array}{l}93 \% \text { enriched uranium; } \\
\text { handling error. }\end{array}$ \\
\hline $\begin{array}{l}01 / 30 / 68 \\
\text { Oak Ridge }\end{array}$ & No-one irradiated & $1.1 \times 10^{16}$ fissions & $\begin{array}{l}\text { Accident in a uranyl nitrate } \\
\text { solution; injection of air bubbles } \\
\text { caused a solution mass increase. }\end{array}$ \\
\hline $\begin{array}{l}\text { 10/14/68 } \\
\text { Isis } \\
\text { Mockup/ } \\
\text { Saclay }\end{array}$ & $\begin{array}{l}\text { Low exposure of } \\
\text { an operator }\end{array}$ & & $\begin{array}{l}\text { Removal of a meter used for } \\
\text { spectra measurements, while all } \\
\text { the reactor rods were not in low } \\
\text { position. Error of the operator } \\
\text { who did not rely on what was } \\
\text { indicated concerning rod position } \\
\text { (ie some rods were still in an } \\
\text { upper position). The chain } \\
\text { reaction was stopped by the } \\
\text { operator who let the counting } \\
\text { device drop. }\end{array}$ \\
\hline
\end{tabular}


Table XI. (continued)

\begin{tabular}{|c|c|c|c|}
\hline $\begin{array}{l}\text { Date } \\
\text { and place }\end{array}$ & $\begin{array}{l}\text { People } \\
\text { irradiated }\end{array}$ & $\begin{array}{l}\text { Number } \\
\text { of fissions }\end{array}$ & $\begin{array}{l}\text { Circumstances, } \\
\text { sequence of events } \\
\text { and causes }\end{array}$ \\
\hline $\begin{array}{l}02 / 15 / 71 \\
\text { Kurtchatov } \\
\text { Institute }\end{array}$ & $\begin{array}{l}2 \text { people with } \\
\text { severe } \\
\text { irradiations on feet }\end{array}$ & $2 \times 10^{19}$ fissions & $\begin{array}{l}\text { Critical mockup of fuel } \\
\text { assemblies of } 20 \% \text { enriched } \\
\text { uranium in water used for the } \\
\text { approach to criticality, with } \\
\text { absorbents and a beryllium } \\
\text { reflector; the tank was filled } \\
\text { before the neutron source was } \\
\text { installed and before the control } \\
\text { rods dropped; shutdown by } \\
\text { water evaporation after } \\
\text { shutdown of the filling pump. }\end{array}$ \\
\hline $\begin{array}{l}05 / 26 / 71 \\
\text { Kurtchatov } \\
\text { Institute }\end{array}$ & $\begin{array}{l}50 \text { successive } \\
\text { power peaks } \\
2 \text { dead } \\
2 \text { severe } \\
\text { irradiations }\end{array}$ & $\begin{array}{l}5 \times 10^{18} \text { fissions } \\
60 \mathrm{~Sv} \text { et } 20 \mathrm{~Sv} \\
700 \text { à } 800 \mathrm{rems} \\
(7 \text { à } 8 \mathrm{~Sv})\end{array}$ & $\begin{array}{l}\text { Critical mockup of } 93 \% \text { enriched } \\
\text { uranium fuel pins; failure of } \\
\text { pin support plate causing their } \\
\text { drop into the lower part still full } \\
\text { of water (even though the } \\
\text { experiment was finished and the } \\
\text { tank was being drained and } \\
\text { technicians were still in the } \\
\text { room). }\end{array}$ \\
\hline $\begin{array}{l}\text { 09/23/83 } \\
\text { Buenos Aires }\end{array}$ & 1 dead & $4 \times 10^{17}$ fissions & $\begin{array}{l}\text { Research reactor zero power; } \\
\text { did not drain reactor before } \\
\text { intervening on the core. }\end{array}$ \\
\hline $\begin{array}{l}\text { 06/17/97 } \\
\text { VNIIEF }\end{array}$ & $\begin{array}{l}\text { Several hours } \\
1 \text { dead }\end{array}$ & $2 \times 10^{17}$ fissions & $\begin{array}{l}\text { A physicist working alone } \\
\text { poorly assembled (manually) } \\
\text { an experimental setup. }\end{array}$ \\
\hline
\end{tabular}

Table XII. Criticality accidents on fuel cycle facilities.

\begin{tabular}{|c|c|c|c|}
\hline Date and place & $\begin{array}{l}\text { Length/People } \\
\text { irradiated }\end{array}$ & $\begin{array}{l}\text { Number } \\
\text { of fissions body } \\
\text { exposures }\end{array}$ & $\begin{array}{l}\text { Circumstances, } \\
\text { sequence of events } \\
\text { and causes }\end{array}$ \\
\hline $\begin{array}{l}06 / 16 / 58 \\
\text { Oak Ridge }\end{array}$ & $\begin{array}{l}20 \mathrm{~min} \\
8 \text { people } \\
\text { irradiated }\end{array}$ & $\begin{array}{l}1.3 \times 10^{18} \text { fissions } \\
20-400 \text { rads } \\
(0.2-4 \mathrm{~Gy})\end{array}$ & $\begin{array}{l}\text { Accidental filling of a } 200 \mathrm{~L} \\
\text { tank with highly enriched } \\
\text { uranyl nitrate; end of } \\
\text { accident by dilution. }\end{array}$ \\
\hline $\begin{array}{l}\text { 12/30/58 } \\
\text { Los Alamos }\end{array}$ & $\begin{array}{l}1 \text { peak } \\
1 \text { dead }\end{array}$ & $\begin{array}{l}1.5 \times 10^{17} \\
\text { fissions } \\
12000 \mathrm{rads}(120 \mathrm{~Gy})\end{array}$ & $\begin{array}{l}\text { Solvent containing } 3.27 \mathrm{~kg} \\
\text { of plutonium on aqueous } \\
\text { phase; reaction when the } \\
\text { mixer started; end of } \\
\text { accident by mixer stopping. }\end{array}$ \\
\hline
\end{tabular}


Table XII. (continued)

\begin{tabular}{|c|c|c|c|}
\hline Date and place & $\begin{array}{l}\text { Length/People } \\
\text { irradiated }\end{array}$ & $\begin{array}{l}\text { Number } \\
\text { of fissions body } \\
\text { exposures }\end{array}$ & $\begin{array}{l}\text { Circumstances, } \\
\text { sequence of events } \\
\text { and causes }\end{array}$ \\
\hline $\begin{array}{l}10 / 16 / 59 \\
\text { Idaho }\end{array}$ & $\begin{array}{l}20 \text { min } \\
\text { no consequence }\end{array}$ & $4 \times 10^{19}$ fissions & $\begin{array}{l}30 \mathrm{~kg} \text { of }{ }^{235} \mathrm{U} \text { in a } 19 \mathrm{~m}^{3} \\
\text { tank; end of accident by } \\
\text { water evaporation and } \\
\text { uranyl nitrate crystallization. }\end{array}$ \\
\hline $\begin{array}{l}\text { 01/25/61 } \\
\text { Idaho }\end{array}$ & $\begin{array}{l}1 \text { peak } \\
\text { no consequence }\end{array}$ & $6 \times 10^{17}$ fissions & $\begin{array}{l}40 \mathrm{~L} \text { of highly enriched } \\
\text { uranyl nitrate; cause: } \\
\text { compressed air injection. }\end{array}$ \\
\hline $\begin{array}{l}04 / 07 / 62 \\
\text { Handford }\end{array}$ & $\begin{array}{l}37 \mathrm{~h} \\
3 \text { people } \\
\text { irradiated }\end{array}$ & $\begin{array}{l}8 \times 10^{17} \text { fissions } \\
\text { with severe } \\
\text { irradiations but } \\
\text { without any } \\
\text { visible clinical lesion }\end{array}$ & $\begin{array}{l}45 \mathrm{~L} \text { of solution; end of } \\
\text { accident by evaporation. }\end{array}$ \\
\hline \multirow{3}{*}{$\begin{array}{l}07 / 24 / 64 \\
\text { Wood River } \\
\text { Junction }\end{array}$} & 1 peak & $1 \times 10^{17}$ fissions & \multirow{3}{*}{$\begin{array}{l}\text { End of accident by the } \\
\text { solution being ejected. } \\
\text { End of accident, then again } \\
\text { dissolving the solution. }\end{array}$} \\
\hline & 1 peak & $2 \times 10^{16}$ fissions & \\
\hline & $\begin{array}{l}1 \text { dead } \\
+2 \text { people } \\
\text { irradiated }\end{array}$ & $\begin{array}{l}10000 \text { rads } \\
(100 \mathrm{~Gy}) \\
\text { people irradiated } \\
\text { without any } \\
\text { visible clinical lesion }\end{array}$ & \\
\hline $\begin{array}{l}08 / 24 / 70 \\
\text { Windscale }\end{array}$ & $5-10 \mathrm{~s}$ & & $\begin{array}{l}\text { Water ingress into a tank of } \\
\text { solvent loaded with } \\
\text { plutonium }(55 \mathrm{~g} / \mathrm{L}) \text {. }\end{array}$ \\
\hline $\begin{array}{l}10 / 17 / 78 \\
\text { Idaho }\end{array}$ & $25 \mathrm{~min}$ & & $\begin{array}{l}\text { Accumulation of highly } \\
\text { enriched uranium in a scrub } \\
\text { column because of change } \\
\text { in the solution quality. }\end{array}$ \\
\hline $03 / 15 / 53$ & 1 peak & $2.5 \times 10^{17}$ fissions & $31 \mathrm{~L}$; during an \\
\hline Mayak & $\begin{array}{l}2 \text { people } \\
\text { irradiated }\end{array}$ & $\begin{array}{l}1000 \text { and } \\
100 \text { rads } \\
(10 \text { Gy and } 1 \mathrm{~Gy})\end{array}$ & $\begin{array}{l}\text { intermediate configuration; } \\
\text { shutdown by the solution } \\
\text { being ejected. }\end{array}$ \\
\hline $04 / 21 / 57$ & $10 \mathrm{~min}$ & $2 \times 10^{17}$ fissions & $100 \mathrm{~L}$; shutdown by \\
\hline Mayak & $\begin{array}{l}1 \text { dead }+ \\
5 \text { people irradiated }\end{array}$ & $\begin{array}{l}\text { clinical } \\
\text { lesions }\end{array}$ & $\begin{array}{l}\text { draining; this was due to } \\
\text { fissile material accumulation } \\
\text { caused by faulty cleaning. }\end{array}$ \\
\hline $\begin{array}{l}01 / 02 / 58 \\
\text { Mayak }\end{array}$ & $\begin{array}{l}1 \text { peak } \\
3 \text { dead }+ \\
1 \text { person irradiated }\end{array}$ & $\begin{array}{l}2.3 \times 10^{17} \text { fissions } \\
\text { clinical lesions }\end{array}$ & $\begin{array}{l}\text { During the manually- } \\
\text { operated draining of a } \\
\text { container by operators, } \\
\text { change of geometry and } \\
\text { increase of reflections. }\end{array}$ \\
\hline
\end{tabular}


Table XII. (continued)

\begin{tabular}{|c|c|c|c|}
\hline Date and place & $\begin{array}{l}\text { Length/People } \\
\text { irradiated }\end{array}$ & $\begin{array}{l}\text { Number } \\
\text { of fissions body } \\
\text { exposures }\end{array}$ & $\begin{array}{l}\text { Circumstances, } \\
\text { sequence of events } \\
\text { and causes }\end{array}$ \\
\hline $\begin{array}{l}12 / 05 / 60 \\
\text { Mayak }\end{array}$ & $\begin{array}{l}2 \text { peaks } \\
\text { several people } \\
\text { irradiated }\end{array}$ & $\begin{array}{l}10^{17} \text { fissions } \\
5 \text { rads }\end{array}$ & $\begin{array}{l}40 \mathrm{~L} \text {; end of accident by the } \\
\text { solution being ejected; poor } \\
\text { assessment of the } \\
\text { plutonium mass. }\end{array}$ \\
\hline $\begin{array}{l}\text { 08/14/61 } \\
\text { Siberian } \\
\text { Chemical Combine }\end{array}$ & $\begin{array}{l}2 \text { peaks } \\
1 \text { person irradiated }\end{array}$ & $\begin{array}{l}5 \times 10^{15} \\
\text { fissions } 10^{16} \\
\text { fissions } \\
200 \text { rads }(2 \mathrm{~Gy})\end{array}$ & $\begin{array}{l}60 \mathrm{~L} \text {; end of accident by the } \\
\text { solution being ejected; } \\
\text { accumulation of } 22.6 \% \\
\text { enriched plutonium in the } \\
\text { oil reservoir of a pump. }\end{array}$ \\
\hline $\begin{array}{l}\text { 09/07/62 } \\
\text { Mayak }\end{array}$ & No consequence & $2 \times 10^{17}$ fissions & $\begin{array}{l}100 \mathrm{~L} \text {; end of accident by } \\
\text { the solution being ejected. }\end{array}$ \\
\hline $\begin{array}{l}01 / 30 / 63 \\
\text { Siberian } \\
\text { Chemical } \\
\text { Combine }\end{array}$ & $\begin{array}{l}10 \mathrm{~h} \\
4 \text { people } \\
\text { irradiated }\end{array}$ & $\begin{array}{l}8 \times 10^{17} \\
\text { fissions } \\
6-17 \text { rads } \\
(0.06-0.17 \mathrm{~Gy})\end{array}$ & $\begin{array}{l}\text { End of accident by the } \\
\text { solution being transferred } \\
\text { into a safe design container. }\end{array}$ \\
\hline $\begin{array}{l}12 / 13 / 63 \\
\text { Siberian } \\
\text { Chemical Combine }\end{array}$ & $\begin{array}{l}18 \mathrm{~h} \\
\text { no consequence }\end{array}$ & $2 \times 10^{17}$ fissions & $\begin{array}{l}100 \mathrm{~L} \text {; end of accident by } \\
\text { cadmium being injected. }\end{array}$ \\
\hline $\begin{array}{l}11 / 13 / 65 \\
\text { Electrostal's } \\
\text { Fuel Fabrication } \\
\text { Plant }\end{array}$ & $\begin{array}{l}1 \text { peak } \\
1 \text { person irradiated }\end{array}$ & $\begin{array}{l}10^{15} \text { fissions } \\
3.5 \text { rads }(0.035 \mathrm{~Gy})\end{array}$ & $\begin{array}{l}6.5 \% \text { enriched uranium } \\
\text { dioxide powder } \\
\text { accumulated in a pump } \\
\text { pan after a filter was } \\
\text { perforated; end of accident } \\
\text { by oxide being dispersed. }\end{array}$ \\
\hline $\begin{array}{l}12 / 16 / 65 \\
\text { Mayak }\end{array}$ & $\begin{array}{l}7 \mathrm{~h} \text { with } \\
11 \text { peaks }\end{array}$ & $\begin{array}{l}7 \times 10^{17} \text { fissions } \\
0.03 \mathrm{rad} \\
\left(3 \times 10^{-4} \mathrm{~Gy}\right)\end{array}$ & $\begin{array}{l}\text { An excessive mass of } \\
\text { highly enriched uranium } \\
\text { was put into a dissolver; } \\
\text { end of accident by } \\
\text { cadmium being injected. }\end{array}$ \\
\hline $\begin{array}{l}12 / 10 / 68 \\
\text { Mayak }\end{array}$ & $\begin{array}{l}2 \text { peaks } \\
1 \text { dead } \\
+1 \text { amputee }\end{array}$ & $\begin{array}{l}10^{16} \text { fissions } \\
\text { then } 5 \times 10^{16} \\
\text { fissions }\end{array}$ & $\begin{array}{l}3 \text { manual drainings in a } \\
\text { row of a } 20 \mathrm{~L} \text { bottle into a } \\
\text { capacity of } 60 \mathrm{~L} \text {, despite the } \\
\text { alarm at the first peak } \\
\text { during the second draining. }\end{array}$ \\
\hline $\begin{array}{l}12 / 13 / 78 \\
\text { Siberian } \\
\text { Chemical } \\
\text { Combine }\end{array}$ & $\begin{array}{l}1 \text { peak } \\
1 \text { person irradiated } \\
+7 \text { people } \\
\text { irradiated }\end{array}$ & $\begin{array}{l}3 \times 10^{15} \\
\text { fissions } 250 \text { rads } \\
(2.5 \mathrm{~Gy}) \\
5-60 \text { rads } \\
(0.05-0.6 \mathrm{~Gy})\end{array}$ & $\begin{array}{l}\text { An excessive number of } \\
\text { plutonium ingots was } \\
\text { inserted into a container. } \\
\text { The fourth ingot was } \\
\text { ejected during its insertion. } \\
\text { The third ingot was } \\
\text { removed manually by the } \\
\text { operator. }\end{array}$ \\
\hline
\end{tabular}


Table XII. (continued)

\begin{tabular}{|c|c|c|c|}
\hline Date and place & $\begin{array}{l}\text { Length/People } \\
\text { irradiated }\end{array}$ & $\begin{array}{l}\text { Number } \\
\text { of fissions body } \\
\text { exposures }\end{array}$ & $\begin{array}{l}\text { Circumstances, } \\
\text { sequence of events } \\
\text { and causes }\end{array}$ \\
\hline $\begin{array}{l}05 / 15 / 97 \\
\text { Novosibirsk } \\
\text { Chemical Plant }\end{array}$ & $26 \mathrm{~h}$ & $10^{16}$ fissions & $\begin{array}{l}\text { Highly enriched uranium } \\
\text { solution }(90 \%) \text { in a } 600 \mathrm{~L} \\
\text { tank ( } 10 \mathrm{~cm} \text { wide); end of } \\
\text { accident by means of a } \\
\text { boron solution, then by } \\
\text { lithium chloride; currently } \\
\text { mentioned causes: } \\
\text { accumulation of uranium } \\
\text { on the walls and the tank } \\
\text { bottom, plugging of a } \\
\text { drainage hole. }\end{array}$ \\
\hline $\begin{array}{l}\text { 09/30/99 } \\
\text { Tokai-mura }\end{array}$ & $\begin{array}{l}17 \mathrm{~h} \\
3 \text { people } \\
\text { irradiated, } \\
2 \text { of whom dead }\end{array}$ & $\begin{array}{l}\approx 2.5 \times 10^{18} \\
\text { fissions }\end{array}$ & $\begin{array}{l}18.8 \% \text { enriched uranium } \\
\text { nitrate solution; use of an } \\
\text { unauthorized procedure } \\
\text { aimed at filling a tank of } \\
\text { more than } 16 \mathrm{~kg} \text { of } \\
\text { uranium, though the } \\
\text { authorized limit was } 2.4 \mathrm{~kg} \\
\text { end of reaction by } \\
\text { feedwater draining and } \\
\text { neutronic poisoning using } \\
\text { boron. }\end{array}$ \\
\hline
\end{tabular}

\section{Brief bibliography on the Tokai-mura accident}

This bibliography concerns the Tokai-mura criticality accident and presents documentation on the victims as well as the secondary medical management of all the slightly irradiated people involved.

A.E.N. Bulletin de droit nucléaire (2000) L'accident de Tokai-mura au Japon. Aspects de responsabilité civile nucléaire et de réparation, $\mathrm{n}^{\circ} 66$.

Akashi M. (2000) Initial symptoms of three victims in the Tokai-mura criticality accident, The Medical Basis for Radiation-Accident preparedness, Ricks R.C., Berger M.E., O'Hara F.M. Jr Eds., Washington DC, The Parthenon Publishing Group, pp. 303-311.

Akashi M. (2001) Exposure to neutron irradiation in the criticality accident in Tokaimura Chiba (Japan), Japanese Journal of Cancer Clinics 47 (1), 55-58.

Akashi M., Hirama T., Tanosaki S., Kuroiwa N., Nakagawa K., Tsuji H., Kato H., Yamada S., Kamata T., Kinugasa T., Ariga H., Maekawa K., Suzuki G., Tsujii H. (2001) Initial symptoms of acute radiation syndrome in the JCO criticality accident in Tokai-mura, J. Radiat. Res. 42, Suppl. S157-S166.

Andurand R. (2000) Un risque peu connu: la "criticité", Première partie, Préventique - Sécurité, 50. 
Andurand R. (2000) Un risque peu connu: la "criticité", les Paramètres Déterminants, Deuxième partie, Préventique - Sécurité, 51.

Andurand R. (2000) Un risque peu connu: la "criticité", Les conséquences biologiques, Troisième partie, Préventique - Sécurité, 52.

Andurand R. (2000) Un risque peu connu: la "criticité ", Le réacteur fossile d'Oklo, Quatrième partie, Préventique - Sécurité, 53.

Barbry F. (2001) Ensemble de détection d'accident de criticité (EDAC), Méthodologie pour sa mise en œuvre et dispositions associées en matière d'intervention, Note technique DPEA/SRSC 01-02.

Barbry F., Fouillaud P. (2001) Criticality accident studies and research performed in the Valduc Criticality Laboratory France, Rapport SRSC n ${ }^{\circ} 01$ 233, International Conference On Topical Issues in Nuclear Safety, IAEA, 3-6 September 2001, Vienna.

Blakely W.F. (2002) Multiple parameter biodosimetry of exposed workers from the JCO criticality accident in Tokai-mura, J. Radiol. Prot. 22 (1), 5-6. Review.

Chiba S., Saito A., Ogawa S., Takeuchi K., Kumano K., Seo S., Suzuki T., Tanaka Y., Saito T., Izutsu K., Yuji K., Masuda S., Futami S., Nishida M., Suzuki G., Gale R.P., Fukayama M., Maekawa K., Hirai H. (2002) Transplantation for accidental acute high-dose total body neutron- and gamma-radiation exposure, Bone Marrow Transplant 29 (11), 935-939. Review.

Clefs CEA (2001) La sûreté des installations vis à vis du risque de criticité, $\mathrm{n}^{\circ} 45$, 54-90.

Cross W.G. (1981) Neutron Activation of Sodium in Phantoms and the Human Body, Health Phys. 41, 105-121.

Endo A., Yamaguchi Y. [Japan Atomic Energy Research Inst., Tokai, Ibaraki (Japan). Tokai Research Establishment], Ishigure N. [National Inst. of Radiological Sciences, Division of Radiotoxicology and Protection, Chiba (Japan)] (2001) Analysis of dose distributions for the heavily exposed patients in the criticality accident at Tokai-mura. Joint research program between JAERI and NIRS, Japan Atomic Energy Research Inst., Tokyo (Japan). Report Number: JAERI-Research 2001-035.

Endo A., Yamaguchi Y. (2003) Analysis of dose distribution for heavily exposed workers in the first criticality accident in Japan, J. Radiat. Res. 159 (4), 535-542.

Endo A., Yamaguchi Y., Sakamoto Y., Yoshizawa M., Tsuda S. (2001) External doses in the environment from the Tokai-mura criticality accident, Radiat. Prot. Dosim. 93 (3), 207-214.

Fujimoto K. Ed. (2002) Final report on the dose estimation for three victims of the JCO accident, National Institute of Radiological Sciences, Chiba, Japan, NIRSR-47.

Goans R.E., Holloway E.C., Berger M.E., Ricks R.C. (2001) Early dose assessment in criticality accidents, Health Phys. 81 (4), 446-449.

Hayata I., Kanda R., Minamihisamatsu M., Furukawa M., Sasaki S. (2001) Cytogenetical dose estimation for 3 severely exposed patients in the JCO criticality accident in Tokai-mura, J. Radiat. Res. 42, Suppl. S149-S155.

Hirama T., Tanosaki S., Kandatsu S., Kuroiwa N., Kamada T., Tsuji H., Yamada S., Katoh H., Yamamoto N., Tsujii H., Suzuki G., Akashi M. (2003) Initial medical management of patients severely irradiated in the Tokai-mura criticality accident, Br. J. Radiol. 76 (904), 246-253. 
Hult M., Martinez Canet M.J., Johnston P.N., Komura K. (2002) Thermal neutron fluence from ultra low-level gamma-ray spectrometry of spoons activated during the JCO criticality accident at Tokai-mura in 1999, J. Environ. Radioact. 60 (3), 307-318.

IAEA (1982) Dosimetry for Criticality Accidents, A Manual, Technical Reports Series $\mathrm{n}^{\circ} 211$, Vienna.

IAEA (1999) Report on the preliminary fact finding mission following the accident at the nuclear fuel processing facility in Tokai-mura, Japan, 35 pages, Vienna.

Imanaka T. (2001) Transport calculation of neutrons leaked to the surroundings of the facilities by the JCO criticality accident in Tokai-mura, J. Radiat. Res. 42, Suppl. S31-S44.

Inaba J. (1999) Criticality Accident at Tokai-mura, Institute for Environmental Sciences, Rokkasho-mura, Japan, Radiological Protection Bulletin 217.

Inaba J. (2000) Radiological and environmental aspects of the criticality accident in Tokai-mura, Radiat. Prot. Dosim. 92 (1-3), 239-246.

Ishigure N. [National Inst. of Radiological Sciences, Chiba (Japan)]; Endo A., Yamaguchi Y., Kawachi K. (2001) Calculation of the absorbed dose for the overexposed patients at the JCO criticality accident in Tokai-mura, J. Radiat. Res. 42, Issue: suppl. PBD.

Ishigure N., Endo A., Yamaguchi Y., Kawachi K. (2001) Calculation of the absorbed dose for the overexposed patients at the JCO criticality accident in Tokai-mura. J. Radiat. Res. 42, Suppl. S137-S148.

Ishii T., Futami S., Nishida M., Suzuki T., Sakamoto T., Suzuki N., Maekawa K. (2001) Brief note and evaluation of acute-radiation syndrome and treatment of a Tokai-mura criticality accident patient, J. Radiat. Res. 42, Suppl. S167-S182.

The Tokai-mura Accident, Special Issue, J. Environm. Radioact. (2000) 50 (1-2), 174 p.

Kanda R., Hayata I. Lloyd (1998) Easy biodosimetry for high-dose radiation exposure using drug-induced, prematurely condensed chromosomes, Int. J. Radiat. Biol. 74, 457-462.

Kanda R., Minamihisamatsu M., Hayata I. (2002) Dynamic analysis of chromosome aberrations in three victims of the Tokai-mura criticality accident, Int. J. Radiat. Biol. 78 (9), 857-862.

Kojima S., Imanaka T., Takada J., Mitsugashira T., Nakanishi T., Seki R., Kondo M., Sasaki K.I., Saito T., Yamaguchi Y., Furukawa M. (2001) Determination of radionuclides induced by fast neutrons from the JCO criticality accident in Tokai-mura, Japan for estimating neutron doses, J. Radiat. Res. 42, Suppl. S45-S53.

Komura K. (2001) Radiochemical approach to the JCO criticality accident in Tokaimura, 1999, an overview of the radiochemistry group, J. Radiat. Res. 42, Suppl. S17-S29.

Kugeler K., Brockmann H., Phlippen P.W., Scherer W., Singh J. (1999) Analysis of the Tokai-mura criticality accident, Informationen und Analysen zum Kritikalitaetsunfall in Tokai-mura, Institut fuer Sicherheitsforschung und Reaktortechnik, ATW, Internationale Zeitschrift fuer Kernenergie (AIZKFE) 44 (11), 630-634.

Mechitoua B. (2001) Tokai-Mura criticality accident: point model stochastic neutronic interpretation, 2001, ANS Annual Meeting, Milwaukee, WI (US), 06/17/2001-06/21/2001, Trans. Am. Nucl. Soc. 84, PBD: 17 Jun 2001, Published: June 17, 2001. 
Mijuin D. (2001) L'accident de criticité de Tokai-mura, Clefs CEA 45, 76-79.

Miyamoto K. et al. (2002) Reconstruction of two victims'posturing based on the induced radioactivities in their bones in the criticality accident in Tokai-mura, Japan, Health Phys. 83 (1), 19-25.

Miyamoto K., Takeda H., Nishimura Y., Yukawa M., Watanabe Y., Ishigure N., Kouno F., Kuroda N., Akashi M. (2003) Validation and verification of the ICRP biokinetic model of 32P: the criticality accident at Tokai-mura, Japan, Radiat. Prot. Dosim. 105 (1-4), 199-208.

Momose T., Tsujimura N., Tasaki T., Kanai K., Kurihara O., Hayashi N., Shinohara K. (2001) Dose evaluation based on ${ }^{24} \mathrm{Na}$ activity in the human body at the JCO criticality accident in Tokai-mura, J. Radiat. Res. 42, Suppl. S95-S105.

Muramatsu Y., Noda Y., Yonehara H., Ishigure N., Yoshida S., Yukawa M., Tagami K., Ban-Nai T., Uchida S., Hirama T., Akashi M., Nakamura Y. (2001) Determination of radionuclides produced by neutrons in heavily exposed workers of the JCO criticality accident in Tokai-mura for estimating an individual's neutron fluence, J. Radiat. Res. 42, Suppl. S117-S128.

Murata K., Akashi S. Eds. (2000) Report of criticality accident at the uranium processing facility in Tokai village. National Institute of Radiological Sciences, NIRS.M.143, Chiba (in Japanese).

Murata Y., Muroyama T., Kawabata Y., Yamamoto M., Komura K. (2001) Activation of soil and chemical reagents exposed to the neutrons released by the JCO criticality accident in Tokai-mura, J. Radiat. Res. 42, Suppl. S55-S74.

Murata, Hajime (Ed.) The report of the criticality accident in a uranium conversion test plant in Tokai-mura, [National Inst. of Radiological Sciences, Chiba, Japan. Research Center for Charged Particle Therapy]; Akashi, Makoto (Ed.) [National Inst. of Radiological Sciences, Chiba (Japan). Research Center for Radiation Emergency Medicine].

Nénot J.C. (2001) Les accidents d'irradiation, 1950-2000, leçons du passé, Radioprotection 36 (4), 431-450.

Nishimura Y., Takeda H., Miyamoto K., Watanabe Y., Kouno F., Kuroda N., Kim H.S., Yukawa M. (2002) Determination of 32P in urine for early estimation of the neutron exposure level for three victims of the JCO criticality accident, J. Radiol. Prot. 22 (1), 25-29.

Nuclear Safety Commission Investigation Committee (1999) Report of the criticality accident at uranium processing facility, December 24, 1999, Nuclear Safety Commission, STA, Japan, Tokyo (in Japanese).

Rapport de la Science and Technology Agency (STA) à propos de l'incendie et de l'explosion survenus le 11 mars 1997 à Tokai-mura, 27 pages, 16 mai 1997, Site Internet: www.sta.go.jp/nuclear/tokai/cyuho/index.htm

$R G N n^{\circ} 5$ (1999) L'accident de Tokai-mura: erreur humaine et défaut de procédure, pp. $72-74$.

RGN nº 6 (1999) Après l'accident de Tokai-mura: les suites et les conséquences, pp. 54-56.

Ronald E. Goans et al. (2001) Early dose assessment in criticality accidents, Health Phys. 81 (4), 446-449.

Sasaki M.S., Hayata I., Kamada N., Kodama Y., Kodama S. (2001) Chromosome aberration analysis in persons exposed to low-level radiation from the JCO criticality accident in Tokai-mura, J. Radiat. Res. 42, Suppl. S107-S116. 
Sasaki, Masao S. [Kyoto Univ. (Japan). Radiation Biology Center], Hayata I., Kamada N., Kodama Y., Kodama S. (2001) Chromosome aberration analysis in persons exposed to low-level radiation from the JCO criticality accident in Tokai-mura, J. Radiat. Res. 42, Issue: suppl. PBD.

Sasaki Y., Ando K., Komura K., Niwa O., Sasaki M.S., Susuki N. Eds. (2001) The Tokai-mura criticality accident: biomedical and environmental effects, J. Radiat. Res. 42, Suppl. S1-186.

Shiraishi K., Iwasaki M., Miyazawa C., Yonehara H., Matsumoto M. (2002) Dose estimation by ESR on tooth enamel from two workers exposed to radiation due to the JCO accident, J. Radiat. Res. 43 (3), 331-335.

Takada J. (2001) External doses to $350 \mathrm{~m}$ zone residents due to anisotropic radiation from the JCO criticality accident in Tokai-mura, J. Radiat. Res. 42, Suppl. S75-S84.

Takada J., Suga S., Kitagawa K., Ishikawa M., Takeoka S., Hoshi M., Watanabe H., Ito A., Hayakawa N. (2001) Directional distribution of radiation around an accident at a uranium fuel factory in Tokai-mura, 1999, J. Radiat. Res. (Tokyo) 42 (1), 47-55.

Takagi J., the Citizens' Nuclear Information Center (2000) Criticality accident at Tokai-mura, 80 pages, Translated by Hoerner G., Fukami A., Miwa T.

Takeda H., Miyamoto K., Yukawa M., Nishimura Y., Watanabe Y., Kim H.S., Fuma S., Kuroda N., Kouno F., Joshima H., Hirama T., Akashi M. (2001) Bioassay for neutron-dose estimations of three patients in the JCO criticality accident in Tokai-mura by measuring beta-ray emitters, J. Radiat. Res. 42, Suppl. S129-S135.

Tanaka S.I. (2001) Summary of the JCO criticality accident in Tokai-mura and a dose assessment, J. Radiat. Res. 42, Suppl. S1-S9.

Toohey R.E. (2000) Notes from Chiba, report on the Tokai-mura, Japan criticality accident, The Health Physics Society's Newletter XXVIII, 21-25.

Tsunoda Katsuya (2001), Public response to the Tokai nuclear accident, Risk Analysis 21 (6), 1039-1046.

Uchiyama G., Watanabe K., Miyauchi M. [Japan Atomic Energy Research Inst., Tokai, Ibaraki (JP)] et al. (2001) Analysis of a uranium solution for evaluating the total number of fissions in the JCO criticality accident in Tokai-mura, J. Radiat. Res. 42, Issue: suppl. PBD. 


\section{RADIOPROTECTION \\ Revue de la Société française de radioprotection

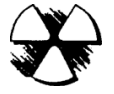

EDITORIAL BOARD

$\begin{array}{ll}\text { Chairman } & \text { H. Métivier, SFRP } \\ \text { Vice-Chairman } & \text { J. Lallemand, EDF } \\ \text { Emeritus Chairman } & \text { D. Blanc, SFRP } \\ \text { Members } & \text { B. Barelaud (Université de Limoges), Ph. Bérard (CEA), J.M. Bertho (IRSN), A. Cazoulat (SPRA), } \\ & \text { P. Crouail (CEPN), G. Laurent (EDF), L. Makovicka (Université Franche Comté), H. Maubert } \\ & \text { (CEA), F. Paquet (IRSN), B. Quesne (AREVA NC), A. Rannou (IRSN), C. Tamponnet (IRSN), } \\ & \text { G. Tymen (Université Bretagne Occidentale), J.C. Varin (AREVA NC) }\end{array}$ Foreign Members: L. Arranz Carrillo (Spain), M. Bailey (UK), A. Bouville (USA), P. Deboodt (IAEA), D. Depiesse (Italy), Ph. Duport (Canada), S. Fakhi (Morocco), M. Gelev (Bulgaria), B. Katz (Argentina), M.A. Lopez (Spain), M.C. Lourenco (Brazil), I. Lund (Sweden), Ch. Murith (Switzerland), H. Ogata (Japan), C. Organo (Ireland), Fr. Spurny (Czech Republic), M. Thieme (Germany), H. Vanmarcke (Belgium)

\section{EDITORIAL OFFICE}

SFRP, BP 72, 92263 Fontenay-aux-Roses Cedex Tel.: + 33158357285 - Fax: + 33158358359

Instructions for authors are available at: http://www.radioprotection.org

\section{SUBSCRIPTION}

Édition Diffusion Presse Sciences

17 avenue du Hoggar, BP 112, Parc d'Activités de Courtabœuf, 91944 Les Ulis Cedex A Tel.: + 33169187575 - Fax: +33169860678-e-mail: subscribers@edpsciences.org

Price of this issue: $39 €$ (VAT included)

Editor in chief: Henri Métivier

Production: Agnès Henri, Sophie Hosotte

\section{ADVERTISEMENT}

Aurélie Lefebvre, EDP Sciences
Tel.: + 33169181810 - Fax: + 33169288491 - e-mail: lefebvre@edpsciences.org

Radioprotection is indexed in: INIS Atomindex, PASCAL, Chemical abstracts and Cambridge scientific abstracts

Impression JOUVE, 11 boulevard de Sébastopol, 75001 Paris, France - Dépôt légal: octobre 2008 